\title{
Recent Progress in Stabilizing Hybrid Perovskites for Solar Cell Applications
}

Jianqing Chen ${ }^{\star}$, Xin Caia , Donghui Yanga, Dan Songa, Jiajia Wanga, Jinghua Jianga, Aibin Maa, Shiquan $\mathrm{Lv}^{b}$, Michael Z. Hu${ }^{\star c}$, Chaoying Ni ${ }^{* d}$

a College of Mechanics and Materials, Hohai University, Nanjing, 210098, P.R. China, Email:

${ }^{b}$ Key Laboratory of Functional Materials Physics and Chemistry of the Ministry of Education, Jilin Normal University, Siping 136000, P.R. China.

c Oak Ridge National Laboratory, Oak Ridge, TN 37831 USA

d Department of Materials Science and Engineering, University of Delaware

Newark, DE 19716, USA

Corresponding author: Jianqing Chen E-mail: chenjq@hhu.edu.cn; Chaoying Ni, E-mail: cni@udel.edu

Abstracts: Hybrid inorganic-organic perovskites have quickly evolved as a promising group of materials for solar cells and optoelectronic applications mainly owing to the inexpensive materials, relatively simple and versatile fabrication and high power conversion efficiency (PCE). The certified energy conversion efficiency for perovskite solar cell (PSC) has reached above $20 \%$, which is compatible to the current best for commercial applications. However, long-term stabilities of the materials and devices remain to be the biggest challenging issue for realistic implementation of the PSCs. This article discusses the key issues related to the stability of perovskite absorbing layer including crystal structural stability, chemical stability under moisture, oxygen, illumination and interface reaction, effects of electron-transporting materials (ETM), hole-transporting materials (HTM), contact electrodes and preparation conditions. Towards the end, prospective strategies for improving the stability of PSCs are also briefly discussed and summarized. We focus on recent understanding of the stability of materials and devices and our perspectives about the strategies for the stability improvement.

Keywords: hybrid perovskite solar cell, stability, perovskite modification, interface engineering, protection layer, encapsulation, ion migration

Content:

1. Introduction

2. Stability of perovskite absorbing layer

2.1 Crystal structural stability

2.2 Stability under illumination

2.3 Humidity sensitivity

2.4 Effect of interface reaction

2.5 Synergistic effect of illumination, temperature and water reaction

3. Effect of mesoporous $\mathrm{TiO} 2$ on the stability of PSCs 
3.1 UV light-related stability

3.2 $\mathrm{TiO} 2$ as electron acceptor reducing charge recombination and parasitic reaction

3.3 Replacement and modification of $\mathrm{TiO} 2$

4. Effect of HTM on the stability of PSCs

4.1 Stability of HTM

4.2 Dopants induced hygroscopicity and pinholes of spiro-OMeTAD

4.3 Hydrophobic organic semiconductor as HTM

4.4 Effect of PEDOT:PSS on the stability of PSSc

4.5 HTM-free PSCs

5. Effect of contact electrode on the stability of PSCs

6. Effect of preparation condition on the stability of PSCs

7. Effect of ion migration on the stability of PSCs

8. Strategies to improve the stability

8.1 Perovskite material modification

8.2 Interfacial engineering

8.2.1 Engineering of perovskite/ETM interface

8.2.2 Engineering of perovskite/HTM interface

8.2.3 Engineering of $\mathrm{HTM} /$ contact electrode interface

8.2.4 Engineering of ETM/contact electrode interface

8.3 Protection layer

8.4 Encapsulation

9. Summary and perspectives

\section{Introduction}

The research of hybrid inorganic-organic perovskites in photovoltaic and optoelectronic applications has been expanding exponentially [1]. The "gold triangle" of solar cells for commercial application is power conversion efficiency (PCE), cost, and stability. The PCE of perovskite solar cells (PSCs) has been improved from 3.83\% [2] to 22.1\% [3] in a few years and remarkably, PSCs consist of non-precious elements and can be fabricated by processes including low-cost solution processes or procedures utilizing existing solar cell manufacturing platforms. PSCs have therefore shown great potentials in PCE, cost, and resource and environmental sustainability. However, solar cells are subject to use under ambient conditions for a long-term and they need to sustain daily and seasonal temperature swings. Also, the temperature of the solar cells may arise under the sun illumination and is in fact a contributing factor associated with the efficiency loss. Furthermore, the PSCs can be sensitive to the chemically active oxygen and moisture in the air and thus require a more costly air-tight protection environment during the device fabrication and handling and especially during the service after the implementation. Improving the long-term stability is therefore critical for the 
PSC applications.

The degradation of solar cells can occur due to intrinsic instability, elevated temperature, UV illumination, and exposure to ambient atmosphere.

Crystal Si solar cells exhibit outstanding intrinsic stability. The failure or degradation of crystal Si solar cells operated outdoor often come from the mechanical fracture of Silicon wafer or the corrosion of the electrode and module element. EVA (ethylene vinyl acetate) encapsulation inhibits the moisture ingress. Ce-doped glass can filter the ultra violet (UV) light, avoiding the UV-induced ageing of EVA. As the application of glass substrate and solution of the mechanical problems, the crystal Si solar cells can survive in outdoor humidity atmosphere for up to 25 years and even longer.

Development and application of amorphous Si film solar cells aims to decrease the usage of silicon and cut the cost. However, amorphous Si solar cells suffer from the StaeblerWronski effect. Numerous researches focused on the mechanism of the instability of amorphous Si solar cells and corresponding approaches and technologies.

The degradation of CIS (CuInSe) and CIGS (CuInGaSe) film solar cells originate from the corrosion of the front contact electrode in humidity environment. This is a kind of extrinsic stability and relies on the development of electrode and encapsulation technology.

One of the degradation paths of $\mathrm{CdSe}$ and $\mathrm{CdTe}$ film solar cell using $\mathrm{Cu} / \mathrm{C}$ as back electrode comes from the diffusion of $\mathrm{Cu}$ into the absorbing layer, blocking the charge transport and resulting in performance degradation. Corrosion of back contact electrode in the moisture environment also exists in $\mathrm{CdSe} / \mathrm{CdTe}$ film solar cells. Development of a moisture stable back contact electrode, which also should block the diffusion of $\mathrm{Cu}$ into the active layer, is a key in $\mathrm{CdSe} / \mathrm{CdTe}$ film solar cells.

The degradation of dye sensitized solar cell (DSSC) relates to the dye desorption, changes in the electron collection at photo anode, leakage of electrolyte, and corrosion of counter electrode, etc. Application of solid-state electrolyte in DSSC is one of the effective methods to improve the stability of DSSC.

The stability of organic solar cells (OPV) is confined by the morphology change, photooxidation, and interface degradation of the organic active layer, hyperoxide traps in metal oxide electron transport layer (ETL), moisture/oxygen sensitive hole transport materials (HTMs), etc.

Due to the hydroscopic ammonium cation, the perovskite is notoriously sensitive to the moisture in air and is prone to decomposition into $\mathrm{PbI}_{2}$, leading to the $\mathrm{PCE}$ degradation of the of PSCs. Apart from the moisture sensitivity of the perovskites, the $\mathrm{TiO}_{2}$ scaffold, hole transportation materials and contact electrodes of the PSCs may also be sensitive to the illumination, temperature, humidity and oxygen.

Therefore, the stability of the perovskite absorber and the device performance remains as critical research frontiers of the PSCs and has attracted increasing research interests since 2014 [4-13]. Liduo Wang et al. [4] contributed a review on this topic at the end of last year, which summarized the chemical stability of PSCs associated with different environmental conditions, such as oxygen and moisture, UV light, solution process and thermal stress. Since then, there have been important advancements in the stability study of PSCs related to the degradation mechanism of perovskite, the effect of $\mathrm{TiO}_{2}$ and especially the intrinsic stability of PSC devices due to interface reactions. Tomas Leijtens [5] and coworkers overviewed the 
potential instability issues due to electrical, atmospheric, heat and light stresses. Hongwei Han et al. [6] focused on mesoporous perovskite solar cells (MPSC). Effects of environment (moisture, oxygen, heat and light soaking) and device components on the stability of MPSC are reviewed. Hongjin Fan et al. [7] reviewed the thermal decomposition and degradation mechanism of perovskite in ambient air, as well as the device degradation caused by other components of PSC. Strategies for improving the stability of PSCs, such as modification of perovskite and additives in HTMs, using polymer and inorganic HTMs to replace humidity sensitive spiro-OMeTAD (2,2'7,7'-tetrakis(N,N-di-p-methoxyphenylamine)-9,9'spirobifluorene) and PEDOT:PSS (poly(3,4-ethyllenedioxythiophene):Polystyrene sulfonate) or even using HTM-free structure, are discussed. Wei-Nien $\mathrm{Su}$ et al. [8] overviewed the oxygen, light, moisture and temperature induced failure and associated degradation mechanism of perovskite material as well as origins of PSCs degradation. The device degradation originates from device components (including perovskite, HTL and metal counter electrode), device architecture (planar (regular) $\mathrm{TiO}_{2}$ based, inverted (PEDOT:PSS based) and mesoporous $\mathrm{TiO}_{2}$ based), and interface (ion migration and interface reactivity). Hongxia Wang et al. [9] also reviewed the factors influencing the stability of perovskite materials and perovskite solar cell device. Factors influencing the stability of perovskite materials include water, perovskite composition, temperature and UV light. Factors influencing the stability of the PSC device include perovskite material, fabrication method, metal oxide film and different HTM. Deqing Gao et al. [11] overviewed the degradation mechanisms in PSCs caused by moisture and oxygen, UV light illumination and temperature and methods to improve the stability of PSCs including perovskite materials modification, preparation methods, device structure and encapsulation. Dian Wang et al. [12] also reviewed the stability of the perovskite layer, electron transport layer, hole transport layer, buffer layer, and electrode in PSCs. Effect of encapsulation, hysteresis and ion migration on the stability are also discussed.

Timothy L. Kelly et al. [14] discussed the decomposition and cell failure mechanisms in lead halide perovskite solar cells. The cell failure mechanisms in PSCs are mainly attributed to humidity-, light- and heat-induced structural change of the perovskite, interfacial layers failure and electrode corrosion. Tingli Ma et al. [15] reviewed the origin of the instability problem in PSCs and the approaches to improving the long-term stability of perovskite materials and devices. The origin of the instability problem in PSCs comes from the instability of perovskite layer, ETLs, HTMs and electrodes and the corresponding strategies for improving the long-term stability of PSCs include engineering of perovskite materials, application of alternative HTMs, electrodes, interfacial modification, and encapsulation or surface passivation, etc. Mingkui Wang et al. [16] reviewed the stability of perovskite materials upon moisture, temperature and light exposure, and stability of charge transport materials in PSCs. Solutions to increase the stability of PSCs, including strategies for reduction of perovskite materials degradation, UV-light induced degradation, charge transport materials and PSCs using inorganic oxide frameworks, are discussed. Nam-Gyu Park et al. [17] also reviewed the materials and device stability in perovskite solar cells. Stability of bulk perovskite (including moisture effect in dark, light coupled with moisture and oxygen effect and thermal stability), stability related to interface interplay (including chemical reaction at interface, degradation on top electrode), stability of selective contacts (ETLs and HTMs) and 
corresponding intrinsic and extrinsic methods for improving stability are discussed. Nripan Mathews et al. [18] focused on the sources of instability in conventional 3-dimensional (3D) perovskites, such as moisture complexation, ion migration, thermally induced chemical decomposition and phase transition. Multidimensional perovskite photovoltaic was proposed as a possible solution for the instability of 3D perovskites.

The stability issue of PSCs has received significant attention in some reviews $[10,13,19,20,21,22,23]$. Zuo-Quan Jiang et al. [19] discussed the role of dopant-free HTMs role in enhancing PSC stability in a review on small molecule HTMs for PSCs. Tsutomu Miyasaka et al. [20] reviewed the effect of metal oxide ETL modification on the stability of high performance PSCs. Huanping Zhou et al. [21] emphasized interface design and modification in protecting perovskite from moisture and light induced degradation as well as the degradation related to phase transition, chemical composition, and chemical reaction between adjacent layers. Tae-Woo Lee et al. [24] also discussed role of the interfacial layer in enhancing long-term stability of planar PSC devices. Johann Boucle et al. [25] reviewed the application of graphene in PSCs, such as being used as electrodes, semitransparent electrodes, HTMs and ETMs, lead to improved stability. Clemens Burda et al. [26] emphasized the modification of crystal structure and the coordination engineering as the way to improve the stability of organic-inorganic hybrid perovskites.

This review focuses on the most recent progresses in stability of PSCs, including the stability of perovskite absorbing layer, effect of mesoporous $\mathrm{TiO}_{2}$ and hole transport materials, contact electrode and promising strategies to improve the stability. The stability of perovskite absorbing layer includes crystal structural stability, material and device stability under illumination, humidity or interfacial reaction, and the synergistic effect of illumination, temperature and water reaction. Due to the photoactivity of $\mathrm{TiO}_{2}$, the PSCs with mesoporous $\mathrm{TiO}_{2}$ scaffold suffer from UV-induced instability. However, $\mathrm{TiO}_{2}$ as electron acceptor can reduce the charge recombination and parasitic reaction in perovskite active layer, benefiting to the stability of PSCs. Replacement and modification of $\mathrm{TiO}_{2}$ were also discussed. The most popular HTM in PSCs is spiro-OMeTAD, however, dopant-induced hygroscopicity and pinholes in spiro-OMeTAD can lead to the degradation of perovskite active layer. PEDOT:PSS is widely used in reverted planar PSCs. However, the acid and hygroscopic property of PEDOT:PSS deteriorates the stability of PSCs. In addition, the stability of HTM itself is also an issue in the stability of PSC device. Application of hydrophobic organic semiconductor and dopant-free HTM, or even HTM-free is a way to improve the stability of PSC. The effect of electrode on the stability of PSCs relates to the interface between contact electrode and charge-transport material, the corrosion of the electrode and penetrating of contact electrode element into ETL or HTL. The strategies for improving the stability of PSCs, i.e. perovskite modification, interface engineering, using of protection layer and device encapsulation, are reviewed.

\section{Stability of perovskite absorbing layer}

The stability of the perovskite absorbing layer is a function of multiple variables including the crystal structural stability of the perovskite within the working temperature range of the cells (up to $45{ }^{\circ} \mathrm{C}$ higher than the environmental temperature) [27], interaction with humidity in the environment, redox reactions involving oxygen, and the radiation 
stability of the perovskite.

\subsection{Crystal structural stability}

$\mathrm{CH}_{3} \mathrm{NH}_{3} \mathrm{PbI}_{3}\left(\mathrm{MAPbI}_{3}\right)$, the most studied and efficient perovskite absorbing material in PSCs, can be orthorhombic, tetragonal, or cubic depending just on the level of disorder of the MA (Methylammonium, MA) ions. It is tetragonal at room temperature and changes to cubic at $327 \mathrm{~K}\left(\sim 54^{\circ} \mathrm{C}\right)$, well within the general operating temperature range of a typical solar cell, which accompanies with volume change and can lead to the change in the electronic property of the material [28] . Furthermore, the coefficient of thermal expansion (CTE) of $\mathrm{MAPbI}_{3}$ is about $1.57 \times 10^{-4} \mathrm{~K}^{-1}$ for both the tetragonal and cubic phases, which is 6 times higher than that of soda lime glass and CIGS, 11 times larger than that of CdTe. The CTE could affect the mechanical stability of PSCs in temperature cycling upon day-night operation [29]. However, Claudio Quarti et al. [30] studied the structural and optical properties of $\mathrm{MAPbI}_{3}$ by temperature resolved UV-vis absorption, spectral photocurrent response measurements, and $\mathrm{ab}$ initio simulation and the results showed that the $\mathrm{MAPbI}_{3}$ band-gap did not abruptly change when exceeding the transition temperature from tetragonal to cubic structure. Instead, it exhibits a monotonically blue shift following the same temperature evolution observed within tetragonal phase, which is due to the fact that on the electronic transitions time scale, the material rarely experiences an increasingly distorted tetragonal environment rather than a cubic one. The high temperature cubic structure is just a static average while the actual system greatly deviates from the cubic structure in the sub-picosecond time scale.

First principle calculations show that decomposition of $\mathrm{CH}_{3} \mathrm{NH}_{3} \mathrm{PbI}_{3}$ to $\mathrm{CH}_{3} \mathrm{NH}_{3} \mathrm{I}$ and $\mathrm{PbI}_{2}$ is exothermic, i.e., the room temperature tetragonal phase is thermodynamically unstable independent of the humidity or oxygen in the atmosphere. [31] Alessandra Alberti et al. [32] investigated the degradation path of $\mathrm{MAPbI}_{3}$ films and found they exhibit similar degradation dynamics in air or under vacuum conditions, which means that the degradation mechanism can be intrinsic based on thermodynamics and is not necessarily associated with humidity. The tetragonal lattice tends to transform toward a "more cubic" atomic arrangement followed by the nucleation of $\mathrm{PbI}_{2}$ at defects or interfaces as the $\mathrm{MAPbI}_{3}$ loses its volatile parts (likely $\mathrm{HI}$ and $\mathrm{CH}_{3} \mathrm{NH}_{2}$ ). This "intrinsic" degradation process is thermally activated and the activation energy relates to a dynamic exchange of protons from the organic moieties to the inorganic cage which produces volatile species. The energy is found to be $\sim 1.54 \mathrm{eV}$ without water action in inert condition and is reduced to $\sim 0.96 \mathrm{eV}$ in the presence of water molecules. [33] Due to enhanced interaction between organic molecules (FA) and the inorganic cage $\left(\mathrm{PbI}_{3}\right)$, substituting $\mathrm{MA}^{+}$with $\mathrm{FA}^{+}$inside the inorganic lattice leads to an improvement of perovskite stability. Fig.S1 shows the representation degradation behavior of the $\mathrm{MAPbI}_{3}$ films upon storage at air, vacuum and inert ambient environment. [32]

In addition to a better thermal stability due to the enhanced hydrogen bonding between FA cations and iodide ions [34,35], the band-gap of $\mathrm{NH}_{2} \mathrm{CH}=\mathrm{NH}_{2} \mathrm{PbI}_{3}\left(\mathrm{FAPbI}_{3}\right)$ is narrower than that of the conventional $\mathrm{MAPbI}_{3}$ [36], it has therefore the potential to achieve higher $\mathrm{PCE}$ while maintaining higher stability $[37,38]$. However, structurally, $\mathrm{FAPbI}_{3}$ is more stable in the hexagonal $\delta$-phase (yellow phase) and due to its large tolerance factor, the phase transition temperature of $\delta$ to a more desirable trigonal $\alpha$ phase is about $400 \mathrm{~K}$. [39] The $\alpha$ - 
phase (black phase) $(\mathrm{P} 3 \mathrm{~m} 1)$ of $\mathrm{FAPbI}_{3}$ formed at a higher temperature $\left(\sim 130{ }^{\circ} \mathrm{C}\right)$ is therefore prone to phase change to a wide band-gap hexagonal (P63mc) symmetry at room temperature. Employing a mixture of MA ions (MAI) and FA ions (FAI) in the film deposited via a twostep approach resulted in stabilized trigonal $\mathrm{FAPbI}_{3}$ at room temperature. Temperaturedependent XRD results showed that no structural changes in the trigonal phase $\mathrm{FA}_{0.87} \mathrm{MA}_{0.13} \mathrm{PbI}_{3}$ in the temperature range studied between 25 and $250{ }^{\circ} \mathrm{C}$. [37] Sang Il Seok et al. [40] reported the incorporation of $\mathrm{MAPbBr}_{3}$ into $\mathrm{FAPbI}_{3}$, leading to a stabilization of the perovskite phase due to the co-substitution of MA to FA and Br to I, as shown in Fig. S2. Xiaojia Zheng et al. [41] proposed that the existence of an anisotropic strained lattice in the (111) plane drove the phase transformation into the $\delta$-phase and MABr alloying could cause lattice contraction, which relaxing the lattice strain, and thereby stabilizing $\alpha$-phase of $\mathrm{FAPbI}_{3} . \mathrm{MACl}$ and $\mathrm{FACl}$ can be used as additives to modulate the evolution of $\mathrm{FAPbI}_{3}$ through assisting the formation of non- $\delta-\mathrm{FAPbI}_{3}$ intermediate phase, which then converts to $\alpha-\mathrm{FAPbI}_{3}$ during thermal annealing. [42] Yuanyuan Zhou et al. [43] reported that the $\alpha$ to $\delta$ phase transition of $\mathrm{FAPbI}_{3}$ could be retarded by mesoporous $\mathrm{TiO}_{2}$ scaffold due to the synergistic effect of partial 3-D encapsulation of $\alpha-\mathrm{FAPbI}_{3}$ by the mesoporous $\mathrm{TiO}_{2}$ and the increased energy barrier for phase transition associated to the high contact area between the perovskite and $\mathrm{TiO}_{2}$.

$\mathrm{CsPbI}_{3}$ was also used to stabilize the active perovskite phase of $\mathrm{FAPbI}_{3}$. [44-47] Kai Zhu et al. tuned the Goldschmidt effective tolerance factor of the $\mathrm{FA}_{1-\mathrm{x}} \mathrm{C}_{\mathrm{x}} \mathrm{PbI}_{3}$ by alloying $\mathrm{FAPbI}_{3}$ with $\mathrm{CsPb}_{3}$ to stabilize the active perovskite structure. Fig. $\mathrm{S} 3$ shows a correlation between tolerance factor and crystal structure of perovskite materials. $\mathrm{FA}_{0.85} \mathrm{Cs}_{0.15} \mathrm{PbI}_{3}$ perovskite alloy shows much improved stability in a high-humidity environment and better solar cell performance, as shown in Fig. S4. [44] $\mathrm{CsPbI}_{3}$ and $\mathrm{FAPbI}_{3}$ are miscible in the perovskite phase but not miscible in the $\delta$ phase due to the fact that perovskite phases $\mathrm{CsPb}_{3}$ and $\mathrm{FAPbI}_{3}$ are very similar in atomistic structure and volume but not in the latter. So the mixing of the perovskite phases is energetically favorable while the mixing in the $\delta$ phase leads to a large energy penalty. [46]

Black perovskite phase $\mathrm{CsPbI}_{3}$ is unstable at room temperature and transforms to the yellow non-perovskite phase. However, doping $\mathrm{CsPbI}_{3}$ with $\mathrm{Br}\left(\mathrm{CsPb}_{2} \mathrm{Br}, \mathrm{CsPbIBr}_{2}\right)$ leads to increased ambient stability of the perovskite structure. $\mathrm{CsPbI}_{2} \mathrm{Br}$ is used in PSCs exhibiting stabilized power output of 5.6\% and J-V scanning efficiency for up to 9.8\%. [48] Compared with $\mathrm{MAPb}\left(\mathrm{Br}_{\mathrm{x}} \mathrm{I}_{1-\mathrm{x}}\right)_{3}[49,50], \mathrm{CsPbBr}_{2}$ exhibits no photoinduced phase segregation and enhances thermal stability. [51] $\mathrm{CsPbIBr}_{2}$ exhibits good thermal stability in $\mathrm{N}_{2}$ environment and ambient conditions showing no obvious degradation at $150{ }^{\circ} \mathrm{C}$ for $120 \mathrm{~min}$ in air or 200 ${ }^{\circ} \mathrm{C}$ for $12 \mathrm{~h}$ in $\mathrm{N}_{2}$. [52] Heavy chloride doping, particularly approaching the solubility limit for chloride in $\mathrm{CsPb}_{3}$, is also reported to stabilize the perovskite phase of $\mathrm{CsPbI}_{3}$. [53] Mixed polycrystalline thin film of $\mathrm{CsPbI}_{3-\mathrm{x}} \mathrm{Cl}_{\mathrm{x}}$ exhibits enhanced stability towards phase change in humid conditions.

Michael Saliba et al. [54] introduced Cs into $\mathrm{MA} / \mathrm{FAPbI}_{3}$ to form cesium-containing triple cation PSCs with enhanced stability (stabilized power output of $\sim 21.1 \%$ and $\sim 18 \%$ after $250 \mathrm{~h}$ under operational conditions). The smaller Cs serves to lower the effective Cs/MA/FA cation radius and shift the tolerance factor directing to a cubic structure that matches the black perovskite phase. 


\subsection{Stability under illumination}

Binary lead halides tend to exhibit photodecomposition. The band-gap of $\mathrm{PbI}_{2}$ is about $2.47 \mathrm{eV}$ and absorbs visible photons to generate electron-hole pairs. The electrons could be trapped on $\mathrm{Pb}^{2+}$ and the $\mathrm{Pb}^{2+}$ can be reduced to $\mathrm{Pb}^{+}$and further to $\mathrm{Pb}$ [55], leading to the decomposition of $\mathrm{PbI}_{2}$. Similar to perovskite methylammonium lead halides, the lead halide parts may also exhibit such photodecomposition [55]. Alexksandra B. Djurisic et al. [56] studied the effect of excess $\mathrm{PbI}_{2}$ on the stability of the perovskite layer and found that the existence of a small fraction of excess $\mathrm{PbI}_{2}$ led to the degradation of the perovskite layer under illumination even when it was stored in inert atmosphere. Moreover, the perovskite film with excess $\mathrm{PbI}_{2}$ degraded faster than the perovskite films without excess $\mathrm{PbI}_{2}$ when illuminated in ambient atmosphere. Only the samples containing excess $\mathrm{PbI}_{2}$ exhibit degradation under illumination in inert atmosphere, which is attributed to the photodecomposition of $\mathrm{PbI}_{2}$ and the reaction products further react with the perovskite to result in its degradation. Ni Zhao et al. [57], Hongkun Cai et al. [58] and Wallace C.H. Choy et al. [59] also reported the negative effect of residue $\mathrm{PbI}_{2}$ on the long-term stability of PSCs. However, Eugene A. Katz et al. [60] exposed $\mathrm{CH}_{3} \mathrm{NH}_{3} \mathrm{PbI}_{3}$ films to 100 suns for 60 minutes at $\sim 25{ }^{\circ} \mathrm{C}$ and observed no degradation. But $\mathrm{CH}_{3} \mathrm{NH}_{3} \mathrm{PbI}_{3}$ begins to decompose after exposure to the same light intensity and dose for the same time at elevated temperature $\left(45 \sim 55{ }^{\circ} \mathrm{C}\right)$. Brian C. O'Regan et al. [61] revealed sealed mp-TiO $2 / \mathrm{MAPbI}_{3} /$ spiro cells can survive for $60 \mathrm{~h}$ with only $8 \%$ decrease in photocurrent under 40 SEs continuous illumination. Arie Zaban et al. [62,63] reported reversible structural changes in encapsulated $\mathrm{MAPbI}_{3}$ films under illumination.

Bertrand Philippe et al. [64] confirmed X-ray-induced degradation of $\mathrm{CH}_{3} \mathrm{NH}_{3} \mathrm{PbI}_{3}$ by the formation of $\mathrm{Pb}^{0}$ during heating to above $100{ }^{\circ} \mathrm{C}$. Perovskites are also sensitive to electron beam irradiation, given the energy of e-beam is much higher than that of a solar photon. The heating effect of the e-beam is considered the most obvious factor that leads to the cell degradation [65] . Haifeng Yuan et al. [66] observed dramatic changes in photoluminescence intensity, continuously tuning of energy band gaps and thinning of the film during the electron beam scanning. The authors attributed these changes to the e-beam induced formation of defects and vacancies and directional ions migration in perovskite. Upon e-beam scanning, $\mathrm{CH}_{3} \mathrm{NH}_{3}{ }^{+}$moves toward the top surface and forms $\mathrm{CH}_{3} \mathrm{NH}_{2}$ there. The formed $\mathrm{CH}_{3} \mathrm{NH}_{2}$ is readily removed from the surface by the high vacuum leading to the thinning of the film. This electron beam induced degradation highlight the concern in the characterization of the PSC using scanning electron microscopy or transmission electron microscopy techniques. Low energy electrons also affect the structural and chemical properties of $\mathrm{MAPbI}_{3}$. The electrons first interact with the organic part of the perovskite, leading to the broken of $\mathrm{C}-\mathrm{N}$ bond in $\mathrm{MA}^{+}$, which eventually leads to the escape of gaseous species $\left(\mathrm{NH}_{3}\right.$ and $\left.\mathrm{HI}\right)$ and formation of $\mathrm{PbI}_{2}$ and polymer hydrocarbon residue $\left(-\mathrm{CH}_{2}-\right)$ on the surface. [67] Felix Lang et al. [68] investigated the radiation hardness and self-healing of PSCs and results showed that the perovskite absorber could withstand proton doses up to $10^{12} \mathrm{p} \mathrm{cm}^{-2}$, which exceeded the damage threshold of c-Si by almost 3 orders of magnitude, and a self-healing process happened when the proton irradiation is terminated.

B.L. Oksengendler et al. [69] proposed a model of degradation mechanism of 
perovskite-based solar cells under irradiation, according to which, a close Frenkel pair in the sublattice of iodine is formed and there is a non-monotonic dependence of the stationary number of defects on the intensity of solar radiation, which allows the optimization of the conditions for reducing the radiation degradation of devices. Aitya D. Mohite et al. [70] reported that the degradation of crystalline large-grain-size PSCs under illumination was due to the degradation of the photocurrent. The photocurrent degradation could be attributed to the formation of light-induced meta-stable trap states. The accumulation of these meta-stable trap states leads to macroscopic charged areas and causes non-homogeneous electric fields in perovskite layer and further leads to the degradation of the photocurrent. Ivan G. Scheblykin [71] studied the mechanism of photo-induced degradation in $\mathrm{CH}_{3} \mathrm{NH}_{3} \mathrm{PbI}_{3}$ perovskite nanocrystals by super-resolution luminescence micro-spectroscopy. Results show that the degradation starts from the vacancies defects due to the migration of $\mathrm{MA}^{+}$induced by the filed caused by the photogenerated carrier accumulation. The migration of $\mathrm{MA}^{+}$distorts the lattice structure, changes the $\mathrm{Pb}-\mathrm{I}-\mathrm{Pb}$ bond angle, leading to the $3 \mathrm{D} \mathrm{MAPbI}_{3}$ crystal structure collapse to the 2D layered $\mathrm{PbI}_{2}$ structure, as shown in Fig. S5. Christoph J. Brabec et. al [72] investigated the photoinduced degradation of $\mathrm{MAPbI}_{3}$ in different conditions. Results show that there is no obvious photoinduced degradation in $\mathrm{N}_{2}$ atmosphere. In vacuum, the $\mathrm{MAPbI}_{3}$ degraded to metallic lead and $\mathrm{PbI}_{2}$ under light illumination. $\mathrm{MAPbI}_{3}$ degraded to lead salt $\left(\mathrm{PbO}, \mathrm{Pb}(\mathrm{OH})_{2}, \mathrm{PbCO}_{3}\right)$ under environmental conditions due to the combination effect of light, oxygen and moisture.

In addition to the photodecomposition of lead halide part in $\mathrm{CH}_{3} \mathrm{NH}_{3} \mathrm{PbI}_{3}$, the extended lifetime of photo-excited electrons in the perovskite layer may also lead to destructive side reactions and pose serious stability problems [71,73-76]. The photoexcited electrons in the perovskite may transfer to molecular oxygen, leading to the formation of superoxide if the electrons couldn't be extracted efficiently. The resulting superoxide attacks the perovskite absorber to form methylamine, lead iodide, iodine and water as degradation products, as shown in Fig. S6. [74] Recently, Flannan T.F. O’Mahony et al. [73] compared the performance stability of $\mathrm{TiO}_{2^{-}}, \mathrm{Al}_{2} \mathrm{O}_{3}$-based and bilayer PSCs (without mesoporous scaffold) in ambient environment and found that the long-time charge carrier separation degraded rapidly in mesoporous $\mathrm{Al}_{2} \mathrm{O}_{3}$ and bilayer system. However, this process has little effect on the sensitized mesoporous $\mathrm{TiO}_{2}$ films. Furthermore, the degradation is only found to occur when both light and oxygen are present due to the parasitic reactions taking place between the photo-generated electrons and molecular oxygen in the perovskite-absorbing layer. At the presence of electron acceptor $\mathrm{TiO}_{2}$, photo generated electrons could be rapidly extracted and subsequently avoid the parasitic reaction between these electrons and oxygen in the environment, thus $\mathrm{TiO}_{2}$ based PSC showed better stability. These observations suggest that the rapid extraction of electrons from perovskite sensitizer in the presence of mesoporous $\mathrm{TiO}_{2}$ acceptor is critical for the stability improvement of the PSCs and the adaptability to a variety of environments. Saif A. Haque et al. [75] compared the performance and stability of $\mathrm{MAPbI}_{3}$ based solar cells exposed to light/oxygen (light, in dry air) and light/humidity (light, $85 \% \mathrm{RH}$ in $\mathrm{N}_{2}$ ) and found that the device exposed to light/oxygen exhibited a 50\% drop of the initial PCE within $2 \mathrm{~h}$ while the device exposed to light/humidity showed only $10 \%$ decrease in PCE during the 12 hour aging period. The authors proposed that dominant degradation process of $\mathrm{MAPbI}_{3}$ based solar cells under ambient operating conditions was light and oxygen 
induced rather than moisture induced. Michael D. McGehee et al. [49] reported the reversible, light-induced trap formation due to the halide segregation of the mixed halide perovskite. The mixed halide perovskite $\mathrm{MAPb}\left(\mathrm{Br}_{\mathrm{x}} \mathrm{I}_{1-\mathrm{x}}\right)_{3}$ segregates into iodide-rich minority and bromide-enriched majority domains under illumination with the former acting as a recombination trap center. Prashant V. Kamat et al. [77] tracked the segregation of iodide and bromide ions in mixed halide lead perovskites during photo-irradiation and found that the phase separation occurred in a time scale of 0.1-0.3 $\mathrm{s}$ and the recovery time is about several minutes to an hour. The thermodynamic origin of the light-induced phase segregation in mixed-halide perovskite is considered rooted in halide migration and possibly affected by lattice strain. [78] Therefore, increasing compositional uniformity and reducing defect concentrations may significantly improve the stability of mixed halide perovskite. Eugene A. Katz et al. studied the effect of halide composition on the photochemical stability of perovskite photovoltaic materials. [79] $\mathrm{MAPbBr}_{3}$ films exhibited no degradation upon exposure to concentrated illumination of 100 suns and to outdoor 1sun, while $\mathrm{MAPbI}_{3}$ and mixed $\operatorname{MAPb}\left(\mathrm{Br}_{x} \mathrm{I}_{1-\mathrm{x}}\right)_{3}$ films degraded to $\mathrm{PbI}_{2}$ along with decrease of solar light absorption and mixed halide films exhibited ever faster absorption degradation. However, it was also found that as $\mathrm{Br}$ content increased in the mixed halide the FWHM of the XRD peaks increased and resulted in accelerated degradation. Therefore, it was speculated that the degradation of the perovskite might be correlated to the increased defect concentration in mixed films rather than the halide composition. Henry J. Snaith et al. [76] investigated the oxygen-induced degradation in mesoporous $\mathrm{Al}_{2} \mathrm{O}_{3} / \mathrm{MAPbI}_{3-\mathrm{x}} \mathrm{Cl}_{\mathrm{x}} \mathrm{PSC}$ and proposed a two-step degradation mechanism. When the device is operated in the presence of oxygen, the oxygen first induces the mass loss of the sample and forming of mobile defects within the device. The formed defects in the device lead to the reduction of the charge extraction efficiency and accumulation of charges. Over prolonged continuous operation under illumination in presence of oxygen, the accumulated charges lead to the oxidation of the perovskite material and further decomposition of it.

Fukashi Matsumoto et al. [80] studied the photodecomposition and morphology evolution of organometal halide PSCs and found that the perovskite material itself is much more stable under exposure to light and humidity than a device is after [6,6]-phenyl- $\mathrm{C}_{61}{ }^{-}$ butyric acid methyl ester (PCBM)/bathocuproine (BCP)/Al layers have been added. The perovskite film itself undergoes a multistep degradation behavior, i.e. there is a small enhancement of the electronic properties up to $1500 \mathrm{~J} / \mathrm{cm}^{2}$ followed by a plateau with little or no degradation until $\sim 3000 \mathrm{~J} / \mathrm{cm}^{2}$ and after that there is a sudden drop in the UV-vis absorption along with a decrease in PCE. The sudden failure of the perovskite film correlates with the morphology change from small to larger crystals and the formation of $\mathrm{PbI}_{2}$.

\subsection{Humidity sensitivity}

Due to the hygroscope of methylammonium cation, $\mathrm{CH}_{3} \mathrm{NH}_{3} \mathrm{PbI}_{3}$ is extremely sensitive to the humidity in the air and it is prone to decomposition by releasing $\mathrm{CH}_{3} \mathrm{NH}_{3} \mathrm{I}$ and leaving $\mathrm{PbI}_{2}$ behind, which leads to the decrease of the PCE of PSCs. The devices stored in either dry air or nitrogen retained $80 \%$ of the initial PCE after $24 \mathrm{~h}$ and $20 \%$ after 6 days, whereas the devices stored in ambient air retained less than $20 \%$ of the initial PCE after $24 \mathrm{~h}$ and $5 \%$ after 6 days [81] . 
To investigate the humidity-driven decomposition process of $\mathrm{CH}_{3} \mathrm{NH}_{3} \mathrm{PbI}_{3}$, Liduo Wang et al. [82] stored the $\mathrm{TiO}_{2} / \mathrm{CH}_{3} \mathrm{NH}_{3} \mathrm{PbI}_{3}$ films at $35^{\circ} \mathrm{C}, 60 \% \mathrm{RH}$ (relative humidity) for $18 \mathrm{~h}$. $\mathrm{UV}$-Vis spectroscopy and X-ray diffraction were used to characterize the absorption property and phase changes of the perovskite before and after the storage. Comparing the absorption property and XRD pattern of the perovskite before and after the storage, the decomposition process of the $\mathrm{CH}_{3} \mathrm{NH}_{3} \mathrm{PbI}_{3}$ is proposed as follows:

$\mathrm{CH}_{3} \mathrm{NH}_{3} \mathrm{PbI}_{3}(\mathrm{~s})=\mathrm{CH}_{3} \mathrm{NH}_{3} \mathrm{I}(\mathrm{aq})+\mathrm{PbI}_{2}(\mathrm{~s})\left(\mathrm{H}_{2} \mathrm{O}\right)$

$\mathrm{CH}_{3} \mathrm{NH}_{3} \mathrm{I}(\mathrm{aq})=\mathrm{CH}_{3} \mathrm{NH}_{2}(\mathrm{aq})+\mathrm{HI}(\mathrm{aq})$

$4 \mathrm{HI}(\mathrm{aq})+\mathrm{O}_{2}=2 \mathrm{I}_{2}(\mathrm{~s})+2 \mathrm{H}_{2} \mathrm{O}$

Here, $\mathrm{CH}_{3} \mathrm{NH}_{3} \mathrm{PbI}_{3}$ is considered decomposing directly into $\mathrm{PbI}_{2}$. However, some researchers showed the formation of a hydrated intermediate during the decomposition of the perovskite. Indeed, Timothy L. Kelly et al. [83] demonstrated the formation of a hydrated intermediate $\left(\mathrm{CH}_{3} \mathrm{NH}_{3}\right)_{4} \mathrm{PbI}_{6} \cdot 2 \mathrm{H}_{2} \mathrm{O}$ using in situ absorption spectroscopy and in situ grazing incidence X-ray diffraction to monitor the phase changes of perovskite degradation process in a chamber with carefully controlled relative humidity. Fig. S7 shows powder X-ray diffraction patterns for a sample of $\mathrm{CH}_{3} \mathrm{NH}_{3} \mathrm{PbI}_{3}$ powder, before and after the addition of a small amount of liquid water, exhibiting the existence of hydrated intermediate phase. Prashant V. Kamat et al. [84] also found that the absorption of the perovskite stored in dark for 14 days at room temperature and $50 \% \mathrm{RH}$ decreased not only in wavelength greater than $500 \mathrm{~nm}$ but also in the rest of entire visible spectrum. Moreover, the XRD pattern of the $\mathrm{CH}_{3} \mathrm{NH}_{3} \mathrm{PbI}_{3}$ film after stored in dark showed some diffraction peaks which could be indexed as $\left(\mathrm{CH}_{3} \mathrm{NH}_{3}\right)_{4} \mathrm{PbI}_{6} \cdot 2 \mathrm{H}_{2} \mathrm{O}$ but did not show any diffraction peaks of $\mathrm{PbI}_{2}$, as shown in Fig. S8. The absorbance and the XRD data suggest that the $\mathrm{CH}_{3} \mathrm{NH}_{3} \mathrm{PbI}_{3}$ in the film are not converted to $\mathrm{PbI}_{2}$ directly and instead, $\mathrm{CH}_{3} \mathrm{NH}_{3} \mathrm{PbI}_{3}$ is able to combine with $\mathrm{H}_{2} \mathrm{O}$, forming a hydrate product similar to $\left(\mathrm{CH}_{3} \mathrm{NH}_{3}\right)_{4} \mathrm{PbI}_{6} \cdot 2 \mathrm{H}_{2} \mathrm{O}$ as shown below:

$$
4 \mathrm{CH}_{3} \mathrm{NH}_{3} \mathrm{PbI}_{3}+\mathrm{H}_{2} \mathrm{O}=\left(\mathrm{CH}_{3} \mathrm{NH}_{3}\right)_{4} \mathrm{PbI}_{6} \cdot 2 \mathrm{H}_{2} \mathrm{O}+3 \mathrm{PbI}_{2}
$$

Stored in vacuum or dry air for a period, $\left(\mathrm{CH}_{3} \mathrm{NH}_{3}\right)_{4} \mathrm{PbI}_{6} \cdot 2 \mathrm{H}_{2} \mathrm{O}$ can dehydrate to form $\mathrm{CH}_{3} \mathrm{NH}_{3} \mathrm{PbI}_{3}$, which is in accordance with the reversible degradation of $\mathrm{CH}_{3} \mathrm{NH}_{3} \mathrm{PbI}_{3}$ stored in dark. The absorbance spectrum of $\mathrm{CH}_{3} \mathrm{NH}_{3} \mathrm{PbI}_{3}$ films stored in light closely matches the absorbance of $\mathrm{PbI}_{2}$, indicating that $\mathrm{CH}_{3} \mathrm{NH}_{3} \mathrm{PbI}_{3}$ films have converted to $\mathrm{PbI}_{2}$ in the presence of moisture under light. Clemens Burda et al. [85] reported the curing of degraded $\mathrm{MAPbI}_{3}$ perovskite films by X-ray, UV and electron beam irradiation, storage in low humidity condition or heat treatment at $35^{\circ} \mathrm{C}$ for $45 \mathrm{~min}$.

Aurelien Leguy et al. [86] detailed the different effects of water vapor and liquid water. They found that hydrated crystal phases $\left(\mathrm{CH}_{3} \mathrm{NH}_{3}\right)_{4} \mathrm{PbI}_{6} \cdot \mathrm{H}_{2} \mathrm{O}$ and $\left(\mathrm{CH}_{3} \mathrm{NH}_{3}\right)_{4} \mathrm{PbI}_{6} \cdot 2 \mathrm{H}_{2} \mathrm{O}$ (upon long exposure times) were formed when $\mathrm{CH}_{3} \mathrm{NH}_{3} \mathrm{PbI}_{3}$ was exposed to water vapor at room temperature and these phase changes were fully reversed when the material was subsequently dried, as showed in Fig.S9. The short circuit current $\left(\mathrm{J}_{\mathrm{SC}}\right)$ decreased $90 \%$ and open circuit voltage $\left(\mathrm{V}_{\mathrm{OC}}\right)$ decreased $200 \mathrm{mV}$ once the $\mathrm{CH}_{3} \mathrm{NH}_{3} \mathrm{PbI}_{3}$ film was in contact with water vapor. And, the short circuit current and open circuit voltage could recover quickly after storage in dry nitrogen for $6 \mathrm{~h}$. But the hysteresis of the I-V curve increased rapidly after the dehydration, which was considered to be related to the increase of the defect density and morphology change during recrystallization in the dehydration process. However, in contrast to the water vapor, $\mathrm{CH}_{3} \mathrm{NH}_{3} \mathrm{PbI}_{3}$ converted to $\mathrm{PbI}_{2}$ irreversibly in the presence of liquid water. 
Aron Walsh et al. [87] also proposed a possible decomposition path of $\mathrm{CH}_{3} \mathrm{NH}_{3} \mathrm{PbI}_{3}$ in the presence of water, as shown in Fig. 1a, which shows that only one water molecule is required to initiate the degradation of $\mathrm{CH}_{3} \mathrm{NH}_{3} \mathrm{PbI}_{3}$ through the following reaction equation:

$$
\mathrm{H}_{2} \mathrm{O}+\mathrm{n}\left[\left(\mathrm{CH}_{3} \mathrm{NH}_{3}{ }^{+}\right) \mathrm{PbI}_{3}\right]=\left[\left(\mathrm{CH}_{3} \mathrm{NH}_{3}{ }^{+}\right]_{\mathrm{n}-1}\left(\mathrm{CH}_{3} \mathrm{NH}_{2}\right) \mathrm{PbI}_{3}\right] \mathrm{H}_{3} \mathrm{O}
$$

However, there must be enough water to dissolve the reaction products such as $\mathrm{HI}$ and $\mathrm{CH}_{3} \mathrm{NH}_{2}$. In the presence of only a small amount of water, $\mathrm{CH}_{3} \mathrm{NH}_{3} \mathrm{PbI}_{3}$ will partly decompose until the water is saturated by $\mathrm{HI}$ or the vapor pressure of $\mathrm{CH}_{3} \mathrm{NH}_{2}$ will reach saturation. If there is enough water, all the $\mathrm{CH}_{3} \mathrm{NH}_{3} \mathrm{PbI}_{3}$ will convert to $\mathrm{PbI}_{2}$.

$\mathrm{Ab}$ initio molecular dynamics simulation results show that the water molecule can be easily trapped between and $\left[\mathrm{PbI}_{3}\right]^{-}$ions with negative oxygen towards the positive $\mathrm{MA}^{+}$and the positive hydrogen towards the negative $\left[\mathrm{PbI}_{3}\right]^{-}$, which significantly weakens the ionic bonding between $\mathrm{MA}^{+}$and $\left[\mathrm{PbI}_{3}\right]^{-}$ions. Fig. 1b schematically displays the degradation process. As temperature increases, the $\mathrm{H}_{2} \mathrm{O}$ molecule penetrates into between the two iodine atoms of the $\left[\mathrm{PbI}_{3}\right]^{-}$anion with its oxygen towards one of them. Then the water molecule pushes the iodine away due to the repulsion force between negative charged oxygen and iodine. Then the highly electronegative isolated iodine seizes a proton from the $\mathrm{NH}_{3}$ group in $\mathrm{MA}^{+}$forming $\mathrm{HI}$, then the $\mathrm{HI}$ escapes adhering to the $\mathrm{H}_{2} \mathrm{O}$ molecule with $\mathrm{PbI}_{2}$ and $\mathrm{CH}_{3} \mathrm{NH}_{2}$ left behind. [88]
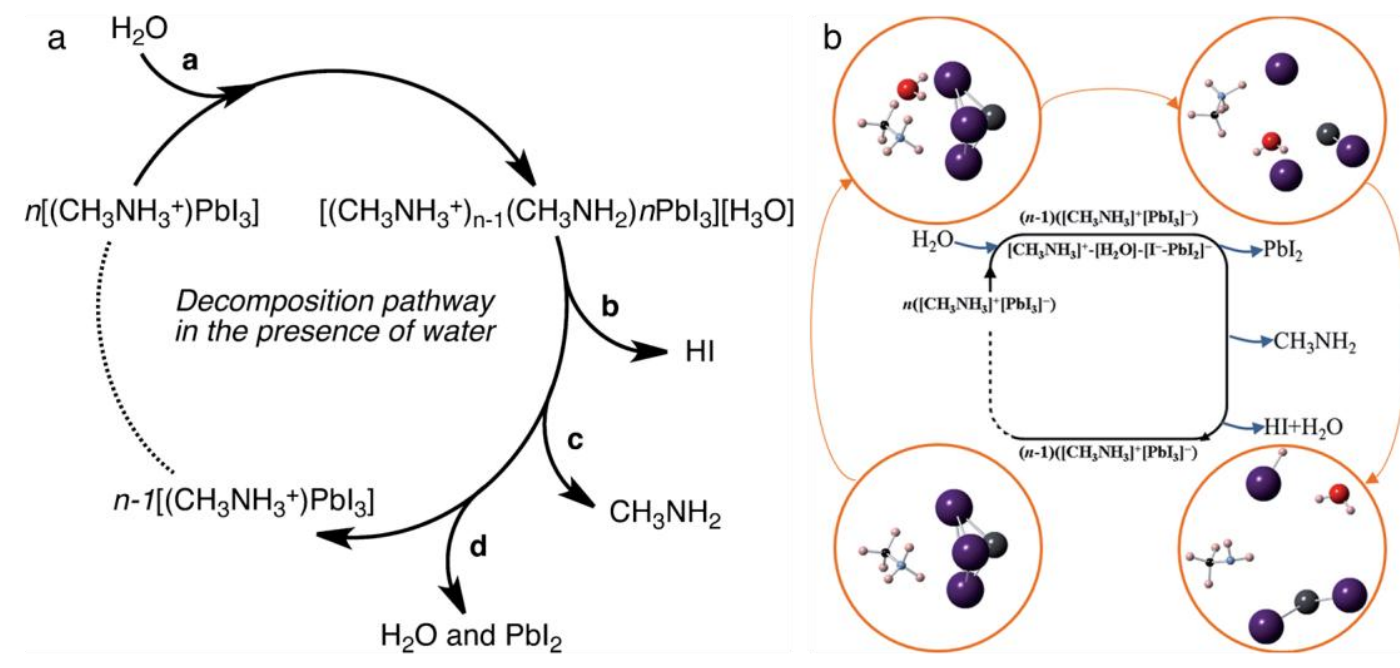

Fig. 1 (a) Possible decomposition pathway [87] and (b) schematic degradation mechanism [88] of hybrid halide perovskites in the presence of water ( $\mathrm{Pb}$ : lead back; I: purple; N: cyan; C: black; O: red; H: pink) Fig. 1(a) is reprinted with permission from ref 87. Copyright 2014, American Chemical Society. Fig. 1(a) is reprinted with permission from ref 88. Copyright 2016, Royal Society of Chemistry.

Hiroyuki Fujiwara et al. [89] studied the degradation mechanism of ultra-smooth $\mathrm{CH}_{3} \mathrm{NH}_{3} \mathrm{PbI}_{3}$ layers by a surface phase change sensitive real-time spectroscopic ellipsometry characterization. Results show that, at $40 \% \mathrm{RH}, \mathrm{CH}_{3} \mathrm{NH}_{3} \mathrm{PbI}_{3}$ layer degrades by two parallel reactions of (i) the desorption of $\mathrm{CH}_{3} \mathrm{NH}_{3} \mathrm{I}$ and formation of $\mathrm{PbI}_{2}$ by reaction (1) and (ii) the formation of $\mathrm{CH}_{3} \mathrm{NH}_{3} \mathrm{PbI}_{3}$ hydrate by $\mathrm{H}_{2} \mathrm{O}$ incorporation by reaction (4). Chen Gao et al. [90] also confirmed the existence of intermediate monohydrate $\mathrm{CH}_{3} \mathrm{NH}_{3} \mathrm{PbI}_{3} \cdot \mathrm{H}_{2} \mathrm{O}$ and proposed that the final decomposition products were $\mathrm{PbI}_{2}$ and aqueous $\mathrm{CH}_{3} \mathrm{NH}_{3} \mathrm{I}$ in the moisture induced degradation of $\mathrm{CH}_{3} \mathrm{NH}_{3} \mathrm{PbI}_{3}$. The moisture can disintegrate $\mathrm{CH}_{3} \mathrm{NH}_{3} \mathrm{PbI}_{3}$ and then 
change the distribution of the decomposition products, which results in incomplete reversible $\mathrm{CH}_{3} \mathrm{NH}_{3} \mathrm{PbI}_{3}$ hydrolysis reaction and degradation of photovoltaic performance. Rudiger Berger et al. [91] interpreted the incomplete recoverable performance in humidity-induced degradation of the PSC by the humidity-induced grain boundaries in the perovskite layer. Upon exposure to humidity, appearance of monohydrate $\left(\mathrm{CH}_{3} \mathrm{NH}_{3} \mathrm{PbI}_{3} \cdot \mathrm{H}_{2} \mathrm{O}\right)$ Bragg reflections agreed with the appearance of additional grain boundaries. The monohydrate is not stable under dry condition and will dehydrate to form $\mathrm{CH}_{3} \mathrm{NH}_{3} \mathrm{PbI}_{3}$. However, the humidityinduced grain boundaries won't disappear and affect the photovoltaic performance. Michael J. Heeben et al. [92] investigated the stability of perovskite solar cell in humid air by monitoring the spatial evolution of the quantum efficiency of PSCs during the exposure to humid atmosphere using laser beam induced current LBIC measurements. Results show that the degradation process has four steps and the first three of them are reversible. The fourth step is irreversible, which leads to decomposition of $\mathrm{MAPbI}_{3}$. The interactions between $\mathrm{MAPbI}_{3}$ and water were explained by a series of equilibriums within the $\mathrm{PbI}_{2}-\mathrm{CH}_{3} \mathrm{NH}_{3} \mathrm{I}-\mathrm{H}_{2} \mathrm{O}$ system, i.e. formation and decomposition of $\mathrm{CH}_{3} \mathrm{NH}_{3} \mathrm{PbI}_{3}$, formation and dehydration of monohydrate $\mathrm{CH}_{3} \mathrm{NH}_{3} \mathrm{PbI}_{3} \cdot \mathrm{H}_{2} \mathrm{O}$, formation and dehydration of dehydrate $\left(\mathrm{CH}_{3} \mathrm{NH}_{3}\right)_{4} \mathrm{PbI}_{6} \cdot 2 \mathrm{H}_{2} \mathrm{O}$, water-catalyzed decomposition to the starting components. [92]

Martin Ledinsky et al. [93] studied the Raman spectra of pristine $\mathrm{CH}_{3} \mathrm{NH}_{3} \mathrm{PbI}_{3}$ layers and the Raman bands that develop during moisture induced degradation and unambiguously proved that the final degradation products contain pure $\mathrm{PbI}_{2}$.

Jianning Ding et al. [94] analyzed the structural stability of $\mathrm{CH}_{3} \mathrm{NH}_{3} \mathrm{PbI}_{3}$ according to the strength of chemical bond between the organic and inorganic component. Results show that only one water molecule may weaken the strength of the hydrogen bond between $\mathrm{PbI}_{3}$ and $\mathrm{CH}_{3} \mathrm{NH}_{3}$ and two water molecules may almost break the hydrogen bond between $\mathrm{PbI}_{3}$ and $\mathrm{CH}_{3} \mathrm{NH}_{3}$ and lead to complete decomposition of $\mathrm{CH}_{3} \mathrm{NH}_{3} \mathrm{PbI}_{3}$. Due to the strong polarity of $\mathrm{H}_{2} \mathrm{O}$, the strength of the hydrogen bond between $\mathrm{H}_{2} \mathrm{O}$ and $\mathrm{CH}_{3} \mathrm{NH}_{3}$ is much greater than that of $\mathrm{PbI}_{3}$ and $\mathrm{CH}_{3} \mathrm{NH}_{3}$. This is consistent with general experimental results that $\mathrm{CH}_{3} \mathrm{NH}_{3} \mathrm{PbI}_{3}$ is relatively stable in low humidity but degrades rapidly in high humidity. However, because of the strong polarity of water molecular, the decomposition of $\mathrm{CH}_{3} \mathrm{NH}_{3} \mathrm{PbI}_{3}$ to $\mathrm{PbI}_{2}$ is inevitable in the presence of water and it is thus necessary to encapsulate the $\mathrm{CH}_{3} \mathrm{NH}_{3} \mathrm{PbI}_{3}$.

Hard X-ray photoelectron spectroscopy (HXRPES) are used to track the changes of $\mathrm{CH}_{3} \mathrm{NH}_{3} \mathrm{PbI}_{3}$ upon exposure to various environments such as water, temperature as well as long term storage in air and argon [64] . Results show that after exposure to water, the carbon and nitrogen in the perovskite surface completely disappeared, suggesting that the $\mathrm{CH}_{3} \mathrm{NH}_{3}$ was completely released from the film surface. The ratio of $\mathrm{I} / \mathrm{Pb}$ decreased from 3.3 to 1.9 after the exposure to water, indicating the conversion of $\mathrm{CH}_{3} \mathrm{NH}_{3} \mathrm{PbI}_{3}$ to $\mathrm{PbI}_{2}$. The ratio of $\mathrm{I} / \mathrm{Pb}$ decreased from 3.1 to 2.9 and 2.8, the ratio of $\mathrm{N} / \mathrm{Pb}$ from 0.9 to 0.7 and 0.6 after stored in dark for 10 weeks in argon $\left(\mathrm{O}_{2}<1 \mathrm{ppm}, \mathrm{H}_{2} \mathrm{O}<1 \mathrm{ppm}\right)$ and ambient air respectively, indicating that perovskite is unstable even in argon. Furthermore, $\mathrm{CH}_{3} \mathrm{NH}_{3} \mathrm{PbI}_{3}$ began to decompose as soon as the temperature got close to $100{ }^{\circ} \mathrm{C}$ in vacuum, and illumination of $\mathrm{X}$-ray also led to the degradation of $\mathrm{CH}_{3} \mathrm{NH}_{3} \mathrm{PbI}_{3}$ to form $\mathrm{Pb}$ atoms. PES results did not show the existence of hydrated intermediate due to the existence of liquid water since the water exposure on $\mathrm{CH}_{3} \mathrm{NH}_{3} \mathrm{PbI}_{3}$ was performed by putting a drop of liquid deionized water on a tilted perovskite $\mathrm{TiO}_{2} /$ FTO sample that was then allowed to dry in air for $2 \mathrm{~h}$. 
Jiang Tang et al. [95] investigated the interaction between perovskite films and moisture by in situ electrical resistance measurement and time-resolved X-ray diffraction analysis. Results show that upon short-time moisture exposure, the interaction between perovskite film and moisture is chemisorption and the resistance decrease is reversible. As the exposure time extends, the interaction transforms to chemical reaction experiencing hydration and successive decomposition of perovskite film. High-precision single-crystal X-ray diffraction of pristine and the crystals aged in wet air exhibits that the $\mathrm{H}_{2} \mathrm{O}$ inserts in the aged crystals and the $\mathrm{H}_{2} \mathrm{O}$ insertion changes the hydrogen bonds between $\mathrm{MA}^{+}$cation and I atoms. [96] In situ infrared spectroscopy, mass monitoring and X-ray diffraction were used to study the interaction between organic cation and $\mathrm{H}_{2} \mathrm{O}$ molecule in perovskite $\mathrm{MAPbI}_{3}$. [97] Results show that $\mathrm{H}_{2} \mathrm{O}$ molecules can penetrate into the perovskite lattice and share the space with MA up to one $\mathrm{H}_{2} \mathrm{O}$ per MA at high-humidity levels without formation of hydrogen bonding. The hydrogen bonding between $\mathrm{MA}$ and $\mathrm{H}_{2} \mathrm{O}$ won't form until the phase transition to monohydrate.

Yongli Gao et al. [98,99] investigated the degradation of coevaporated $\mathrm{CH}_{3} \mathrm{NH}_{3} \mathrm{PbI}_{3}$ thin films as exposed to oxygen, low pressure atmospheric air, atmospheric air and $\mathrm{H}_{2} \mathrm{O}$ using XPS and XRD. Results show that the $\mathrm{CH}_{3} \mathrm{NH}_{3} \mathrm{PbI}_{3}$ film is insensitive to oxygen and dry air. Upon exposure to $\mathrm{H}_{2} \mathrm{O}$, there is no $\mathrm{CH}_{3} \mathrm{NH}_{3} \mathrm{PbI}_{3}$ degradation observed when the pressure is less than $2 \times 10^{4}$ torr and he $\mathrm{H}_{2} \mathrm{O}$ acts as an $\mathrm{n}$-dopant. When the exposure is larger than $2 \times 10^{4}$ torr, the film begins to decompose and all of $\mathrm{N}$ and part of I are removed with crystalline $\mathrm{PbI}_{2}$, hydrocarbon complex, and O left on the substrate. Sylwia Ptasinska et al. [100] also reported the formation of $\mathrm{PbCO}_{3}, \mathrm{~Pb}(\mathrm{OH})_{2}$ and $\mathrm{PbO}$ as the degradation products of $\mathrm{CH}_{3} \mathrm{NH}_{3} \mathrm{PbI}_{3}$ upon exposure under ambient condition. Furthermore, instead of $\mathrm{PbI}_{2}$, Sylwia Ptasinska et al. proposed that $\mathrm{PbI}_{2+\mathrm{x}}{ }^{\mathrm{x}-}$ appeared as a transient phase upon $\mathrm{CH}_{3} \mathrm{NH}_{3} \mathrm{PbI}_{3}$ degradation and $\mathrm{PbI}_{2}$ powder degraded even faster than $\mathrm{CH}_{3} \mathrm{NH}_{3} \mathrm{PbI}_{3}$ under the same conditions.

Diverse preparation methods not only result in varied properties but also incongruent degradation pathways and products. Detailed simulation may shed some lights on the interaction of water molecular and perovskite lattice/surface. G. Grancini et al. [101] demonstrated that the crystal edge or boundary is susceptible to water intercalation due to hydrogen-bond interactions with the perovskite lattice. At the same time, the calculated formation energies for $4 \mathrm{MAPbI}_{3} \cdot 1 \mathrm{H}_{2} \mathrm{O}$ and $4 \mathrm{MAPbI}_{3} \mathrm{O}_{2}$ are $-0.45 \mathrm{eV}$ and the $0.17 \mathrm{eV}$ respectively, indicating spontaneous incorporation of $\mathrm{H}_{2} \mathrm{O}$ into the perovskite lattice while the incorporation of $\mathrm{O}_{2}$ is unfavorable. The incorporation of $\mathrm{H}_{2} \mathrm{O}$ molecule extends the depth of the surface region further into the bulk of the perovskite, which leads to more water incorporation and further results in lattice distortion and corresponding volume increase and bandgap widening. As four $\mathrm{H}_{2} \mathrm{O}$ molecules are incorporated, the perovskite lattice $\left(4 \mathrm{MAPbI}_{3} \cdot 4 \mathrm{H}_{2} \mathrm{O}\right)$ is not stable anymore and a non-perovskite structure hydrated $\mathrm{MAPbI}_{3}$ phase is formed. Robert Lovrincic et al. [102] revealed that there was no water absorption at $<10 \% \mathrm{RH}$ but a sudden increase at $10 \% \mathrm{RH}$. This process does not change the light absorption of the perovskite in the visible range but results in photocurrent increase instead, as shown in Fig.S10. The authors ascribed the observed increase in photocurrent upon exposure to water and oxygen to ionic conduction via hydrogen migration.

Filippo De Angelis et al. [103] investigated the atomic details of the interaction between $\mathrm{MAPbI}_{3}$ perovskites surface and a liquid water environment by ab initio molecular 
dynamics simulation. Results show that MAI-terminated surfaces undergo a rapid solvation process due to the interaction of water molecules with $\mathrm{Pb}$ atoms, which prompts the release of $\mathrm{I}$ atoms. $\mathrm{PbI}_{2}$-terminated surfaces exhibit more robust degradation due to stronger $\mathrm{Pb}$-I bonds, as shown in Fig. S11a. Results also show that the incorporation of one water molecule into $\mathrm{PbI}_{2}$-terminated slab could be the first step in the formation of an intermediate hydrated phase. Wanzhen Liang et al. [104] also found that the $\mathrm{PbI}_{2}$-terminated surface was the most stable surface while both the MAI-terminated and $\mathrm{PbI}_{2}$-defective surfaces underwent structural reconstruction, leading to the formation of hydrated compounds in humid environment. Recent experimental research demonstrated that $\mathrm{PbI}_{2}$ at the grain boundaries in $\mathrm{PbI}_{2}$ excess devices function acted as a barrier towards moisture ingress leading to higher moisture stability compared to MAI excess devices. [105] Li-Min Liu et al. [106] investigated the interaction between the water molecules and (001) surface of $\mathrm{CH}_{3} \mathrm{NH}_{3} \mathrm{PbI}_{3}$ by first-principle calculations. Results show that the water adsorption energy on the $\mathrm{CH}_{3} \mathrm{NH}_{3} \mathrm{PbI}_{3}$ (001) surface is $\sim 0.30 \mathrm{eV}$, suggesting that water can easily penetrate into the surface in the form of molecular state due to the large interspace in the perovskite $\mathrm{CH}_{3} \mathrm{NH}_{3} \mathrm{PbI}_{3}$ structure and the penetrating water molecules can further corrode down the whole structure gradually. Andrew M. Rappe et al. [107] studied the interaction of water with the (001) surface of $\mathrm{CH}_{3} \mathrm{NH}_{3} \mathrm{PbI}_{3}$ using density functional theory. Results suggest that the water adsorption to $\mathrm{CH}_{3} \mathrm{NH}_{3} \mathrm{PbI}_{3}$ (001) surfaces is polarization dependent, i.e., the water molecules more favorably adsorb on the MAI-terminated $\mathrm{P}^{+}$surface (molecules having their $\mathrm{NH}_{3}{ }^{+}$-ends pointing toward the surface) than the corresponding $\mathrm{P}^{-}$(all molecules having their $\mathrm{CH}_{3}$-ends pointing toward the surface) while $\mathrm{PbI}_{2}$-terminated $\mathrm{P}^{-}$surface binds water more strongly than the corresponding $\mathrm{P}^{+}$surface, as shown in Fig.S11b. The water molecule can infiltrate into the hollow site of the surface and get trapped and a higher water concentration will facilitate degradation through increased lattice distortion.

Patrik H.-L. Sit et al. [108] studied the structures of $\mathrm{CH}_{3} \mathrm{NH}_{3} \mathrm{PbI}_{3}$ and $\mathrm{CH}_{3} \mathrm{NH}_{3} \mathrm{PbBr}_{3}$ (110) surfaces and their interactions with water, hydroxyl radicals and hydroxide ions using ab initio density functional theory calculations. Results show that the top-layer surface $\mathrm{CH}_{3} \mathrm{NH}_{3}{ }^{+}$(MA) cations preferentially orient with the $\mathrm{NH}_{3}$ groups pointing downward into the surface so that the hydrogen ions of the $\mathrm{NH}_{3}$ groups form more hydrogen bonds with the halide ions. Deprotonation of the MA cations to form $\mathrm{CH}_{3} \mathrm{NH}_{2}$ and the following desorption of the $\mathrm{CH}_{3} \mathrm{NH}_{2}$ molecules are the key steps in the degradation mechanism. The $\mathrm{H}_{2} \mathrm{O}$ molecules can form hydrogen bonds with halide and take the place of MA cations, however there is no proton transfer from MA cations to $\mathrm{H}_{2} \mathrm{O}$ molecules. Adsorption of $\mathrm{H}_{2} \mathrm{O}$ molecules can only lower the desorption energy slightly. On the other hand, $\mathrm{OH}$ radicals and $\mathrm{OH}^{-}$ions were found to lower desorption energy greatly and spontaneously abstract hydrogens or protons from the MA cations, as shown in Fig.S12, which facilitates the degradation of the perovskites. DFT calculations also show that the formation of $\mathrm{CH}_{3} \mathrm{NH}_{3} \mathrm{PbI}_{3} \cdot \mathrm{H}_{2} \mathrm{O}$ is energetically favorable while the subsequent degradation of this monohydrate is energetically unfavorable (endothermic). [109] However, the presence of $\mathrm{OH}$ or $\mathrm{OH}^{-}$species greatly facilitates the degradation process, as the decomposition reactions of the monohydrate in the presence of $\mathrm{OH}$ are significantly less endothermic.

In summary, $\mathrm{CH}_{3} \mathrm{NH}_{3} \mathrm{PbI}_{3}$ complexes with limited $\mathrm{H}_{2} \mathrm{O}$ molecules to form hydrated intermediate in the presence of water vapor and the process is reversible through drying in 
inert atmosphere. In the presence of liquid water, however, $\mathrm{CH}_{3} \mathrm{NH}_{3} \mathrm{PbI}_{3}$ decomposes to $\mathrm{PbI}_{2}$ directly and irreversibly. Protecting organohalide perovskite thin films from water and ambient humidity therefore plays an indispensable role in the commercial uptake of PSCs.

\subsection{Effect of interface reaction}

Apart from the moisture in the air, the solvents, additives and modifiers used in the fabrication may also affect the stability of perovskite. For example, 4-tert-butylpridine (4tBP), an important additive in the spiro-OMeTAD HTM, is able to corrode $\mathrm{CH}_{3} \mathrm{NH}_{3} \mathrm{PbI}_{3}$ by complexing with $\mathrm{PbI}_{2}$ and forming complexes $\left[\mathrm{PbI}_{2}(4-\mathrm{tBP})_{x}\right]$, which will lead to the extraction of $\mathrm{PbI}_{2}$ from $\mathrm{CH}_{3} \mathrm{NH}_{3} \mathrm{PbI}_{3}$ and the acceleration of its degradation [110] .

Perovskite material may be in contact with charge transport materials such as titania, zinc oxide etc. in a solar device. Seigo Ito et al. [111] considered that $\mathrm{TiO}_{2}$ could extract electrons from $\mathrm{I}^{-}$ions and reduce $\mathrm{I}^{-}$to $\mathrm{I}_{2}$, as shown in Fig. 2, which may lead to the decomposition of $\mathrm{CH}_{3} \mathrm{NH}_{3} \mathrm{PbI}_{3}$ since it is composed of $\mathrm{CH}_{3} \mathrm{NH}_{3}{ }^{+}, \mathrm{Pb}^{2+}$ and I- The deprotonation of $\mathrm{CH}_{3} \mathrm{NH}_{3}{ }^{+}$leads to the evolution of $\mathrm{CH}_{3} \mathrm{NH}_{2}$ and $\mathrm{H}^{+}$, and the electron extracted by $\mathrm{TiO}_{2}$ may come back to the surface to combine with I atom and $\mathrm{H}^{+}$to form $\mathrm{HI}$. As a result, $\mathrm{CH}_{3} \mathrm{NH}_{3} \mathrm{PbI}_{3}$ converts to $\mathrm{CH}_{3} \mathrm{NH}_{2}, \mathrm{HI}$ and $\mathrm{PbI}_{2}$, and since $\mathrm{CH}_{3} \mathrm{NH}_{2}$ and $\mathrm{HI}$ are volatile and they evaporate into the air, $\mathrm{PbI}_{2}$ is left behind on the surface of $\mathrm{TiO}_{2}$. In order to passivate the interface reaction between $\mathrm{TiO}_{2}$ and $\mathrm{CH}_{3} \mathrm{NH}_{3} \mathrm{PbI}_{3}$, a barrier layer of $\mathrm{Sb}_{2} \mathrm{~S}_{3}$ is deposited between $\mathrm{TiO}_{2}$ and $\mathrm{CH}_{3} \mathrm{NH}_{3} \mathrm{PbI}_{3}$ to prevent the contact and the decomposition of $\mathrm{CH}_{3} \mathrm{NH}_{3} \mathrm{PbI}_{3}$ and device degradation [111] .

(a)

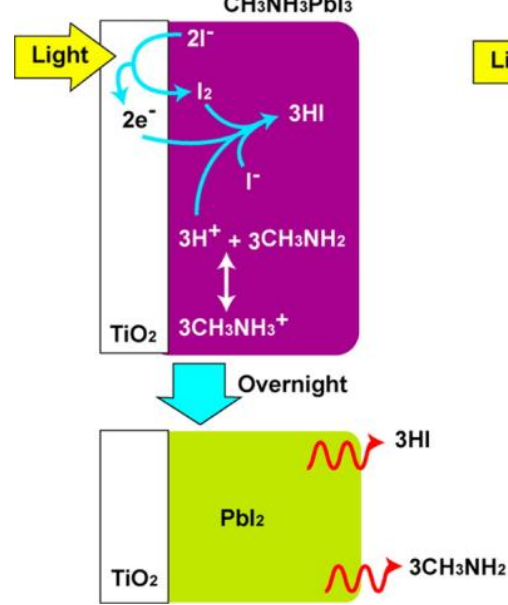

(b)

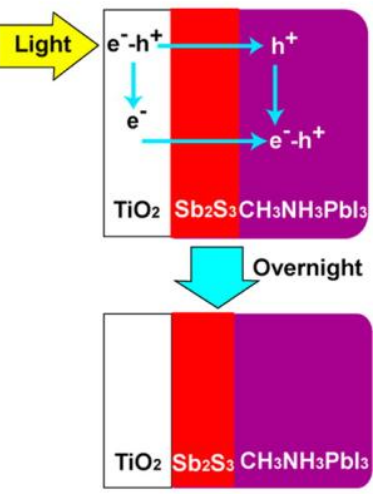

Fig. 2 Degradation of $\mathrm{CH}_{3} \mathrm{NH}_{3} \mathrm{PbI}_{3}$ on the surface of $\mathrm{TiO}_{2}$ and the barrier property of $\mathrm{Sb}_{2} \mathrm{~S}_{3}$ [111] Reprinted with permission from ref 111. Copyright 2014, American Chemical Society.

Besides $\mathrm{TiO}_{2}, \mathrm{ZnO}$ may also react with perovskite under illumination and exacerbate the decomposition of the perovskite deposited on it [112]. A. Dhar et al. [113] reported that the presence of $\mathrm{ZnO}$ accelerated the degradation rate of $\mathrm{MAPbI}_{3}$ films under ambient annealing. Due to the relative basic nature of $\mathrm{ZnO}$ surface, proton-transfer reactions may happen at the $\mathrm{ZnO} / \mathrm{CH}_{3} \mathrm{NH}_{3} \mathrm{PbI}_{3}$ interface, leading to the de-protonation of the methylammonium cation. The de-protonation of methylammonium cation leads to the formation of methylamine and $\mathrm{PbI}_{2}$, i.e., the decomposition/degradation of the perovskite. [114] The presence of hydroxyl groups and residual acetate ligands on the $\mathrm{ZnO}$ surface may further accelerate the 
decomposition process [114-116]. Calcination [114] or aging [117] of the $\mathrm{ZnO}$ layer results in more thermally stable $\mathrm{ZnO} / \mathrm{CH}_{3} \mathrm{NH}_{3} \mathrm{PbI}_{3}$ interface, however, the basic $\mathrm{ZnO}$ surface is the fundamental driver of the perovskite thermal decomposition [114] . Alex A. Zakhidov et al. [118] also confirmed the decomposition of $\mathrm{CH}_{3} \mathrm{NH}_{3} \mathrm{PbI}_{3}$ deposited on the $\mathrm{ZnO}$ electron transport layer (ETL) and found that this decomposition reaction was reversible and could be prevented by a restricted volume solvent annealing process. However, they also found that the decomposition required the presence of a certain amount of the processing solvent within the film and the decomposition did not occur if the processing solvent was removed from the film [118] . J. Idigoras et al. [119] studied the interaction between the $\mathrm{CH}_{3} \mathrm{NH}_{3} \mathrm{PbI}_{3}$ and substrates ( $\mathrm{TiO}_{2}, \mathrm{ZnO}$ and $\mathrm{Al}_{2} \mathrm{O}_{3}$ ) by FTIR spectroscopy and found that $\mathrm{CH}_{3} \mathrm{NH}_{3} \mathrm{PbI}_{3}$ tended to interact with $\mathrm{ZnO}$ through amine group and change its morphology. In the presence of moisture, $\mathrm{ZnO}$ induces a chemical change of the perovskite and this change is related to the chemical nature of the oxide rather than the structural properties of it. Sai-Wing Tang et al. [120] also reported the decomposition of $\mathrm{CH}_{3} \mathrm{NH}_{3} \mathrm{PbI}_{3}$ crystal during the annealing process if the perovskite film was directly in contact with $\mathrm{ZnO}$ layer due to the hydroxide constitutions on the as-synthesized ZnO-NPs surface, as shown in Fig. S13. Poly(ethyleneimine) (PEI) was deposited between the perovskite and $\mathrm{ZnO}$ as buffer layer to avoid direct interaction between the $\mathrm{ZnO}$ and perovskite thin films. Aluminum doping of $\mathrm{ZnO}$ may diminish the Lewis-base chemical reaction between perovskite and $\mathrm{ZnO}$, leading to thermally stable perovskite [121] . $\mathrm{Mg}$-doped $\mathrm{ZnO}\left(\mathrm{Zn}_{1-\mathrm{x}} \mathrm{Mg}_{\mathrm{x}} \mathrm{O}, \mathrm{ZMO}\right)$ is also reported as electron selective contact layers for efficient PSCs. [122] ZMO-based PSCs exhibited improved thermo-stability, durability and photo-stability due to the improved chemical/photochemical stability of ZMO. Rui Zhu et al. [123] also reported that $\mathrm{ZnO}$-based electron-selective layer accelerated the decomposition of $\mathrm{CH}_{3} \mathrm{NH}_{3} \mathrm{PbI}_{3}$ film while $\mathrm{Cs}_{2} \mathrm{CO}_{3}$-modified ITO had less negative effect on the stability of $\mathrm{CH}_{3} \mathrm{NH}_{3} \mathrm{PbI}_{3}$. The decomposition product $\mathrm{PbI}_{2}$ may also act as protection layer preventing the further degradation of the $\mathrm{MAPbI}_{3}$ on $\mathrm{ZnO}$. The $\mathrm{ZnO}$ nanorod array based PSC fabricated in $\sim 70 \%$ RH condition maintained more than $72 \%$ of the initial PCE after stored under $40 \pm 3 \%$ RH conditions without encapsulation for 250 days. [124] The enhanced stability is attributed to the $\mathrm{PbI}_{2}$ passivation layer formed during the fabrication process by the rapid decomposition/separation of $\mathrm{MAPbI}_{3}$, which inhibits the contact and further reaction between $\mathrm{ZnO}$ and $\mathrm{MAPbI}_{3}$. $\mathrm{TiO}_{2}$ can be used to passivate $\mathrm{ZnO}$ nanorods, reducing chemisorbed hydroxyl groups, to improve the thermal stability of $\mathrm{ZnO}$-based devices [125] . An aging step of $\mathrm{ZnO}$ films is also demonstrated to enhance the thermal stability of $\mathrm{MAPbI}_{3} / \mathrm{ZnO}$ bilayer and device [117].

David B. Mitzi et al. [126] reported the diffusion of $\mathrm{Cd}$ into perovskite and formation of insulating $\left(\mathrm{CH}_{3} \mathrm{NH}_{3}\right)_{2} \mathrm{CdI}_{4}$ by the reaction of CdS and MAI in the PSCs using CdS as ETL.

\subsection{Synergistic effect of illumination, temperature and water reaction}

Apart from the chemical degradation through the interaction with water as given in Section 2.3, $\mathrm{MAPbI}_{3}$ also exhibits thermodynamic degradation through the creation of volatile molecular defects [127]. TGA analysis shows that the $\mathrm{MAPbI}_{3}$ single crystal possesses better thermal stability than thin film as the TGA curve of single crystals shows no signature of mass loss up to $240{ }^{\circ} \mathrm{C}$ while thin films decomposes at temperatures of $150{ }^{\circ} \mathrm{C}$ [128] . John A. McLeod et al. [129] found the evidence of measurable quantities of both 
$\mathrm{CH}_{3} \mathrm{I}$ and $\mathrm{NH}_{3}$ within the perovskite, indicating the dissociation of $\mathrm{MA}^{+}$cations in perovskite into metastable $\mathrm{CH}_{3} \mathrm{I}-\mathrm{PbI}_{2}$ defects and trapped $\mathrm{NH}_{3}$. The trapped $\mathrm{NH}_{3}$ may escape from the lattice and lead to the degradation of $\mathrm{MAPbI}_{3}$. Coupled TG-DTA and thermogravimetry-mass spectrometry analysis showed that the thermal degradation of $\mathrm{CH}_{3} \mathrm{NH}_{3} \mathrm{PbI}_{3}$ and $\mathrm{CH}_{3} \mathrm{NH}_{3} \mathrm{I}$ released $\mathrm{NH}_{3}$ and $\mathrm{CH}_{3} \mathrm{I}$ as degradation products. [130] However, Alessandro Latini et al. investigated the thermodynamic stability of methylammonium lead halide perovskites $\left(\mathrm{MAPbCl}_{3}, \mathrm{MAPbBr}_{3}\right.$ and $\left.\mathrm{MAPbI}_{3}\right)$ with non-ambient X-ray diffraction, Knudsen effusionmass spectrometry (KEMS) and Knudsen effusion mass loss (KEML) and found that all the materials decomposed to the corresponding solid lead halide and gaseous methylamine and hydrogen halide. [131] Theoretical analysis indicates that the thermodynamic creation of molecular vacancies is the most probable route toward $\mathrm{PbI}_{2}$ formation due to the low dissociation energies of HI and MAI molecular defects. HI and MAI molecules are highly volatile, which can break the thermodynamic creation/recombination defect equilibrium in vacuum, leading to the partial converting of $\mathrm{MAPbI}_{3}$ into $\mathrm{PbI}_{2}$ in a vacuum chamber at $\sim 10^{-2}$ torr. I. Deretzis et al. [127] demonstrated that the structural decomposition of perovskite could take place in both air and vacuum conditions, as shown in Fig.S14, whereas the degradation process gets strongly accelerated by temperature annealing. The structural defectforming degradation of $\mathrm{MAPbI}_{3}$ to $\mathrm{PbI}_{2}$ can be accelerated by water reaction or through temperature annealing with the $\mathrm{MAPbI}_{3}$ layer being fully converted to $\mathrm{PbI}_{2}$ after only $\sim 14 \mathrm{~h}$ at $150{ }^{\circ} \mathrm{C}$ annealing in vacuum. Bert Conings et al. [132] revealed an intrinsically stability issue of $\mathrm{MAPbI}_{3}$ while heating to $85{ }^{\circ} \mathrm{C}$, a temperatures comparable to the higher range of operational temperatures in full sunlight. The calculated formation energy of $\mathrm{MAPbI}_{3}$ is about 0.11-0.14 eV per unit cell, which is very close to the average thermal energy of $0.093 \mathrm{eV}$ estimated for $85{ }^{\circ} \mathrm{C}$, leading to the instability of individual unit cells upon annealing to such temperatures and resulting in decomposition of $\mathrm{MAPbI}_{3}$ as the annealing time increses. The unit cell of the perovskite breaks down not only for humidity but also due to thermal instability of its constituents. Perovskites and its building blocks disintegrate even in the absence of oxygen and water. [132]

G. Divitini et al. [133] reported the in situ TEM observation of heat-induced degradation of PSCs. But no visible change is observed in the perovskite layer below $150{ }^{\circ} \mathrm{C}$. The device fabricated in air exhibits inhomogeneous perovskite layer, which presents a different degradation pathway from the devices processed in a glovebox. The device fabricated in air exhibits significant migration of iodine into the HTM layer.

D. Venkataraman et al. [134] revealed the quasi-reversible degradation of $\mathrm{MAPbI}_{3}$ and $\mathrm{FAPbI}_{3}$ PSCs via a combination of heat and light facilitates rapid ion diffusion, as shown in Fig.S15, which is ascribe to the light induced and thermally activated diffusion of MA or FA cations in the presence of both IR and visible component illumination. The EIS results indicate that the ion migration can be induced and accelerated by visible light, while the PXRD shows that IR illumination leads to the expansion of perovskite lattice and the decrease of the activation energy barrier for ion transport.

Eugene A. Katz et al. [60] studied the synergistic effect of temperature and concentrated illumination on the stability of perovskite photovoltaic materials. As shown in Fig. S16, $\mathrm{CH}_{3} \mathrm{NH}_{3} \mathrm{PbI}_{3}$ begins to decompose after 60 minutes exposure to 100 suns at an elevated temperature $\left(45 \sim 55^{\circ} \mathrm{C}\right)$. No degradation was observed when the $\mathrm{CH}_{3} \mathrm{NH}_{3} \mathrm{PbI}_{3}$ films 
were exposed to the same light intensity and dose for same amount of time except a lower sample temperature $\left(\sim 25{ }^{\circ} \mathrm{C}\right)$. This indicates that higher temperature drives a faster photodegradation. Furthermore, there was no degradation observed when the $\mathrm{CH}_{3} \mathrm{NH}_{3} \mathrm{PbI}_{3}$ films were heated to $45 \sim 55{ }^{\circ} \mathrm{C}$ in dark. This confirms that the degradation is due to photo decomposition in nature, not thermal decomposition. Considering the above facts, it is concluded that the degradation of $\mathrm{CH}_{3} \mathrm{NH}_{3} \mathrm{PbI}_{3}$ comes from a synergistic effect of temperature and illumination. In addition, no degradation was observed after the exposure of $\mathrm{CH}_{3} \mathrm{NH}_{3} \mathrm{PbBr}_{3}$ to similar stress condition (light intensity, dose and temperature), which indicated that $\mathrm{CH}_{3} \mathrm{NH}_{3} \mathrm{PbBr}_{3}$ is more stable than $\mathrm{CH}_{3} \mathrm{NH}_{3} \mathrm{PbI}_{3}$. This may be interpreted by that $\mathrm{Br}$ is more electronegative and more active to take or hold electrons, which makes it harder for $\mathrm{Pb}$ to be reduced to $\mathrm{Pb}^{0}$. At the same time, the radius of $\mathrm{Br}$ ion is smaller than $\mathrm{I}$ ion and the structure of $\mathrm{CH}_{3} \mathrm{NH}_{3} \mathrm{PbBr}_{3}$ is more compact than that of $\mathrm{CH}_{3} \mathrm{NH}_{3} \mathrm{PbI}_{3}$, which also contributes to the stability of $\mathrm{CH}_{3} \mathrm{NH}_{3} \mathrm{PbBr}_{3} . \mathrm{CH}_{3} \mathrm{NH}_{3} \mathrm{PbBr}_{3}$ exhibits better thermal stability under temperature of $375{ }^{\circ} \mathrm{C}$, and $\mathrm{CH}_{3} \mathrm{NH}_{3} \mathrm{PbBr}_{3}$ is not easier to absorb moisture as the TGA curve of $\mathrm{CH}_{3} \mathrm{NH}_{3} \mathrm{PbBr}_{3}$ film remains unchanged at low temperature $\left(<100{ }^{\circ} \mathrm{C}\right)$ and no mass loss appears related to water evaporation. [135] A recent research showed that the efficiency of $\mathrm{CH}_{3} \mathrm{NH}_{3} \mathrm{PbI}_{2} \mathrm{Br}$ device was well retained after exposure to ambient air for $300 \mathrm{~h}$ without any encapsulation [136] .

Beyond above mentioned stability issues, a most recent paper reported that possible solid-state electrochemical reaction in $\mathrm{CH}_{3} \mathrm{NH}_{3} \mathrm{PbI}_{3}(\mathrm{Cl})$ films would lead to the formation of iodine. Furthermore, if the $\mathrm{I}_{2}$ can leave the cation, the reaction will become reversible and affect the long-term stability of $\mathrm{CH}_{3} \mathrm{NH}_{3} \mathrm{PbI}_{3}(\mathrm{Cl})$ [137]. The characterization process may also lead to the stability concern, Mowafak Al-Jassim et al. [138] reported electron beam induced damage in perovskite film. The electron beam irradiation may lead to the formation of defects and the electron-beam heating can induce the phase transformation of the perovskite. These alert us that attention should be pay to avoid significant change of material properties from a sample's pristine state during measurement.

Meicheng Li et al. [139] reported that the PSC efficiency decreased from $18.2 \%$ to $11.5 \%$ after stored in ambient for 7 days while no decomposition and morphology change of the perovskite film was observed. The degradation of the PSC is attributed to the increased trap states, which improved the electron-hole recombination and lowed the device photovoltaic performance.

Rajan Jose et al. [140] studied the humidity and photo-stability of perovskite films and emphasized that humidity alone was not the major degradation factor. It was the photon dose integrating with humidity exposure that triggered the instability. The perovskite films exhibited minor degradation upon exposure to a humid ( $\mathrm{RH}>70 \%$ ) dark environment, however, once upon exposure to light, the films underwent significant degradation.

\section{Effect of mesoporous $\mathrm{TiO}_{2}$ on the stability of PSCs}

\subsection{UV light-related stability}

Upon UV light exposure, the photogenerated holes in the valence band of $\mathrm{TiO}_{2}$ react with oxygen radicals absorbed at the surface oxygen vacancies, which will lead to the desorption of molecular oxygen from these sites, leaving behind unoccupied, deep surface trap sites and one free electron per site. These electrons are considered being trapped in the 
unoccupied deep surface trap sites, as shown in Fig. S17 [141], and will recombine with the excess holes in the heavy doped p-type hole transporter. Upon photo excitation of the $\mathrm{CH}_{3} \mathrm{NH}_{3} \mathrm{PbI}_{3}$, photogenerated electrons are injected either into the conduction band of $\mathrm{TiO}_{2}$ followed by being deeply trapped by surface trap sites or directly into the deep surface traps. These deeply trapped electrons are all not mobile and can readily recombine with the holes in the hole-conductor, resulting in a low photogenerated current.

Since the desorption rate of oxygen molecule is in proportion to the oxygen partial pressure and is likely to be slow and reversible, the steady state number of empty deep trap sites will be dependent on the oxygen partial pressure in the pores. Hence the density of deep trap states is far lower in the presence of oxygen than in the absence of oxygen. Oxygen acts as pacifier for these sites. That's why the performance of the devices encapsulated in nitrogen degrades rapidly in short term [141] . A thin layer of CdS shell on the surface of $\mathrm{TiO}_{2}$ may also passivate the $\mathrm{TiO}_{2}$ surface by inhibiting the desorption of oxygen molecular, as shown in Fig. S18, leading to improved light stability, i.e. retaining nearly $80 \%$ of the initial PCE after $12 \mathrm{~h}$ of full sunlight illumination while the bare $\mathrm{TiO}_{2}$ counterpart only maintaining $40 \%$ [142] . CdS further can be used as hole-blocking layer in replacement of $\mathrm{TiO}_{2}$ in $\mathrm{PSCs}_{\text {and }}$ the CdS-based cell retains $90 \%$ of the initial PCE under continuous illumination for $12 \mathrm{~h}$ while that of the $\mathrm{TiO}_{2}$-based device decreases to $18 \%$ [143] .

Inserting a $\mathrm{CsCl}$ modification layer between $\mathrm{TiO}_{2}$ and perovskite can also enhance the UV-induced stability of the perovskite film [144] . The $\mathrm{CsCl}$ modified device maintained $70 \%$ of its initial PCE after exposure to UV $\left(365 \mathrm{~mW} \mathrm{~cm}^{-2}\right)$ for $200 \mathrm{~min}$ at a temperature of $41{ }^{\circ} \mathrm{C}$ and a RH of $30 \%$ while the PCE of the control pristine device decreased to nearly $0 \%$ in $200 \mathrm{~min}$. Henry J. Snaith et al. [145] reported the insertion of $\mathrm{CsBr}$ as interface modification between the $\mathrm{CH}_{3} \mathrm{NH}_{3} \mathrm{PbI}_{3-\mathrm{x}} \mathrm{Cl}_{\mathrm{x}}$ absorber layer and the electron collection layer, which led to an improved UV-light stability of planar heterojunction PSCs. Results show that the $\mathrm{CsBr}$ modified device remained more than $70 \%$ of its initial PCE after 20 min UV irradiation in air while the PCE of the control device degraded to nearly zero under the same exposure and testing conditions. $\mathrm{CsBr}$ modification can reduce the chemical reactivity of $\mathrm{TiO}_{2}$ and defect density at the perovskite/ $/ \mathrm{TiO}_{2}$ interface and defect sites are considered as the most likely sites for the onset of degradation. Amino acids can also be inserted between the compact $\mathrm{TiO}_{2}$ layer and the perovskite layer to prevent the decomposition of the perovskite layer induced by the superoxide anions and hydroxyl radicals generated under illumination from the $\mathrm{H}_{2} \mathrm{O}$ and $\mathrm{O}_{2}$ adsorbed on the $\mathrm{TiO}_{2}$ layer. [146]

Electron beam deposited $\mathrm{TiO}_{2}$ thin films with deep-level hole traps exhibited reduced ultraviolet photocatalytic activity, leading to enhanced long-term stability for planar PSCs. Under continuous operation near the maximum power point, the device yielded a PCE of over $15.4 \%$ for at least $100 \mathrm{~h}$. [147]

In view of stabilization of $\mathrm{TiO}_{2}$-based sensitized solar cell, an UV cutoff filter is often used to eliminate the effect of UV light absorption by $\mathrm{TiO}_{2}$. Results showed that the stability of $\mathrm{TiO}_{2}$-based solar cells was improved obviously upon using an UV filter. However, this stabilization strategy may also lead to the loss in photocurrent and further the decrease in efficiency.

Downshifting nanoparticle layer is another method for mitigating the UV degradation in $\mathrm{TiO}_{2}$-based PSCs. The PSC coated with transparent down-shifting phosphor exhibited 
enhanced stability under prolonged illumination, maintaining more than $50 \%$ of its initial PCE, whereas PSC without the phosphor layer only retained $\sim 35 \%$ of its initial value, as shown in Fig. S19 [148] .

Furthermore, when the absorption of $\mathrm{TiO}_{2}$ extends to visible spectrum, it means that prolonged exposure to visible light may also lead to the degradation of the performance of PSCs. Henry J. Snaith et al. [141] proposed to remove the $\mathrm{TiO}_{2}$ altogether to eliminate the $\mathrm{UV} /$ Vis-induced stability concerns. Mesoporous $\mathrm{Al}_{2} \mathrm{O}_{3}$ is alternatively used to replace $\mathrm{TiO}_{2}$ as the scaffold, photocurrent of $\mathrm{Al}_{2} \mathrm{O}_{3}$-based PSC encapsulated with an epoxy resin and a glass coverslip in a nitrogen-filled glove box remains stable over $1000 \mathrm{~h}$ illumination at $40{ }^{\circ} \mathrm{C}$ while the $\mathrm{TiO}_{2}$-based cells almost completely degraded within $3 \mathrm{~h}$. However, the PCE decreased $50 \%$ in the initial $200 \mathrm{~h}$ of aging due to the decrease of $\mathrm{V}_{\text {OC }}$ (open circuit voltage) and FF (Fill Factor, FF). Seigo Ito et al. [149] examined the light stability of $\mathrm{MAPbI}_{3}, \mathrm{MAPBr}_{3}, \mathrm{FAPbI}_{3}$ and $\mathrm{FAPbBr}_{3}$ on $\mathrm{TiO}_{2}$ and $\mathrm{Al}_{2} \mathrm{O}_{3}$ scaffold in the air and found that all of the perovskites (except for $\mathrm{FAPbI}_{3}$ ) degraded on $\mathrm{TiO}_{2}$ rapidly under visible and $\mathrm{UV}$-vis light for $24 \mathrm{~h}$ in air. All of the perovskites are stable on $\mathrm{Al}_{2} \mathrm{O}_{3}$ scaffold under the same conditions. Apart from the replacement of $\mathrm{TiO}_{2}$, doping $\mathrm{TiO}_{2}$ with $\mathrm{Al}$ may also passivate the surface nonstoichiometric defects. Since $\mathrm{Al}^{3+}$ is stable, substitution of $\mathrm{Ti}^{4+}$ with $\mathrm{Al}^{3+}$ may remove the oxygen vacancies from the lattice without the formation of deep trap sites, as shown in Fig. S20. Both of the enhancement in solar cell performance and the increase in stability are attributed to the reduction of nonstoichiometric oxygen-induced defects in the $\mathrm{TiO}_{2}$ by Al-doping, which permanently passivates surface and bulk defects, removes deep electronic traps and subbandgap states and raises the conduction band [150] . Nd-doped $\mathrm{TiO}_{2}$ based PSC is also reported to exhibit increased stability and performance due to the $\mathrm{Nd}$ passivation of oxygen defects in $\mathrm{TiO}_{2}$ and thus increase electron transport and reduce charge recombination in the mesoporous $\mathrm{TiO}_{2}$. [151]

The PCE and normalized PCE (PCE/Initial PCE) of a series of devices related to UVinduced instability plotted as a function of storage time for PSCs are shown in Fig. 3. Black squares are the initial PCEs of the devices and blue dots are the normalized PCEs after different storage time. The device configuration, encapsulation condition and storage condition of the devices are summarized in table 1. 


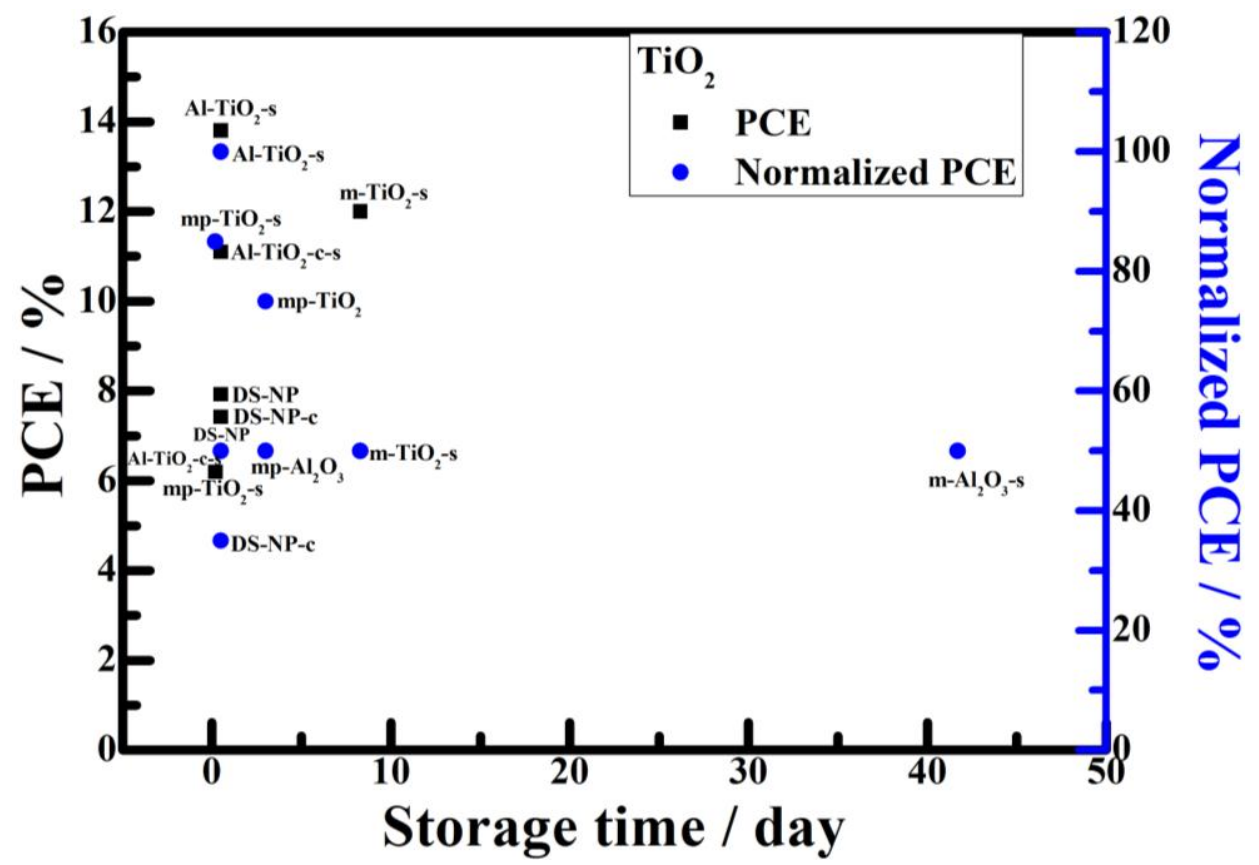

Fig. 3 UV-induced instability, overcoming strategies and associated performance

Table 1 Device configuration, encapsulation and storage condition of PSCs illustrated in Fig.3

\begin{tabular}{|c|c|c|c|c|}
\hline Device configuration & Feature & Seal & $\begin{array}{l}\text { Storage } \\
\text { condition }\end{array}$ & $\begin{array}{l}\text { Refere } \\
\text { nce }\end{array}$ \\
\hline $\begin{array}{l}\mathrm{cTiO}_{2} / \mathrm{mAl}_{2} \mathrm{O}_{3}+\mathrm{MAPbl}_{3-\mathrm{x}} \mathrm{Cl}_{\mathrm{x}} \\
/ \mathrm{HTM} / \mathrm{Au}\end{array}$ & $\mathrm{m}-\mathrm{Al}_{2} \mathrm{O}_{3}-\mathrm{s}$ & $\begin{array}{l}\text { Epoxy resin+ } \\
\text { glass coverslip }\end{array}$ & $\begin{array}{l}40^{\circ} \mathrm{C}, \quad \mathrm{UV}, \\
75 \mathrm{~mW} \mathrm{~cm}^{-2}\end{array}$ & {$[141]$} \\
\hline $\mathrm{cTiO}_{2} / \mathrm{TiO}_{2}+\mathrm{MAPbl}_{3-\mathrm{x}} \mathrm{Cl}_{\mathrm{x}} / \mathrm{HTM} / \mathrm{Au}$ & $\mathrm{m}-\mathrm{TiO}_{2}-\mathrm{S}$ & $\begin{array}{l}\text { in } \mathrm{N}_{2} \text {-filled } \\
\text { glovebox }\end{array}$ & $40^{\circ} \mathrm{C}$, UV filter & \\
\hline $\mathrm{m}-\mathrm{Al}_{2} \mathrm{O}_{3} / \mathrm{MAPbl}_{3} /$ Spiro & $\mathrm{mp}-\mathrm{Al}_{2} \mathrm{O}_{3}$ & Unsealed & Dry air, light & {$[73]$} \\
\hline $\mathrm{m}-\mathrm{TiO}_{2} / \mathrm{MAPIb}_{3} /$ Spiro & $\mathrm{mp}-\mathrm{TiO}_{2}$ & & dry air, light & \\
\hline $\mathrm{c}-\mathrm{TiO}_{2} / \mathrm{Al}_{2} \mathrm{O}_{3}+\mathrm{MAPbl}_{3-\mathrm{x}} \mathrm{Cl}_{\mathrm{x}} /$ Spiro & $\mathrm{Al}-\mathrm{TiO}_{2}-\mathrm{C}-\mathrm{S}$ & Sealed & $\begin{array}{l}\text { inert } \\
\text { atmosphere }\end{array}$ & {$[150]$} \\
\hline $\begin{array}{l}\mathrm{c}-\mathrm{Al} \text {-doped } \mathrm{TiO}_{2} / \mathrm{Al}_{2} \mathrm{O}_{3}+\mathrm{MAPbl}_{3-} \\
{ }_{x} \mathrm{Cl}_{x} / \text { Spiro }\end{array}$ & $\mathrm{Al}-\mathrm{TiO}_{2}-\mathrm{S}$ & & $\begin{array}{l}\text { inert } \\
\text { atmosphere }\end{array}$ & \\
\hline $\begin{array}{l}\text { Down-shift NP } \mathrm{FTO} / \mathrm{c}-\mathrm{TiO}_{2} / \mathrm{m} \text { - } \\
\mathrm{TiO}_{2}+\mathrm{MAPbl}_{3} / \mathrm{HTm} / \mathrm{Au}\end{array}$ & DS-NP & w/o & $\begin{array}{l}25-31^{\circ} \mathrm{C}, 25- \\
40 \% \mathrm{RH}\end{array}$ & {$[148]$} \\
\hline $\mathrm{cTiO}_{2} / \mathrm{TiO}_{2}+\mathrm{MAPbl}_{3} / \mathrm{HTM} / \mathrm{Au}$ & DS-NP-c & & & \\
\hline
\end{tabular}

\section{2 $\mathrm{TiO}_{2}$ as electron acceptor reducing charge recombination and parasitic reaction}

However, there are contradictory results in literature concerning the effects of the mesoporous $\mathrm{TiO}_{2}$ scaffold. Flannan T.F. O'Mahony et al [73] compared the performance stability of $\mathrm{TiO}_{2}-, \mathrm{Al}_{2} \mathrm{O}_{3}$-based and bilayer PSCs (without mesoporous scaffold) in ambient environment and found that the long-time charge carrier separation degraded rapidly in mesoporous $\mathrm{Al}_{2} \mathrm{O}_{3}$ and bilayer system. The authors attributed it to the parasitic reactions between the photogenerated electrons and oxygen molecules in the perovskite-absorbing 
layer. Fig. S21 shows the interfacial charge transfer process occurring in various device architectures incorporating MAPBI3 as an absorber. [73] The photo-generated electrons may transfer to molecular oxygen to form superoxide and then the superoxide acts to breakdown the perovskite by deprotonating the methylammonium cation and deprotonating of the methylammonium cation finally leading to the decomposition/degradation of perovskite [74,76] . Therefore, the rapid extraction of electrons from perovskite in the presence of mesoporous $\mathrm{TiO}_{2}$ acceptor would avoid the parasitic reaction between photoexcited electrons and oxygen in the environment, which is beneficial for the improvement of stability of the PSCs and the adaptability to a variety of environment. Based on this point of view, $\mathrm{TiO}_{2-}$ based PSCs are more stable than $\mathrm{Al}_{2} \mathrm{O}_{3}$-based PSCs, which is in contrast to the results reported by Henry J. Snaith et al. [141] and Seigo Ito et al. [149] . Aldo Di Carlo et al. [152] inserted a layer of lithium-neutralized graphene oxide (GO-Li) as electron transporting layer between mesoporous $\mathrm{TiO}_{2}$ and perovskite, which enhanced the electron injection from perovskite to $\mathrm{m}-\mathrm{TiO}_{2}$ layer, leading to remarkable increased $\mathrm{J}_{\mathrm{SC}}(+10.5 \%)$ and $\mathrm{FF}(+7.5 \%)$, decreased hysteresis, and improved stability upon prolonged illumination. The enhanced device stability under illumination stems mainly from the passivation of $\mathrm{m}-\mathrm{TiO}_{2}$ oxygen vacancies, which are the main reaction centers for moisture attacks.

Lithium salts are important additives to the hole-transport materials (e.g. SpiroOMeTAD) of PSCs to achieve higher hole mobility. However, research shows that intercalation of $\mathrm{Li}^{+}$into $\mathrm{TiO}_{2}$ could lead to the decrease of the open-circuit voltage $\mathrm{V}_{\mathrm{OC}}$. Liduo Wang et al. [153] deposited a layer of spinal lithium titanium oxide (LTO) between $\mathrm{TiO}_{2}$ and hole-transport layer. LTO was found to absorb and consume $\mathrm{Li}^{+}$, preventing the contact of $\mathrm{Li}^{+}$ and $\mathrm{TiO}_{2}$ and the decrease of $\mathrm{V}_{\mathrm{OC}}$, reducing the recombination of electron and holes, and improving the fill factor and the performance of the device.

\subsection{Replacement and modification of $\mathrm{TiO}_{2}$}

$\mathrm{SnO}_{2}$ also could be used as electron-transport materials to replace $\mathrm{TiO}_{2}$. [154-160] The performance of $\mathrm{TiO}_{2}$-based PSCs degrades rapidly in ambient air, while the PCE of $\mathrm{SnO}_{2}-$ based PSCs remains stable after stored for $700 \mathrm{~h}$. [154-156] Wenjing Tian et al. [154] believed that the excellent stability of $\mathrm{SnO}_{2}$-based PSCs was partially attributable to the remnant $\mathrm{PbI}_{2}$ between $\mathrm{SnO}_{2}$ and $\mathrm{CH}_{3} \mathrm{NH}_{3} \mathrm{PbI}_{3}$, which avoided a direct contact of $\mathrm{SnO}_{2}$ and $\mathrm{CH}_{3} \mathrm{NH}_{3} \mathrm{PbI}_{3}$ and reduced the possible degradation of $\mathrm{CH}_{3} \mathrm{NH}_{3} \mathrm{PbI}_{3}$ through charge injection. In addition, the lower hygroscopicity of $\mathrm{SnO}_{2}$ also contributes to the stability of the devices. Alex K.-Y. Jen et al. [159] reported a $\mathrm{SnO}_{2}$-based PSC showing a PCE of $18.8 \%$ and remaining over $90 \%$ of its initial PCE after a storage in ambient with $>70 \%$ RH for 30 days. The enhanced ambient stability is attributed to the formation of a compact and stable protecting layer by the highly crystalline $\mathrm{SnO}_{2}$ nanocrystals. Guo-Jia Fang et al. [158] reported a hierarchical $\mathrm{SnO}_{2}$ (a thin compact $\mathrm{SnO}_{2}+$ a mesoporous layer of $\mathrm{SnO}_{2}$ nanosheets) ETL-based PSC with a PCE of $16.17 \%$, which preserving $90 \%$ of its initial PCE after storage in air for 130 days at room temperature without encapsulation. $\mathrm{Zn}_{2} \mathrm{SnO}_{4}$ is also used ETL in PSCs due to its good ambient stability [161,162] .

Compared to nanoparticles, nanorod or nanotube arrays are found to have the capability to improve the stability of PSCs. [163-166] Perovskite infiltrated in the nano-columnar 1dimensional $\mathrm{TiO}_{2}$ porous film $\left(\mathrm{NC}-\mathrm{TiO}_{2}\right)$ exhibits better stability compared to the mesoporous 
$\mathrm{TiO}_{2}$ layers. The non-encapsulated devices stored in dry air $(<2 \% \mathrm{RH})$ under dark condition exhibits a reduction in PCE of $14.7 \%$ (from $10.53 \%$ to $8.58 \%$ ) for $\mathrm{NC}^{-\mathrm{TiO}_{2}}$ based device and $25 \%$ (from $10.59 \%$ to $7.94 \%$ ) for mesoporous $\mathrm{TiO}_{2}$ based device [163] . Thomas M. Brown and Rajan Jose et al. [164] reported a perovskite solar module (sealed with a $2 \mathrm{~mm}$ thick glass and Surlyn) employing solution-grown $\mathrm{TiO}_{2}$ nanorods (NRs) as ETL, which showed an increase in performance ( $\sim 5 \%)$ during $\sim 2500 \mathrm{~h}$ shelf-life investigation (ISOS-D-1 Shelf) as a result of a slight improvement in its $\mathrm{J}_{\mathrm{sc}}$ while PCE of the compact layer (CL) based device dropped by $\sim 80 \%$ within the first $500 \mathrm{~h}$ and the nanoparticles (NPs) based one showed a gradual decrease in the performance over time and a 50\% drop in PCE after $\sim 2500 \mathrm{~h}$ storage . Oomman K. Varghese and Mohammad Khaja Nazeeruddin et al. [165] showed stable and efficient PSCs based on Titania nanotube arrays (NTs). The unsealed NT-based device maintained about $70 \%$ of its initial performance after a period of 7 days, which was competitive to that of the sealed NPs-based device (sealed with Surlyn and a piece of thin glass). Mesoporous graphene/polymer (mp-GP) is also reported as ETM for PSC. PSCs with mp-GP as ETL exhibited good chemical and thermal stability. [167] Mesoporous graphene offers a stable 3-D scaffold to encapsulate the perovskite crystals within and protect the perovskite from moisture attack and reactive interface formation due to its chemical inertness. Furthermore, the high heat transmission coefficient of graphene can help dissipate the thermal heat, leading to enhanced thermal stability. The low isoelectric point of graphene avoids the interface reaction between the ETL and the perovskite.

\section{Effect of HTM on the stability of PSCs}

\subsection{Stability of HTM}

The most efficient and widely used hole-transport material (HTM) in PSCs is molecular p-type semiconductor Spiro-OMeTAD. The molecular structure of spiro-OMeTAD is fully symmetric, which is prone to crystallization, especially if processed from solution. At an elevated temperature, the growth of large crystalline domains in the hole-transporting layer is one of the causes of solar cell degradation as the crystallization of the material inside the pores of mesostructured device or on the interface of planar device adversely affects the contact between the absorber and the hole transport [168]. Apart from Spiro-OMeTAD, polymer p-type semiconductor poly(3-hexylthiophene-2,5-diyl (P3HT) and PEDOT:PSS, inorganic p-type semiconductor $\mathrm{CuI}, \mathrm{CuSCN}, \mathrm{NiO}_{x}$, etc. are also $\mathrm{HTM}$ candidates. Most organic p-type semiconductors exhibit low hole mobility and conductivity, and Li-TFSI and 4-tert-butylpyridime (tBP) are therefore often used as dopant to improve the hole mobility and conductivity. However, the doping effect of Li-TFSI relies on the oxygen in the air and therefore on the environment condition and encapsulation atmosphere. In addition, due to the mobility arising from the small radius, $\mathrm{Li}^{+}$ions are prone to diffuse in the hole-transport layer and lead to the change of the serial and shunt resistance, which will change the fill factor (FF) of the devices. Furthermore, Li-TFSI exhibits strong hygroscopicity, which makes the HTM as diffusion pathways for water to easily penetrate through the HTM to the surface of $\mathrm{CH}_{3} \mathrm{NH}_{3} \mathrm{PbI}_{3}$, leading to the decomposition of $\mathrm{CH}_{3} \mathrm{NH}_{3} \mathrm{PbI}_{3}$. The oxidation of spior-OMeTAD can improve the conductivity of the HTM and hence enhance the charge transfer at Au/HTM interface, however it also can improve the recombination at $\mathrm{TiO}_{2} / \mathrm{HTM}$ interface. As a result, the initial illumination of a PSC can improve the efficiency, yet longer illumination time can 
decrease the efficiency [169]. Rafael S. Sanchez et al. [170] reported the light-induced oxidation of spiro-OMeTAD as one of the causes that inducing the loss of the performance of the PSCs. In addition, the carbon-carbon double bonds in organic semiconductor tend to break upon prolonged exposure in oxygen condition under illumination, which leads to the change of the semiconductor, decrease of conductivity and deterioration of the device performance. All these would affect the long-term stability and the life of the PSCs. Yi-Bing Chen et al. [171] evaluated the parameters accounting for the degradation of $\mathrm{MAPbI}_{3}$-based solar cells on polymer substrates and proposed that HTM played a significant role in device degradation.

\subsection{Dopants induced hygroscopicity and pinholes of Spiro-OMeTAD}

Apart from acting as hole-conductor, the HTM also serves as barrier layer to seal the hygroscopic perovskite absorbing layer inside. The validity of the "seal" protection depends on the hydrophobicity, permeability and density of the hole-transport materials. The degradation rate of the $\mathrm{CH}_{3} \mathrm{NH}_{3} \mathrm{PbI}_{3}$ covered with pristine Spiro-OMeTAD is lower than that covered with Li-TFSI doped counterpart, which is considered to be originated from the strong hygroscopicity of Li-TFSI that makes diffusion pathways for the water to reach $\mathrm{CH}_{3} \mathrm{NH}_{3} \mathrm{PbI}_{3}$. Ag-TFSI is used to replace Li-TFSI for doping Spiro-OMeTAD and to improve the conductivity of the HTM and the stability of the device. The PCE of the device with Ag-TFSI doped HTM decreased $15 \%$ after stored in $15 \%$ RH in dark for 120 days and the Li-TFSI doped counterpart decreased $40 \%$ [172] . Another kind of non-hygroscopic dopant tetrafluoro-tetracyanoquinodimet-hane (F4-TCNQ) can also be used to dope spiro-OMeTAD. The F4-TCNQ doped spiro-OMeTAD based PSC retains $65 \%$ of the initial performance after $72 \mathrm{~h}$ and $55 \%$ after 7 days while the Li-TFSI doped spiro-OMeTAD based device only retains less than $20 \%$ and $10 \%$ respectively. [173] In order to delaminate the effect of the hygroscopic Li-TFSI and corrosive pyridine derivate dopant in spiro-OMeTAD, Hong Lin et al. [174] took advantage of a p-type and highly conductive reduced graphene oxide combined with dopant-free spiro-OMeTAD as a hole extraction and transport material. The device achieves a maximum PCE of $10.6 \%$ and remains $85 \%$ of the initial PCE after $500 \mathrm{~h}$, whereas the PCE of the device with Li-TFSI and pyridine doped spiro-OMeTAD drops by $65 \%$. Reduced graphene oxide itself also can be used as HTM replacing Spiro-OMeTAD in PSCs to achieve better stability [175] . Lithium salt-free hole transporter layer (HTL) EH44 (2,7-Di(N,N-dimethoxyphenylamino)-N-(2-ethylhexyl)carbazole) doped with its respective oxidized $\mathrm{HTM}^{+} \mathrm{TFSI}^{-}$salt works as $\mathrm{HTM}$ and hydrophobic protective layer in PSCs as replacement of Li-TFSI doped spiro-OMeTAD. [176] The EH44-based device exhibits comparable PCE and enhanced stability and can even survive from being submersed in water. Qiquan Qiao et al. [177] reported the usage of solution processed pristine diketopyrrolopyrrole (DPP) based polymer (PDPP3T: poly(diketo-pyrrolopyrrole-terthiophene) (without Li-TFSI or TBP) as HTM in PSCs, which achieved a similar PCE of $12.32 \%$ as that $(12.34 \%)$ of doped spiro-OMeTAD based cells and much slower degradation than spiroOMeTAD devices. Application of dopant-free HTM is a promise method for avoiding the dopant-induced instability issue. $[19,178,178]$ A dopant-free tetrathiafulvalene derivative (TTF-1: 4-(4-(bis(4-(4-(dibutylamino)styryl)phenyl)-amino)styryl)-N,N-dibutylaniline) can also be used to replace doped spiro-OMeTAD in PSCs [179], and the device achieved a comparable PCE of $11.03 \%$ and two fold stability improvement in $\sim 40 \% \mathrm{RH}$ air (Based on the degradation time associated with a $20 \%$ decrease of efficiency, lifetime of dopant-free 
TTF-1 based device is about $360 \mathrm{~h}$ and the doped spiro-OMeTAD based device is about 120 h). Chenyi Yi et al. [180] reported a dopant-free triphenylamine (TPA)-based HTM (Z1011). The Z1011-based device exhibited comparable PCE and higher long-term stability due to the dopant-free and hydrophobic property of Z1011, which avoiding the detrimental effects of the Li-TFSI and TBP additives and acting as a barrier to protect the perovskite from moisture attack. [180,181] Dopant-free poly(triarylamine) with methylphenylethenyl functional groups (V873) as HTM enabled stable PSCs under 1 sun illumination at maximum power point tracking for about $40 \mathrm{~h}$ at room temperature and in the dark under elevated temperature $\left(85^{\circ} \mathrm{C}\right)$ for more than $140 \mathrm{~h}$. [182] Thiho Park et al. [183] reported a dopant-free random copolymer HTM based on benzo[1,2-b:4,5:b']dithiophene (BDT) and 2,1,3-benzothiadiazole (BT) for highly efficient and stable PSC. The random copolymer HTM based devices maintained their initial PCE over $1400 \mathrm{~h}$ at $75 \% \mathrm{RH}$ while spiro-OMeTAD based devices degraded completely after $900 \mathrm{~h}$. Chemically combining poly(triarylamine) with spiroOMeTAD leads to a dopant-free N2,N2,N2',N2',N7,N7'N7'-octakis(4-methoxyphenyl)-10phenyl-10H-spiro[acridine-9,9'-fluorene]-2,2'7,7'-tetraamine (SAF-OMe), which has more hydrophobic nature and favors to expel moisture away from perovskite film. [184] Replacement of doped spiro-OMeTAD HTM and Au contact electrode with dopant-free copper Phthalocyanine $(\mathrm{CuPc})$ nanorods and carbon demonstrates a significant enhancement of the stability, i.e. CuPc/carbon based device retained $91.5 \%$ of its initial PCE $(16.1 \%)$ during $600 \mathrm{~h}$ durability test and doped spiro-OMeTAD/Au based device dropped to $8 \%$ of the initial PCE [185]. This enhanced stability of CuPc/carbon based device is due to the thermal and chemical stability of $\mathrm{CuPc}$ and carbon counter electrode, which can also work as a protecting layer against humidity to protect the $\mathrm{CH}_{3} \mathrm{NH}_{3} \mathrm{PbI}_{3}$ from humidity damage.

Beside the hygroscopicity of Li-TFSI, as-prepared spin-coating spiro-OMeTAD films often show a high density of pinholes [186], as shown in Fig. S22 [143]. Theses pinholes may facilitate the inward diffusion of $\mathrm{H}_{2} \mathrm{O}$ and $\mathrm{O}_{2}$ in the envrionment into the devices, leading to detrimental effects to the underneath perovskite layer. The pinholes also may also act as the outward diffusion channels of the high vapor pressure chemical elements and compounds, such as iodie-containing volatile species MAI and/or HI, which is the degradation and/or decompostion products of the underneath perovskite layer. The out diffusion of MAI and/or HI may further facilitate the degradation of the perovskite layer. The PCE of PSC employing spin-coated doped spiro-OMeTAD stored in vacuum was found to only decrease for about $14 \%$ compared to a decrease of about $68 \%$ when stored in air, probably due to the water molecules in air diffusing through the spin-coated spiro-OMeTAD layer to reach the perovskite film.

Based on the above, using pinhole-free HTL may improve the stability of PSCs. Indeed, Yabing Qi et al. [187] prepared a PSC using a vacuum evaporated triple-layer pinhole-free n-i-p structured spiro-OMeTAD HTL. The samples with vacuum evaporated n-i-p structured HTL showed good stability after $840 \mathrm{~h}$ (35 days) and the cell with the n-i-p structured layer stored in air exhibited 2.2 times of the initial PCE, while the reference samples decreased and stabilized to a value close to $50 \%$ for the air-stored reference sample and $60 \%$ for the vacuum-stored one. Yabing Qi et al. [188] also developed a convenient method for preparing pinhole-free spiro-OMeTAD HTL by changing the solvent from chlorobenzene to chloroform. The cells with pinhole-free spiro-OMeTAD HTL using chloroform as solvent 
(ClF cells) exhibit a similar PCE as that of the cells with HTL prepared using chlorobenzene as solvent (ClB cells). The PCE of CIB cells degraded to $0 \%$ after $12 \mathrm{~h}$ continuous illumination (AM1.5G) at the bias tracking the maximum power point in air with $\sim 42 \% \mathrm{RH}$, while the CIF cells decreased only $\sim 12 \%$ form the initial PCE during the first $12 \mathrm{~h}$ and remained $50 \%$ of initial PCE after $\sim 100 \mathrm{~h}$ under the same operation condition. Copper salt ( $\mathrm{CuSCN}$ and $\mathrm{CuI}$ ) doped spiro-OMeTAD composite films exhibited reduced pinholes and voids due to the fact that introduction of inorganic copper salts suppressed the film aggregation and crystallization of spiro-OMeTAD films, which could slow down the perovskite degradation due to the avoidance of moisture infiltration to some extent. [189]

The outward diffusion of decomposed volatile species through the pinholes facilitates the degradation of $\mathrm{CH}_{3} \mathrm{NH}_{3} \mathrm{PbI}_{3}$ perovskite film. On the other hand, the trapped MAI and $\mathrm{HI}$ may corrode Ag electrodes by reacting with Ag to produce AgI, which leads to the decrease of the efficiency of the device. [190] Henry J. Snaith et al. [141], Yi-bing Cheng et al. [27] and Manoi A. G. Namboothiry et al. [191] also reported the degradation due to the corrosion of Ag electrode by reacting with perovskite or perovskite degradation product MAI and HI. The HTM between the top electrode and perovskite plays a critical role in preventing or slowing the degradation of perovskite and/or AgI formation, and/or segregating the Ag electrode from contacting with perovskite and decomposition products. [190]

\subsection{Hydrophobic organic semiconductor as HTM}

Replacement Spiro-OMeTAD with other hydrophobic organic semiconductor may restraint the water diffusing through hole-transport to the surface of $\mathrm{CH}_{3} \mathrm{NH}_{3} \mathrm{PbI}_{3}$, preventing water-induced decomposition of $\mathrm{CH}_{3} \mathrm{NH}_{3} \mathrm{PbI}_{3}$ and consequently improving the water resistance of the devices. Henry J. Snaith [192] replaced the Spiro-OMeTAD with a conducting carbon-nanotube insulating polymer composite, which yielded efficient solar cells with greatly enhanced stability and resistance to thermal stressing and water exposure due to good conductivity of the carbon-nanotube and hydrophobicity of poly(methylmethacrylate) (PMAA). Fig. S23 shows the degradation of perovskite layers with different HTLs [192] . Both of the devices based on Spiro-OMeTAD and oligothiophene exhibit good stability of PCE with only $6 \%$ and $2 \%$ decreases after stored in dark for 13 days under lower humidity (20\% RH) respectively. The device based on Li-TFSI and tBP doped Spiro-OMeTAD turned from dark brown to yellow upon stored in 50\% RH under illumination for 3 days due to the decomposition of $\mathrm{CH}_{3} \mathrm{NH}_{3} \mathrm{PbI}_{3-\mathrm{x}} \mathrm{Cl}_{\mathrm{x}}$ to $\mathrm{PbI}_{2}$, while the oligothiphene counterpart remained dark brown, exhibiting good stability. Sung-Ho Jin et al. [193] reported a small molecule HTM CzPAF-SBF (7-(9,9'-spirobifluorene-2-yl)-N-(7-(9,9'-spirobifluorene-2-yl)-9,9-dioctyl9H-fluoren-2-yl)-N-(4-(9H-carbazol-9-yl)phenyl)-9,9'-dicotyl-9H-fluoren-2-amine) with a larger water contact angle of $95.2^{\circ}$, which prevented moisture penetration into the perovskite layer and improved the stability of the resulting PSCs. A functionalized nanographene (perthiolated tri-sulfurannulated hexa-peri-hexabenzoconronene, TSHBC) was also used as HTM in PSCs [194]. On account of the hydrophobic nature of TSHBC, as shown in Fig. S24a, TSHBC and thiolated nanographene (TSHBC/graphene) served as an effective molecular sealing approach for improving the stability of PSCs. The TSHBC-based devices retained over $85 \%$ of their original efficiency after 10 days, the TSHBC/graphene-based devices kept more than $90 \%$ while the spiro-OMeTAD-based devices lost $\sim 80 \%$ of their original efficiency. Under illumination at AM 1.5 G, the efficiency of spiro-OMeTAD-based 
devices decreased to $25 \%$ within 60 min, while the device with TSHBC retained over $60 \%$ of its original efficiency after the same illumination for $400 \mathrm{~min}$ and the device with TSHBC/graphene kept more than 70\%. An oligothiophene, possessing a high hydrophobicity with a water contact angle of $107.4^{\circ}$, as shown in Fig. S24b, was used as HTM for planar PSCs in the replacement of Spiro-OMeTAD [195] . Jing You et al. [196] also reported the hydrophobic HTM based on N,N,N',N'-tetraphenylbenzidine (TPB) and MeO-triphenylamine (MOTPA), showing outstanding thermal stability, film-forming properties, and hole mobilities. TPB-MOTPA-based PSC shows better performance compared to spiro-OMeTADbased device, the PCE of the former decreases only 3\% after $600 \mathrm{~h}$ of storage in ambient atmosphere. Diketopyrrolopyrrole or benzodithiophene-arylamine small molecular hole transporting materials based PSCs exhibited excellent stability due to their excellent thermal stability and the existence of hydrophobic alkyl chains on them. [197] Crosslinked thiolene HTL showed enhanced hydrophobicity and crosslinked HTL based device without encapsulation can maintain over $80 \%$ of its initial PCE under continuous illumination at AM $1.5 \mathrm{G}$ for $600 \mathrm{~min}$ or for $30 \mathrm{~d}$ storage in air with $\sim 50 \% \mathrm{RH}$. [198] Jian Ye et al. [199] reported the use of functional graphene-modified P3HT as HTM in PSCs, which achieved a PCE of $13.82 \%$ and good stability due to the enhanced hole mobility and hydrophobicity of graphene-modified P3HT. The $4 \mathrm{wt} \%$ graphene-modified P3HT based PSCs maintained about $70 \%$ of the initial PCE after storage in ambient condition $\left(25^{\circ} \mathrm{C}, 20-40 \% \mathrm{RH}\right)$, while the pristine P3HT based devices left only $35 \%$ of the initial PCE. Functionalized carbon nanotube and reduced graphene oxide (RGO) are also used to modify P3HT to boost perovskite solar cells performance and stability, which given impressive stability to moisture, air oxygen, and heat. [200] Li-doped P3HT nanofibrils (LP-P3HT)-based flexible PSCs exhibited good mechanical stability (retaining a PCE of $12.96 \%$ after 500 bending cycles at $\mathrm{r}=15 \mathrm{~mm}$ ) and air stability (retaining $87 \%$ of the initial PCE after storage in ambient condition $(30 \% \mathrm{RH})$ for 30 d). [201] Kazunari Matsuda et al. [202] reported an all carbon SWNT/GO/PMAA HTMbased PSC, exhibiting significantly enhanced stability (PCE changing slightly from $10.5 \%$ to $10.0 \%$ during 10 days storage in air (70-80\% RH) at room temperature) in comparison with spiro-OMeTAD based device (PCE declining from $10.5 \%$ to $5.8 \%$ in the same condition). Introducing hydrophobic alkyl chains into HTMs can improve the stability of the PSCs because of the enhanced moisture resistance of the HTMs. [203] PSCs based on 5,7-bis(3hexylthiophene-2-yl)-2,3-dihydrothieno[3,4-b][1,4]dioxine (SP-01) show better stability under $40 \%$ RH atmosphere than the devices based on 2,5-bis(4,4'bis(methoxyphenyl)aminophen-4"'-yl)3,4-ethylene dioxythiophene (H101). The incorporation of two long alkyl chains onto thiophene linkers in SP-01 leads to the formation of effective moisture resistant layer on the interface of PSC film, which contributes to the enhanced stability of SP-01-based PSCs. PSCs with Spiro[fluorene-9,9'-xanthene]-based HTM exhibited better stability in ambient atmosphere (retain 90\% of the initial PCE after $2000 \mathrm{~h}$ storage) than the devices with spiro-OMeTAD as HTM (retain only $28 \%$ of the initial PCE), due to the better hole mobility stability and more hydrophobic nature of the former HTM. [204]

Improved hydrophobicity of the HTM may restrain the contact of moisture and absorbing layer materials and decrease the decomposition rate of the perovskite absorbing layer. It was shown that the PCE of the devices based on Spiro-OMeTAD, with a contact 
angle of $70^{\circ}$, decreased from $7.6 \%$ to $5.5 \%$ upon exposure in $20 \% \mathrm{RH}$, whereas the efficiency of the device based on PDPPDBTE, with a contact angle of $105^{\circ}$, retained $8.4 \%$ after stored $1000 \mathrm{~h}$ [205] . Qingbo Meng et al. [206] reported a PSC with improved stability based on a new HTM, exhibiting no more than $0.9 \%$ decrease in efficiency after stored in ambient air in dark for 7 days without any further encapsulation. PSC with polyaniline as HTM retained $91.24 \%$ of the energy conversion efficiency after $1000 \mathrm{~h}$, indicating the device had a superior long-term stability [207]. Truxene-based material exhibits a high decomposition temperature $\left(432{ }^{\circ} \mathrm{C}\right)$ and glass transition temperature $\left(134{ }^{\circ} \mathrm{C}\right)$ and can be used as HTM in PSCs, which is beneficial to the morphology stability of the HTM and the device. [208]

Doping with more hydrophobic dopant such as Ag-TFSI to improve the hydrophobicity of Spiro-OMeTAD or using other hydrophobic p-type organic semiconductor as holetransporting materials may enhance the long-term stability of the PSCs [172]. However, most of the organic semiconductor containing carbon-carbon double bond may broke down upon prolonged illumination, resulting in the degradation of the HTMs and devices. Replacement of organic HTM with inorganic HTM can be an optional solution to this problem. Seigo Ito et al. [209] substituted organic HTM Spiro-OMeTAD with inorganic ptype semiconductor $\mathrm{CuSCN}$, the cells of $<\mathrm{FTO} / \mathrm{TIO} 2 / \mathrm{CH} 3 \mathrm{NH} 3 \mathrm{PbI} 3 / \mathrm{CuSCN} / \mathrm{Au}>$ did not show strong humidity effects. In contrast, the cell of $<\mathrm{FTO} / \mathrm{TiO}_{2} / \mathrm{CH}_{3} \mathrm{NH}_{3} \mathrm{PbI}_{3} / \mathrm{Spiro}$ $\mathrm{OMeTAD}$ (or polytriarylamine PTAA)/Au $>$ had strong humidity effects [210] .

\subsection{Effect of PEDOT:PSS on the stability of PSCs}

PEDTO:PSS is also widely used as HTM in PSCs, however, its acidic and hygroscopic properties and inability to block electrons efficiently are detremtnal to device stability. Tuning the $\mathrm{pH}$ value of PEDOT:PSS by a mild base, imidazole, resulted in enhanced performance and improved long-term stability, retaining $75 \%$ of its initial PCE after $14 \mathrm{~d}$ storage in ambient condition $(20 \% \mathrm{RH})$ (the pristine device degrading quickly to $38 \%$ of its original PCE under the same condition). [211] $\mathrm{NiO}_{\mathrm{x}}$ [212-215] reduced graphene oxide (RGO) [216], graphene oxide (GO) and GO/PEDOT:PSS [217] , oxo-functionalized graphene (oxoG1) [218], nitrogen-doped graphene oxide nanoribbons (NGONRs) [219] , PhNa-1T (1,4bis(4-sulfonatobutoxy)benzene and thiophene moieties) [220] and neutral PDMT poly(3,4dimethoxythiophene) [221] are also used to replace PEDOT:PSS as a HTM in inverted planar PSCs. $\mathrm{Cu}$ doped $\mathrm{NiO}_{\mathrm{x}}$ was used to replace PEDOT:PSS as HTM in PSCs, leading to improved efficiency (from $11.16 \%$ to $15.40 \%$ ) and stability [212] (devices using $\mathrm{Cu}-\mathrm{NiO}_{\mathrm{x}}$ as HTM retains $90 \%$ of initial PCE after stored in air for $240 \mathrm{~h}$, while PCE of the devices using PEDOT:PSS decreases 50\% in $144 \mathrm{~h}$ and only retains 35\% initial performance after 240 h). The encapsulated $\mathrm{NiO}_{x}$ based PSCs maintained $93 \%$ of its initial efficiency (16.42\%) after storage in ambient air in dark for 30 days, and the un-encapsulated devices retained $80 \%$ of the initial efficiency after $100 \mathrm{~h}$ while the PEDOT:PSS based cell almost degraded completely in $70 \mathrm{~h}$. Furthermore, the $\mathrm{NiO}_{\mathrm{x}}$ based flexible perovskite devices show good mechanical stability, retaining over $80 \%$ of its initial efficiency after 100 bending cycles, as shown in Fig. S25a. [213] The device efficiency of PEDOT:PSS based cells decreased to $0 \%$ after $120 \mathrm{~h}$ of exposure in an ambient conditions $(50 \% \mathrm{RH})$, while the RGO-based devices retained about $62 \%$ of the initial PCE even after $140 \mathrm{~h}$ exposure. The stability of RGO-based devices stems from the nearly neutral properties of RGO with few surface oxygen functionalities and the inherent passivation ability of RGO against moisture and oxygen, which reduces the 
decomposition probability of $\mathrm{CH}_{3} \mathrm{NH}_{3} \mathrm{PbI}_{3}$ perovskite films. About $70 \%$ and $18 \%$ of the initial PCE are maintained for GO- and GO/PEDOT:PSS based PSCs upon exposure under atmospheric condition $\left(21-24{ }^{\circ} \mathrm{C}, 38-55 \% \mathrm{RH}\right)$ for $528 \mathrm{~h}$ while pristine PEDOT:PSS based devices degraded almost completely within about 312 h, as shown in Fig. S25c. [217] Hydrophobic oxo-functionalized graphene effectively slowed down the ingress of moisture into the device, leading to significantly improved environmental stability of nanopackaged Oxo-G1 based PSCs, which retained $92 \%$ and $60 \%$ of the initial PCE after $1900 \mathrm{~h}$ storage in dark and 1000 h 0.5 sun illumination in ambient condition. [218] Lin-Long Deng et al. [222] used hydrophobic $\mathrm{CuI}$ as an excellent ambient stable HTM to replace PEDOT:PSS in PSCs. The CuI-based device maintained $90 \%$ of its initial efficiency after 14 days storage in air, while the PEDOT:PSS-based device retained only $27 \%$ after 14 days, as shown in Fig. S25b. Liyuan Han et al. [223] reported efficient and stable large-area PSCs with heavily p-doped $\mathrm{Ni}_{\mathrm{x}} \mathrm{Mg}_{1-\mathrm{x}} \mathrm{O}\left(\mathrm{Ni}_{1-\mathrm{x}-\mathrm{y}} \mathrm{Mg}_{\mathrm{x}} \mathrm{Li}_{\mathrm{y}} \mathrm{O}\right)$ and $\mathrm{n}$-doped $\mathrm{TiO}_{\mathrm{x}}\left(\mathrm{Ti}(\mathrm{Nb}) \mathrm{O}_{\mathrm{x}}\right)$ as hole and electron extraction layer respectively, which retained more than $90 \%$ of the initial PCE after $1000 \mathrm{~h}$ of light soaking. $\mathrm{CuO}_{\mathrm{x}}$ is also reported as HTM in PSCs. [224,225] The $\mathrm{CuO}_{\mathrm{x}}$ based device maintained about $90 \%$ of its initial PCE after $200 \mathrm{~h}$ storage in air, whereas only $50 \%$ of the initial PCE is retained for PEDOT:PSS based device [224] .

CuSCN-based PSCs also exhibited good thermal stability (maintaining approximately $60 \%$ of its initial PCE while the spiro-OMeTAD-based device degrading to $25 \%$ of the initial PCE after annealing for $2 \mathrm{~h}$ at $125{ }^{\circ} \mathrm{C}$ in air under $40 \% \mathrm{RH}$ ) due to the intrinsically stable crystalline structure of CuSCN itself at high temperature. [226] However, Henry J. Snaith et al. [227] found that $\mathrm{CuSCN}$ appeared to intrinsically facilitate the degradation of perovskite films as accelerating the thermal degradation of $\mathrm{MAPbI}_{3}$ even in inert atmosphere. But the it is also found the degradation could be inhibited by inserting a thin mesoporous $\mathrm{Al}_{2} \mathrm{O}_{3}$ buffer layer between $\mathrm{MAPbI}_{3}$ and $\mathrm{CuSCN}$ following by encapsulating with PMAA on the top of CuSCN, which retained $77 \%$ of the initial PCE after $45 \mathrm{~d}$ thermal stressing $\left(85^{\circ} \mathrm{C}\right)$ in ambient conditions. The photocurrent of the device with p-type $\mathrm{CuI}$ as HTM remained stable within 2 $\mathrm{h}$ tested in ambient condition, whereas that of the device based on Spiro-OMeTAD decreased for $10 \%$ [228]. $\mathrm{Cu}_{2} \mathrm{O}$ is also reported as a potential HTM exhibiting compact, uniform and crack-free surface on the perovskite layer without affecting the perovskite structure and further shielding against moisture and mechanical damages [229] . CuS NPs-based device exhibits superior stability compared with PEDOT:PSS-based device, the former showing relatively smaller loss in PCE as stored in ambient air for $250 \mathrm{~h}$ [230] .

\subsection{HTM-free PSCs}

Hongwei Han et al. [231] prepared a hole-conductor-free device using 5-aminovaleric acid (5-AVA) cations modified perovskite material (5-AVA) ${ }_{x}(\mathrm{MA})_{1-\mathrm{x}} \mathrm{PbI}_{3}$ and a carbon black/graphite counter electrode, $\mathrm{TiO}_{2} / \mathrm{ZrO}_{2} /(5-\mathrm{AVA})_{\mathrm{x}}(\mathrm{MA})_{1-\mathrm{x}} \mathrm{PbI}_{3} / \mathrm{Carbon}$, as shown in Fig. 4, which exhibited excellent stability upon AM 1.5 illumination for $100 \mathrm{~h}$ due to the effect of the 10-um-thick carbon black/graphite composite layer back contact acting as a water-retaining layer. Further outdoor stability measurements in Jeddah, Saudi Arabia of the epoxy resin sealed cell with a thin glass sheet covered on the carbon film back contact, where a Surlyn spacer separated the glass sheet from the TCO front glass, were conducted in a period of 2 
weeks without a UV filter. Results indicated no degradation of the devices under the hot and humid climate conditions in Saudi Arabia for a week [232]. The sealed cells exhibited pretty good stability upon 3 month $80-85{ }^{\circ} \mathrm{C}$ thermal stress stored in argon. Long-term lightsoaking test showed that the unsealed devices had no evidence of significant performance degradation under $100 \mathrm{mWcm}^{-2}$ white light LED illumination at $45^{\circ} \mathrm{C}$ for up to 44 days.

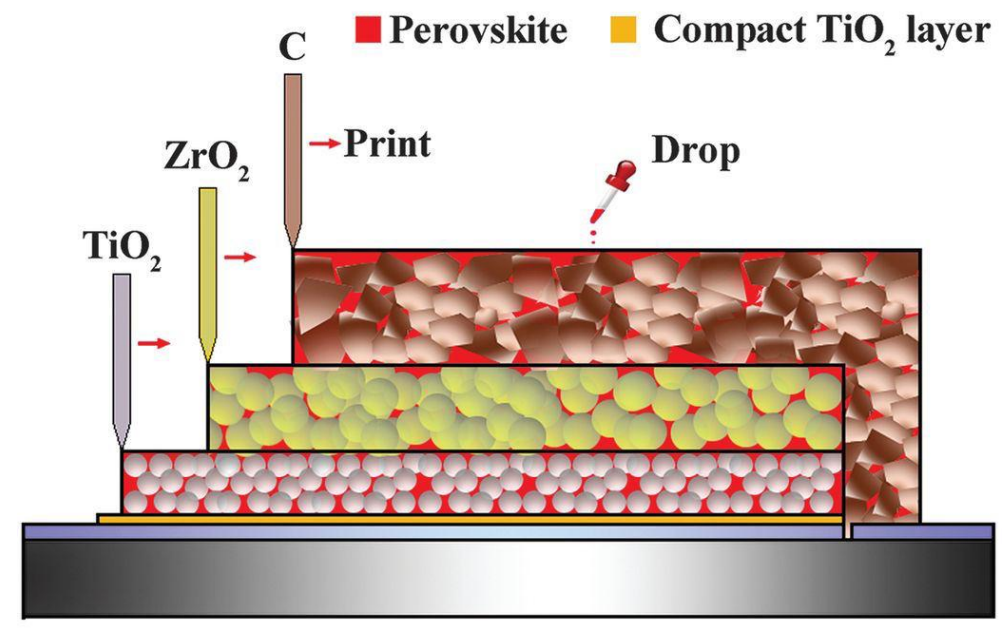

Fig. 4 Schematic illustration of the HTM-free carbon contact electrode mesoscopic PSC [231] Reprinted with permission from ref 231. Copyright 2014, sciencemag.org.

Xichaung Yang et al. [233] also used carbon (commercial carbon paste) as contact electrode for hole-conductor-free $\mathrm{TiO}_{2} / \mathrm{CH}_{3} \mathrm{NH}_{3} \mathrm{PbI}_{3} / \mathrm{Carbon} \mathrm{PSC}$ and demonstrated a conversion efficiency of $8.31 \%$. The PSC remained stable after stored in ambient room temperature environment for $800 \mathrm{~h}$ without further encapsulation. Xingzhong Zhao et al. [234] inserted a carbon/ $\mathrm{CH}_{3} \mathrm{NH}_{3} \mathrm{I}$ composite layer between the $\mathrm{CH}_{3} \mathrm{NH}_{3} \mathrm{PbI}_{3}$ and the compact hydrophobic carbon layer so as to improve the moisture and thermal induced stability of the PSCs. The excess MAI in the carbon/MAI layer inhibited thermal-induced degradation of the perovskite. PMAA encapsulated device maintained $90 \%$ of the initial PCE after water exposure and over $100 \%$ of the initial PCE under thermal stress at $150{ }^{\circ} \mathrm{C}$ for half an hour. UV-curing glue side sealed HTM-free carbon back contact devices exhibits good thermal stability with the PCE remaining almost constant over $1500 \mathrm{~h}$ during $100{ }^{\circ} \mathrm{C}$ thermal test. [235] HTM-free PSCs with porous carbon counter electrodes exhibited improved light stability, maintaining $80 \%$ of the initial PCE after $100 \mathrm{~h}$ light illumination (AM1.5), as a reslut of the moisture-blocking effect of the porous carbon back electrodes. [236] Syed Ghufran Hashimi et al. [237] demonstrated the high stability (almost no change in overall efficiency) of the air processed inkjet infiltrated carbon based HTM-free PSCs subject to continuous full sun light illumination at $35{ }^{\circ} \mathrm{C}$ over a period of $1046 \mathrm{~h}$ without any encapsulation and even under intense and continuous 1.5 sun equivalent ultra-violet light soaking for $1002 \mathrm{~h}$.[c6ta10605f]

Fig. 5 shows the PCEs and normalized PCEs of a series of devices using different HTMs plotting as a function of storage time of the PSCs. Black squares are the initial PCEs of the devices and blue dots are the normalized PCEs after different storage time. The HTMs used in the PSCs, encapsulation and storage condition of the devices are summarized in table 2. 


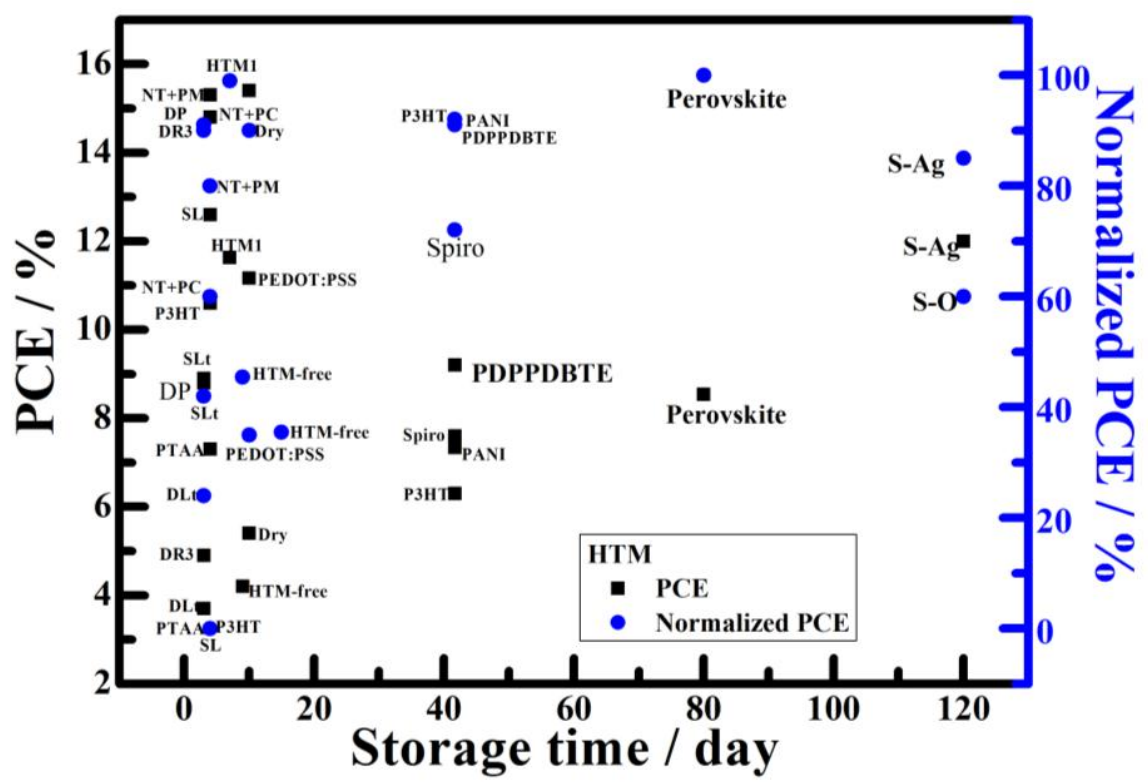

Fig. 5 Lifetime and stability of PSCs using different HTMs

Table 2 Encapsulation and storage condition of PSCs illustrated in Fig. 5

\begin{tabular}{|c|c|c|c|c|}
\hline HTM & Feature & Seal & $\begin{array}{l}\text { Storage } \\
\text { condition }\end{array}$ & Reference \\
\hline DR3TBDTT+Li+tBP & DLt & w/o & $>50 \% \quad \mathrm{RH}, \quad$ air & [195] \\
\hline Spiro+Li+tBP & SLt & & RT, illumination, & \\
\hline DR3TBDTT & Dr3 & & 3days & \\
\hline DR3TBDTT+PDMS & $\mathrm{DP}$ & & & \\
\hline Spiro-Ag & dry & w/o & vacuum & [238] \\
\hline P3HT/SWNTs/PMAA & $\mathrm{NT}+\mathrm{PM}$ & w/o & 96h, air & {$[192]$} \\
\hline P3HT/SWNT-PC & $\mathrm{NT}+\mathrm{PC}$ & & & \\
\hline Li-TFSI doped Spiro & SL & & & \\
\hline $\mathrm{P} 3 \mathrm{HT}$ & P3HT & & & \\
\hline PTAA & PTAA & & & \\
\hline Ag-TFSI doped Spiro & S-Ag & w/o & dark, $<15 \% \mathrm{RH}$ & {$[172]$} \\
\hline Oxygen-doped Spiro & $\mathrm{S}-\mathrm{O}$ & & & \\
\hline Spiro-OMeTAD & Spiro & w/o & $20 \% \mathrm{RH}$ & {$[205]$} \\
\hline P3HT & $\mathrm{P} 3 \mathrm{HT}$ & & & \\
\hline PDPPDBTE & PDPPDBTE & & & \\
\hline Cul & Cul & w/o & ambient, & {$[228]$} \\
\hline Spiro-OMeTAD & Cul-c & & $100 \mathrm{~mW} / \mathrm{cm}^{-2}$ & \\
\hline $\begin{array}{l}\mathrm{MAPbl}_{3}, \\
\mathrm{Pbl}_{2}+\mathrm{MABr} / \mathrm{MAl} 1: 2\end{array}$ & Perovskite & w/o & ambient & {$[239]$} \\
\hline HTM-free & HTM-free & w/o & ambient air & {$[240]$} \\
\hline
\end{tabular}




\begin{tabular}{lllll}
\hline HTM1, HTM2 & HTM1 & w/o & ambient, dark & {$[206]$} \\
\hline PANI & PANI & & $200 \mathrm{mWcm}^{-2}$ & {$[207]$} \\
\hline Cu:NiOx & CuNiOx & w/o & Air & {$[212]$} \\
\cline { 1 - 2 } PEDOT:PSS & PEDOT:PS & & & \\
& S & & & \\
\hline
\end{tabular}

\section{Effect of contact electrode on the stability of PSCs}

Gold, silver, aluminum and calcium etc. are commonly used as contact electrode materials in PSCs. The stability issues related to the contact electrode may rely on the contact interface between the metal contact electrode and charge-transporting layer [241-243], the corrosion of the contact electrode by perovskite degradation product $[27,141,190,191]$, or the penetration of the metal elements into ETL or HTL and to contact with perovskite layer [244-246] . Nima E. Gorji et al. [247] modeled the degradation and recovery of PSCs and found that the efficiency stability of the PSCs is determined by the stability of FF rather than $\mathrm{J}_{\mathrm{SC}}$ and $\mathrm{V}_{\mathrm{OC}}$, emphasizing the crucial role of metallic contacts for stable PSCs.

Bingchu Yang and Junliang Yang et al. [248] reported the formation of bubbles at the PCBM/Al interface, as shown in Fig. S26, which lead to the peeling of the contact electrode from the device and the loss of efficiency. The $\mathrm{CH}_{3} \mathrm{NH}_{3} \mathrm{PbI}_{3}$ can react with the water and decomposes to $\mathrm{CH}_{3} \mathrm{NH}_{3} \mathrm{I}$ and $\mathrm{PbI}_{2}$. The $\mathrm{CH}_{3} \mathrm{NH}_{3} \mathrm{I}$ further decomposes to $\mathrm{HI}$, which ultimately produces $\mathrm{H}_{2}$ under the light. The $\mathrm{H}_{2}$ penetrates and passes through the PCBM layer, leading the formation of Al bubbles. [242,243] Bubbles also were found on the surface of Ag contact electrode. Besides the $\mathrm{H}_{2}$ bubbles induced delamination of contact electrode, irradiation may also break the Au-O bond between HTM and Au metal contact. [241] The damaged contact at the HTM/Au decreases the hole diffusion from the HTM to Au and the efficiency of the device consequently.

In the presence of moisture, the $\mathrm{MAPbI}_{3}$ degradation products MAI and $\mathrm{HI}$ may corrode $\mathrm{Ag}$ electrodes by reacting with $\mathrm{Ag}$ to produce $\mathrm{AgI}$, as shown in Fig. S27, which leads to the decrease of the efficiency of the device. [190] Henry J. Snaith et al. [141], Yi-bing Cheng et al. [27] , Manoi A. G. Namboothiry et al. [191] and Hong Lin et al. [249] reported the degradation due to the corrosion of $\mathrm{Ag}$ electrode by reacting with perovskite or perovskite degradation product MAI and HI. Hong Lin et al. [249] deposited a layer of ultrathin Au between the HTM and halide-reactive AgNWs top-electrode as physical separation to prevent the corrosion of Ag by perovskite or perovskite degradation products. Joseph M. Luther et al. [250] revealed that introducing a layer of MoOx between $\mathrm{HTM} /$ metal contact electrode led to the filling of pinholes in the spiro-OMeTAD and inhibited decomposition of $\mathrm{MAPbI}_{3}$ layer under illumination in ambient laboratory conditions. $\mathrm{MoO}_{\mathrm{x}}$ interlayer not only mitigates the reaction between the perovskite and the metal contact electrodes but also facilitates the formation of a protective oxide layer on the metal contact electrodes.

In the absence of water, the metal contact may be degraded by reaction with the perovskite. Au was found to penetrate into PCBM and contact with perovskite, leading to (1) the degradation of metal contact by reacting with perovskite and (2) modification of the energy profile within the perovskite layer close to the contacts, which can dramatically reduce the device efficiency. [245] Al is also found to diffuse into PCBM layer, as shown in Fig. 
S28, which leads to the direct contact of perovskite and Al layer. This would undoubtedly lead to severe damage to the metal contact electrode [244]. Furthermore, it is reported that $\mathrm{Al}^{0}$ can rapidly reduce $\mathrm{Pb}^{2+}$ to $\mathrm{Pb}^{0}$ even in absence of oxygen or illumination, which leads to the converting of $\mathrm{CH}_{3} \mathrm{NH}_{3} \mathrm{PbI}_{3}$ to $\left(\mathrm{CH}_{3} \mathrm{NH}_{3}\right)_{4} \mathrm{PbI}_{6} \cdot 2 \mathrm{H}_{2} \mathrm{O}$ and then to $\mathrm{CH}_{3} \mathrm{NH}_{3} \mathrm{I}$. [251] Moisture first facilitates the ion diffusion and enables the continuous reaction of the $\mathrm{Al}$ and perovskite layers before severing as decomposition reagent for the perovskite film. [215] Au is observed diffusion across the HTL into the perovskite layer and the diffused Au in-turn causes the reversible loss of $\mathrm{V}_{\mathrm{OC}}, \mathrm{FF}$, and $\mathrm{J}_{\mathrm{SC}}$ in the $\mathrm{PSC}$ aged at $75{ }^{\circ} \mathrm{C}$ [252] . Insertion of a thin $\mathrm{Cr}$ interlayer between the HTL and Au is likely to mitigate the diffusion of Au across spiroOMeTAD into the perovskite and alleviate the problem of device degradation at elevated temperatures. Apart from the penetration of the metal ions through HTL/ETL contacting with perovskite, the iodide ions in the perovskite may also diffuse through the organohalide crystal and PCBM and corrode the metal contact [190,253-255]. Kwanghee Lee et al. [253] introduced an amine-mediated titanium suboxide $\left(\mathrm{AM}-\mathrm{TiO}_{\mathrm{x}}\right)$ as a chemical inhibition layer (CIL) between the PCBM and Ag contact electrode. The amine group in $\mathrm{AM}-\mathrm{TiO}_{\mathrm{x}}$ acts as a corrosion inhibitor and protect the Ag electrodes from corrosion of halide ions by extracting and stabilizing the halide ions. PSCs with CIL exhibit long-term stability, maintaining almost $80 \%$ of their initial PCEs after 1 year $(9000 \mathrm{~h}$ ) storage in nitrogen and $80 \%$ of the initial PCEs after $200 \mathrm{~h}$ in ambient conditions without any encapsulation.

Among the commonly used metal contact electrodes, $\mathrm{Al}$ and $\mathrm{Ag}$ may be corroded by the halide ions from the perovskite photoactive layer or perovskite degraded products. Mo is chemically more stable against reaction with halides and oxidation. Mo-cathode-based devices show superior mechanical and scratch-resistance properties compared to Au-based devices. [256] $\mathrm{Cu}$ is also more stable against reaction with halide perovskite. Unsealed FA/MA mixed-cation PSC with Cu electrode exhibits a stability of longer than 20-30 days in air while Al electrode device degrades within only a few days [257] . Very recently, Jinsong Huang et al. [258] reported the evaluation of the potential of $\mathrm{Cu}$ as the electrode material in PSCs for long-term stability. Results showed that there is no interface reaction occurred while $\mathrm{Cu}$ in direct contact with $\mathrm{MAPbI}_{3}$ at laboratory time scales in encapsulated devices that limit exposure to oxygen and moisture, and it is predicted to be stable for almost 170 years at room temperatures and 22 years at the nominal operating cell temperature of $40{ }^{\circ} \mathrm{C}$. The device with a Cu electrode exhibited a PCE above $20 \%$ and retained $98 \%$ of the initial efficiency after 816 hours storage in an ambient environment without encapsulation. AgAl alloy electrode demonstrates more stability than $\mathrm{Ag}$ and $\mathrm{Al}$. Al atoms diffusing out of $\mathrm{AgAl}$ alloy tend to oxidize to form $\mathrm{AlO}_{\mathrm{x}}$, which acts as a barrier layer to inhibit not only the diffusion and agglomeration of $\mathrm{Ag}$ atoms but also the penetration of moisture and degradation products. [243,259,260] The AgAl-based cells without encapsulation retain $78 \%$ of the initial PCE after stored in air for 380 days. Even after continuous scanning for $10 \mathrm{~min}$, the photocurrent was very stable and its high value of $18.3 \mathrm{~mA} \mathrm{~cm}^{-2}$ at $0.8 \mathrm{~V}$ resulted in the stabilized PCE of about $15 \%$. [256]

Michael D. McGehee et al. [261] demonstrated the use of ITO as electrode with Al:ZnO nanoparticles as the hole-blocking layer and sputtering buffer layer. The device based on ITO electrode degraded to $80 \%$ of its original efficiency $\left(\mathrm{T}_{80}\right)$ after $124 \mathrm{~h}$ storage at $100{ }^{\circ} \mathrm{C}$, whereas the metal electrode device shows a $\mathrm{T}_{80}$ of $1.5 \mathrm{~min}$ at $100{ }^{\circ} \mathrm{C}$. Replacing metal contact 
electrode with ITO prevented the egress of methylammonium iodide and ingress of moisture, which mitigated the electrode corrosion caused by the reaction between the egressed MAI and metal contact electrode and avoided the catastrophic degradation of the device.

\section{Effect of preparation condition on the stability of PSCs}

Due to the strong hygroscopicity of the perovskite absorbing layer, PSCs are fabricated in vacuum or glove box with adequate environment. The widely used solvents such as DMF, GBL and DMSO are hygroscopic and could be a problem both during manufacturing and after the device production. [262,263] However, some research results [102,264-270] show that the effects of the moisture in the environment are not fully negative. The perovskites prepared under anhydrous conditions are poorly crystalline powders, which is non-emissive and the lifetime of the emission for the bromide is very short. Once exposure to a small amount of moisture, poorly crystallized powders of $\mathrm{CH}_{3} \mathrm{NH}_{3} \mathrm{PbBr}_{3} \mathrm{CH}_{3} \mathrm{NH}_{3} \mathrm{PbI}_{3}$ crystallized into cubic unit cell for $\mathrm{CH}_{3} \mathrm{NH}_{3} \mathrm{PbBr}_{3}$ and tetragonal cell for $\mathrm{CH}_{3} \mathrm{NH}_{3} \mathrm{PbI}_{3}$, which is considered to originate from moisture-induced nucleation and crystallization [264]. Mild moisture may have a positive effect on the perovskite film formation, leading to increased grain size, carrier mobility, and charge carrier lifetime [271] . Yongfang Li et al. [272] reported a room-temperature water-vapor annealing for high-performance planar PSC, in which water molecules catalyzed the dissolution and recrystallization of the perovskite grain edges and void area, resulting in void-free and large sized crystals in perovskite films and improved photovoltaic performance. Time-domain $\mathrm{Ab}$ Initio simulations show that moderate humidity delays electron-hole recombination in perovskites, which may be attributed to the localization of photoexcited electron close to the surface and avoiding of deep electron traps due to the perturbing of perovskite surface by small amounts of water molecules. [270] The PCE can be improved effectively to $19.3 \%$ by carefully controlling the relative humidity to be less than $30 \% \mathrm{RH}$ in fabrication process to control the crystallization process of perovskite absorbing layer [81]. Kai $\mathrm{Zhu}$ et al. [273] fabricated $\mathrm{FAPbI}_{3}$ planar heterojunction solar cells by a solvent engineering method in controlled humidity conditions. Fig. S29 shows the effect of the relative humidity on the morphology of the perovskite thin films. The films prepared under $2 \% \mathrm{RH}$ to $20 \% \mathrm{RH}$ exhibit good coverage and few pinholes. As the relative humidity increasing from $20 \%$ to $30 \% \mathrm{RH}$, the coverage of perovskite decreases about $13 \%$ and pinholes begins to appear on the film surface. As the relative humidity further increased to $40 \%$, the coverage decreases to $75 \%$ and pinholes size increases to above $200 \mathrm{~nm}$ and even to $1 \mu \mathrm{m}$. The device fabricated in low relative humidity (2\%) shows highly uniform and crystalline perovskite absorbing film and achieves an efficiency of $16.6 \%$ while the counterpart fabricated in high relative humidity $(40 \%)$ has inhomogeneous film with the presence of voids and an efficiency of $8.6 \%$. Pinholes are found to act as a source of increased degradation over time even when devices were stored in dry glovebox environment, indicating the importance of developing pinhole free solar cells. [274] Qingbo Meng et al. investigated the effect of humidity on the crystallization process of two-step spin-coated perovskites and the results show that moisture (below $60 \% \mathrm{RH}$ ) has little detremental effect in fabricating high-quality perovskite films by using two-step spin coating method. [275] Moisture appears to play a crucial role during the fabrication of PSC. Qing Zhao et al. [276] reported the reversible healing effect of $\mathrm{H}_{2} \mathrm{O}$ molecules on fully crystallized metal-halide 
perovskite film. The device with water vapor spray exhibits a significantly decreased density of defect states. The water molecules form hydrogen bond with the uncoordinated ions on the perovskite surface, inducing the deactivation process and changing the defect states to shallow ones.

Chihaya Adachi et al. [277] observed the formation of hole traps in PSCs after degradation by continuous illumination and proposed that the formation of hole traps results from photo-degradation of $\mathrm{CH}_{3} \mathrm{NH}_{3} \mathrm{PbI}_{3}$ in the presence of water. The PCE of the solar cell fabricated in nitrogen dropped to about $81 \%$ of the initial value after $500 \mathrm{~h}$ of illumination while that of the device fabricated in air (about $30 \% \mathrm{RH}$ ) dropped to about $10 \%$ of the initial value.

Tom Wu et al. [238] studied the effect of drying atmosphere of Spiro-OMeTAD on the PCE of the device. Results show that the device dried in air exhibits the highest PCE of $11.2 \%$ compared to a PCE of $5.4 \%$ or $7.2 \%$ of the devices prepared in vacuum or $\mathrm{N}_{2}$ atmosphere respectively, for the oxygen in air is critical to the p-doping of Spiro-OMeTAD.

Tao Chen et al. [278] prepared high-quality perovskite film by a modified chemical vapor transport (mCVT) reaction approach, which is stable for 100 days in air with $40 \% \mathrm{RH}$, as shown in Fig. S30. Mukundan Thelakkat et al. [279] reported the preparation of an extraordinarily stable perovskite layer by MAI vapor-assisted crystallization method and its using in PSCs. The film prepared by MAI vapor-assisted crystallization method exhibits no degradation for about 3 months storage in ambient condition of about $50 \% \mathrm{RH}$, whereas the films prepared by one-step coating and two-step method decomposes to form $\mathrm{PbI}_{2}$ after 5 days storage. The PSC made from the stable perovskite film shows good long-term stability as the device parameters $\mathrm{J}_{\mathrm{SC}}, \mathrm{V}_{\mathrm{OC}}, \mathrm{FF}$, and PCE are almost constant and exhibit no noticeable degradation. Alex K.-Y Jen et al. [280] reported the large grained perovskite film prepared from single-crystal perovskite powders. The film is highly crystalline and compact, exhibiting negligible degradation without forming any new peaks after being stored in air $\left(25{ }^{\circ} \mathrm{C}, 55 \%\right.$ RH) after $48 \mathrm{~h}$. Shengzhong (Frank) Liu et al. [281] reported highly stabilized perovskite solar cell prepared using vacuum deposition. The vacuum deposited device without encapsulation degraded by only 7\% in efficiency after exposure in ambient condition for 1488 hours while the solution processed device degraded by $30 \%$ in the first 144 hours.

\section{Effect of ion migration on the stability of PSCs}

The migration behaviors of ions and defects are considered relating to the hysteresis effect and stability-related issues in hybrid perovskite materials. Ho Won Jang et al. [282] highlighted the inhibition of ion migration as a key for reliable perovskite-based devices. SaiWing Tsang et al. [283] correlated the PCE and shelf-life time of the PSCs to the excess mobile ion concentration in the perovskites, the lower mobile ion concentration the higher PCE and longer shelf-life time. The excess mobile ions trigger the deformation of perovskite to $\mathrm{PbI}_{2}$, which severely decreases the lifetime of device. Qiaoliang Bao et al. [284] found that the ion migration, especially the migration of $\mathrm{MA}^{+}$ions, could cause a reversible structural swell-shrink in the perovskites. The maximum quantity of migration ions could be as high as about $30 \%$, which could lead to a lattice swell or shrink of approximately $4.4 \%$. Furthermore, the lattice distortion in this reversible structural swell-shrink process could accelerate the degradation of perovskites.

Andrew M. Rappe et al. [285] studied the interstitial hydrogen in the perovskite and 
found that the barrier effect to the proton migration was relatively low due to the iodide displacements in organic-inorganic perovskite crystal structure, indicating that the hydrogen defects could be mobile and might play an important role in the intrinsic stability of PSCs.

In addition to hydrogen migration, defects in methylammonium lead iodide can also easily diffuse in the organohalide crystal. [254] The calculated migration activation energy of iodine vacancies (interstitials) is about $0.1 \mathrm{eV}$. The $\mathrm{MA}$ and $\mathrm{Pb}$ vacancies have calculated activation energies of $\sim 0.5$ and $0.8 \mathrm{eV}$ respectively. The calculated activation energy of MA vacancy migration is in agreement with the reported experimental activation energy value for electrode polarization in PSCs. Charged defects migrating in perovskite crystal and piling up close to the interfaces may also cause intrinsic stability issues of the PSCs. Jun Haruyanma et al. [286] investigated anion and cation diffusion in tetragonal $\mathrm{MAPbI}_{3}$ and $\mathrm{FAPbI}_{3}$ by first principles activation energy calculations of the vacancy and impurity migrations. The calculated activation energies of $\mathrm{I}^{-}$anion in both $\mathrm{MAPbI}_{3}$ and $\mathrm{FAPbI}_{3}$ suggest that it can easily diffuse with low barriers of ca. $0.45 \mathrm{eV}$, and $\mathrm{MA}^{+}$and $\mathrm{FA}^{+}$cations also have rather low energy barriers for the migrations ( 0.57 and $0.61 \mathrm{eV}$, respectively). Mao-Hua Du et al. [287] calculated the diffusion barriers and formation energies for the native defects $\left(\mathrm{V}_{\mathrm{I}}^{+}, \mathrm{MA}_{\mathrm{i}}^{+}\right.$, $\mathrm{V}_{\mathrm{MA}}^{-}, \mathrm{I}_{\mathrm{i}}^{-}$) and the Au impurity in $\mathrm{MAPbI}_{3}$. It is found that the diffusion barriers of $\mathrm{V}_{\mathrm{I}}^{+}, \mathrm{MA}_{\mathrm{i}}^{+}$ and $\mathrm{I}_{\mathrm{i}}^{-}$are low and the formation energy of $\mathrm{V}_{\mathrm{I}}^{+}$is lower than that of $\mathrm{MA}_{\mathrm{i}}^{+}$and $\mathrm{I}_{\mathrm{i}}^{-}$.

Furthermore, the formation energy and diffusion barrier of $\mathrm{Au}$ is also low, indicting easy diffusion of $\mathrm{Au}$ into $\mathrm{MAPbI}_{3}$ layer. Juan-Pablo Correa-Baena et al. [252] observed the diffusion of $\mathrm{Au}$ across the HTL into perovskite at elevated temperature. Jinsong Huang reported the field-switchable photovoltaic effect in $\mathrm{MAPbI}_{3}$ devices due to the formation of reversible $p$-i-n structures caused by field-induced $\mathrm{MA}^{+}$or iodine vacancy migration [288] and further reported a direct observation of electro migration of $\mathrm{MA}^{+}$[289] and direct evidence for the macroscopic migration of $\mathrm{V}_{\mathrm{I}}$ in $\mathrm{MAPbI}_{3}$ perovskite film at an elevated temperature of $330 \mathrm{~K}$ [290]. Both MA and iodine ion migration could contribute to the performance instability of $\mathrm{MAPbI}_{3}$. [291] Light could greatly reduce the ion migration energy barrier in both polycrystalline and single crystalline perovskite and result in ultrafast ion migration in polycrystalline thin films. [292] Elemental mapping of perovskite solar cells shows the migration of iodine into the spiro-OMeTAD towards the Au electrode, leading to severe degradation of photoactive layer. [293] Samuel D. Stranks et al. [294] presented the direct visual evidence for photo-induced halide migration in the neat perovskite materials by imaging the photo-induced "brightening" regions with time-of-flight secondary-ionspectrometry. Annamaria Petrozza et al. [295] observed the migration of $\mathrm{I}^{-}$and its interaction with PCBM. I' can migrate from perovskite layer to the interface between PCBM and the perovskite and interacte with PCBM, leading to the modification of the electronic properties of PCBM at the interface. [295] $\mathrm{I}^{-}$could also migrate through PCBM [253] and react with Ag contact electrode, leading to the degradation of the PSCs.

Furthermore, the $\mathrm{MA}^{+}$can also migrate under the light-generated photovoltage and the migration of ions enhances rather than impairs the performance of $\mathrm{MAPbI}_{3}$ device under illumination [296]. Tomas Leijtens et al. also reported electric field-induced switchable poling and structural degradation of perovskite film. [297] Results show that the electric field poling in inert conditions is reversible, but at the presence of moisture, small polar molecules, or hydrogen-bonding molecules, the electric field lead to irreversible degradation of the 
perovskite films due to the loosely bounded $\mathrm{MA}^{+}$migration in the hydrated $\mathrm{MAPbI}_{3}$. Recent reports by M. Saiful Islam et al. [298] and Joachim Maier et al. [299] revealed that perovskites were mixed ionic-electronic conductors [134] . M. Saiful Islam et al. [298] calculated the activation energy for ionic migration in $\mathrm{CH}_{3} \mathrm{NH}_{3} \mathrm{PbI}_{3}$ and extracted the kinetic data from the current-voltage response of the PSC. The calculated activation energies for $\mathrm{I}^{-}$, $\mathrm{MA}^{+}$and $\mathrm{Pb}^{2+}$ are $0.58 \mathrm{eV}, 0.84 \mathrm{eV}$ and $2.31 \mathrm{eV}$ respectively. The activation energy derived from photocurrent relaxation at biased preconditioning is $0.60-0.68 \mathrm{eV}$, which is in good agreement with the calculated activation energy for $\mathrm{I}^{-}$. Joachim Maier et al. [299] observed the formation of $\mathrm{PbI}_{2}$ at $\mathrm{Pb}$-anode/ $\mathrm{MAPbI}_{3}$ interface and revealed a clue about possible $\mathrm{I}^{-}$ migration at elevated temperature. The formation of the $\mathrm{PbI}_{2}$ could be attributed to the migration of $\mathrm{I}^{-}$in $\mathrm{MAPbI}_{3}$ to the interface and the reaction with $\mathrm{Pb}$-anode. However, it could also be explained by the decomposition of the $\mathrm{MAPbI}_{3}$ due to the leaving of $\mathrm{MA}^{+}$from the region close to the anode.

Diffusion of intrinsic ionic defects in organo-lead halide perovskites plays a critical role in long-term stability and performance of PSC devices. The iodide ions can move to the perovskite/spiro-OMeTAD interface and react with spiro-OMeTAD+ under positive bias, however, the spiro-OMeTAD can only partially return to its oxidized conductive state under negative bias. [300] This irreversible ionic reaction occurs between iodide ions in spiroOMeTAD and $\mathrm{MAPbI}_{3}$ leading to a progressive reduction in the conductivity of spiroOMeTAD layer and a detrimental effect on the photovoltaic performance. Kenjiro Miyano et al. [301] showed that the ion migration was inevitable but it was not detriment to the PV operation based on various evidences. They attributed the degradation of the device to the chemical change at interfaces between carrier selective layers and the perovskite rather than the compositional change of lead-iodide perovskite bulk. Quentin Jeangros et al. [302] also observed bias-induced degradation of $\mathrm{MAPbI}_{3}$ occurring at the interface with the hole transport layer, which was triggered by both the migration of iodide into the positive hole transport layer and the volatilization of iodine and organic species.

Yi-Bing Cheng et al. [303] reported the fatigue behavior of planar PSCs by light on/off diurnal cycling. Results showed that the device fatigue was strongly dependent on the cell temperature, which could be attributed to the temperature-limited diffusion of mobile species in the solar cell materials.

\section{Strategies to improve the stability}

The strategies that we believe especially critical toward the material and device performance stability include holistic consideration and optimization on perovskite material modification, interface engineering between perovskite and other components in a device, coating layer protection of perovskite, and encapsulation protection.

\subsection{Perovskite material modification}

Molecular level control of perovskite structure is important to tailor the material stability. Partially replancement of I with $\mathrm{Br}$ or $\mathrm{Cl}, \mathrm{Pb}$ with $\mathrm{Sn}$, or the organic cation $\mathrm{CH}_{3} \mathrm{NH}_{3}$ with inorganic $\mathrm{Cs}$, leads to the enhanced stability of perovskites and no spontaneous phaseseparation. [31] Strengthening interaction between the organic cation and inorganic anion of the perovskite framework lead to the enhancement of the chemical stability of perovskite. Substitution of $\mathrm{CH}_{3} \mathrm{NH}_{3}{ }^{+}$with protonated $\mathrm{CH}_{3} \mathrm{PH}_{3}{ }^{+}, \mathrm{CH}_{3} \mathrm{SH}_{2}{ }^{+}, \mathrm{SH}_{3}{ }^{+}$to form stronger 
hydrogen bond, or substitute $\mathrm{I}^{-}$and $\mathrm{Br}^{-}$with more electronegative $\mathrm{F}^{-}$and $\mathrm{Cl}^{-}$anions to improve the electronic coupling between the cations and perovskite octahedral frameworks, both of them can improve the stability of perovskites. [304,305] For example, substitution of larger I atoms with smaller $\mathrm{Br}$ atoms in $\mathrm{MAPb}\left(\mathrm{I}_{1-\mathrm{x}} \mathrm{Br}_{\mathrm{x}}\right)_{3}$ leads to a more compact and stable perovskite structure as a result of reduction in lattice constants and the transition to a cubic phase. Additionally, stronger hydrogen-bond interactions between bromide and organic cation can suppress the transition of the perovskite to the monohydrate and consequently stabilize the organic-inorganic perovskite layers. [306] Sang Il Seok et al. [210] reported the substitution of $\mathrm{I}$ by $\mathrm{Br}$ in the $\mathrm{CH}_{3} \mathrm{NH}_{3} \mathrm{~Pb}\left(\mathrm{I}_{1-\mathrm{x}} \mathrm{Br}_{\mathrm{x}}\right)_{3}$ material with $\mathrm{x} \geq 0.2$, which led to a greater resistance toward high humidity ( $\geq 55 \%$ ) at room temperature, as shown in Fig. S31. Tao Yu et al. reported enhanced PCE (14.25\%) and stability (retained up to $93 \%$ of the initial PCE after exposure in air for 14 days without encapsulation) of the device based on $\mathrm{CH}_{3} \mathrm{NH}_{3} \mathrm{PbI}_{3-\mathrm{x}} \mathrm{Br}_{\mathrm{x}}$ film prepared two-step spin-coated $\mathrm{CH}_{3} \mathrm{NH}_{3} \mathrm{PbI}_{3}$ film by halide exchange with $\mathrm{CH}_{3} \mathrm{NH}_{3} \mathrm{Br}$ solution post-treatment. [307] $\mathrm{CH}_{3} \mathrm{NH}_{3} \mathrm{PbBr}_{3}$ based PSCs exhibits more moisture resistant and thermal stability because of its close-packed crystal structure. [308] The devices based on $\mathrm{CH}_{3} \mathrm{NH}_{3} \mathrm{PbBr}_{3}$ were stable for up to $2500 \mathrm{~h}$. [309] Yalin $\mathrm{Lu}$ et al. reported that $\mathrm{CH}_{3} \mathrm{NH}_{3} \mathrm{PbI}_{3-\mathrm{x}} \mathrm{Cl}_{\mathrm{x}}$ had no phase transition in the range $25-100{ }^{\circ} \mathrm{C}$ and lower heat generation in absorbing photon process $\left(20 \%\right.$ lower than $\left.\mathrm{CH}_{3} \mathrm{NH}_{3} \mathrm{PbI}_{3}\right)$, leading to better thermal stability. [310] $10 \% \mathrm{CsPbBr}_{3}$ doped $\mathrm{MAPbI}_{3} \mathrm{PSC}$ exhibited improved stability under UV irradiation and in ambient atmosphere, which was mainly attributed to the incorporation of $\mathrm{Cs}$ and $\mathrm{Br}$ into the unit cell and contraction of the cell parameters and the contracted crystal structures were resistant to the ingression of moisture from the atmosphere. [311] However, photo instability is observed in some mixed-halide solar cells such as $\mathrm{CH}_{3} \mathrm{NH}_{3} \mathrm{~Pb}\left(\mathrm{I}_{1-\mathrm{x}} \mathrm{Br}_{\mathrm{x}}\right)_{3}$ based PSCs due to Spinodal decomposition with I- and Br-rich phases. It is unstable between $0.3<$ $\mathrm{x}<0.6$ with respect to Spinodal decomposition at $300 \mathrm{~K}$. [50] Incoporation of $\mathrm{Cs}$ in $\mathrm{Cs}_{\mathrm{y}} \mathrm{FA}_{1-}$ ${ }_{y} \mathrm{~Pb}\left(\mathrm{BrI}_{1-\mathrm{x}}\right)_{3}$ [312] or substitution of $\mathrm{Pb}$ with $\mathrm{Sn}$ in $\mathrm{MAPb}_{0.75} \mathrm{Sn}_{0.25}\left(\mathrm{I}_{1-\mathrm{y}} \mathrm{Br}_{\mathrm{y}}\right)_{3}$ [313] can suppress the phase segregation and enhance the photo-stability.

Nam-Gyu Park et al. substituted part of $\mathrm{HC}\left(\mathrm{NH}_{2}\right)_{2}{ }^{+}$with $\mathrm{Cs}^{+}$in $\mathrm{HC}\left(\mathrm{NH}_{2}\right)_{2} \mathrm{PbI}_{3}$ perovskite and found significant improved photo- and moisture stability of perovskite film due to contraction of cubo-octahedral volume and thereby enhanced FA-I interaction. [45] David Cahen et al. demonstrated that $\mathrm{CsPBBr}_{3}$ showed a higher thermal stability than $\mathrm{MAPbBr}_{3}$ by thermogravimetric analysis (TGA) [314]. This thermal stability contributes to both the operational stability and shelf-life of the Cs-based PSCs. Mixed $\mathrm{FA}_{x} \mathrm{MA}_{x} \mathrm{PbI}_{3}$ exhibits better long-term and thermal stabilities than $\mathrm{MAPbI}_{3}$ [315] . Zhaoxin Wu et al. [316] demonstrated the stabilization of $\alpha-\mathrm{FAPbI}_{3}$ by doping with $\mathrm{MABr}$. The PCE of the modified $\mathrm{FAPbI}_{3}$-based PSC decreased only $1.03 \%$ in 1 month exposure to $35 \%$ RH in the dark, whereas the PCE of the primitive $\alpha$-FAPbI3-based device decreased to $0.68 \%$. M. Ibrahim Dar et al. [317] reported intrinsically (under nitrogen) and extrinsically (in ambient conditions) stable $\mathrm{FAPbBr}_{3}$, with unsealed devices maintaining $95 \%$ of the initial efficiency under continuous illumination for $150 \mathrm{~h}$ in nitrogen and dry air and $80 \%$ in $60 \%$ relative humidity. Robert L. Z. Hoye et al. explored methylammonium bismuth iodide as a lead-free, stable hybrid organicinorganic solar absorber [318,319] .

Replacing chemical reactive halide ions with more robust pseudohalogen polyanions appears to be a promising approach for enhancing the chemical stability of perovskites [320- 
326] Tao $\mathrm{Xu}$ et al. [322] replaced two iodides in $\mathrm{CH}_{3} \mathrm{NH}_{3} \mathrm{PbI}_{3}$ by two pseudohalide thiocyanate ions $\left(\mathrm{SCN}^{-}\right)$to form $\mathrm{CH}_{3} \mathrm{NH}_{3} \mathrm{~Pb}(\mathrm{SCN})_{2} \mathrm{I}$. Gang Wu et al. [327] reported that introduction of $\mathrm{SCN}^{-}$via addition of $\mathrm{NH}_{4} \mathrm{SCN}$ in the precursor could suppress the formation of yellow $\delta-\mathrm{FAPbI}_{3}$ and improve the moisture stability of $\mathrm{FAPbI}_{3}$ due to the strong interaction between $\mathrm{SCN}^{-}$and $\mathrm{Pb}^{2+}$ ions. Due to the stronger interaction between the lone pairs of electrons from the $\mathrm{S}$ and $\mathrm{N}$ atoms in $\mathrm{SCN}^{-}$and $\mathrm{Pb}^{2+}$ ions, the frame structure of $\mathrm{CH}_{3} \mathrm{NH}_{3} \mathrm{~Pb}(\mathrm{SCN})_{2} \mathrm{I}$ is more stable than $\mathrm{CH}_{3} \mathrm{NH}_{3} \mathrm{PbI}_{3}$ upon moisture exposure, as shown in Fig. S32. $\mathrm{CH}_{3} \mathrm{NH}_{3} \mathrm{~Pb}(\mathrm{SCN})_{2} \mathrm{I}$ perovskite films showed no significant degradation after exposed to air with $95 \% \mathrm{RH}$ for $4 \mathrm{~h}$, while $\mathrm{CH}_{3} \mathrm{NH}_{3} \mathrm{PbI}_{3}$ films degraded in less than $1.5 \mathrm{~h}$. Ziqi Liang et al. [320] also reported addition of a small amount of $\mathrm{Pb}(\mathrm{SCN})_{2}$ into $\mathrm{PbI}_{2}$ in a two-step solution method to facilitate heterogeneous nucleation and crystallization of the perovskite. $\mathrm{CH}_{3} \mathrm{NH}_{3} \mathrm{PbI}_{3-\mathrm{x}}(\mathrm{SCN})_{\mathrm{x}}$ exhibits enhanced optical absorption, larger crystal size and less traps than $\mathrm{CH}_{3} \mathrm{NH}_{3} \mathrm{PbI}_{3}$, which lead to improved PCE and higher stability. PCE of $\mathrm{CH}_{3} \mathrm{NH}_{3} \mathrm{PbI}_{3-\mathrm{x}}(\mathrm{SCN})_{\mathrm{x}}$-based PSC decreased only $8 \%$ under 1 sun illumination for $1 \mathrm{~h}$ while that of $\mathrm{CH}_{3} \mathrm{NH}_{3} \mathrm{PbI}_{3}$-based PSC decreased about $42 \%$. [320] Unencapsulated $\mathrm{CH}_{3} \mathrm{NH}_{3} \mathrm{PbI}_{3-}$ ${ }_{x}(\mathrm{SCN})_{\mathrm{x}}$-based PSCs prepared with $\mathrm{Pb}(\mathrm{SCN})_{2}$ as precursor maintains $86.7 \%$ of their initial average PCE after $500 \mathrm{~h}$ storage in open air with an average $\mathrm{RH}$ over $70 \%$ while the $\mathrm{CH}_{3} \mathrm{NH}_{3} \mathrm{PbI}_{3}$-based devices lose nearly 40\%. [324] David O. Scanlon et al. [328] found a 2D layered structure, $\left(\mathrm{CH}_{3} \mathrm{NH}_{3}\right)_{2} \mathrm{~Pb}(\mathrm{SCN})_{2} \mathrm{I}_{2}$ (MAPSI), to have a band gap of $1.53 \mathrm{eV}$ and an electronic structure similar to that of the $3 \mathrm{D}$ structure perovskite $\mathrm{CH}_{3} \mathrm{NH}_{3} \mathrm{PbI}_{3}$. The decomposition energy of $\mathrm{MAPbI}_{3}$ by the pathway showed in equation (1) is negative ($0.09 \mathrm{eV}$ ) while the decomposition energies of MAPSI through the routes showed in equation (6) and (7) are both positive (0.38 eV for equation (6) and $1.97 \mathrm{eV}$ for equation (7). [328] :

$$
\begin{aligned}
& \left(\mathrm{CH}_{3} \mathrm{NH}_{3}\right)_{2} \mathrm{~Pb}(\mathrm{SCN})_{2} \mathrm{I}_{2}=2 \mathrm{CH}_{3} \mathrm{NH}_{3} \mathrm{I}+\mathrm{Pb}(\mathrm{SCN})_{2} \\
& \left(\mathrm{CH}_{3} \mathrm{NH}_{3}\right)_{2} \mathrm{~Pb}(\mathrm{SCN})_{2} \mathrm{I}_{2}=2 \mathrm{CH}_{3} \mathrm{NH}_{3}(\mathrm{SCN})+\mathrm{PbI}_{2}
\end{aligned}
$$

With respect to phase separation, MAPSI is thermodynamically stable since the two possible decomposition pathways are all unfavorable, which is likely the source of the increased stability reported in experiments. [320-325]

Two-dimensional (2D) layered perovskite readily forms high-quality films and exhibits more resistant to humidity than the 3D analogues due to incorporated hydrophobic long-chain organic cations [329-332] . Hemamala I. Karunadasa et al. [329] prepared high-quality films of $(\mathrm{PEA})_{2}(\mathrm{MA})_{2}\left[\mathrm{~Pb}_{3} \mathrm{I}_{10}\right]$ (PEA denotes phenylethylammonium) by one-step coating. The $2 \mathrm{D}$ layered $(\mathrm{PEA})_{2}(\mathrm{MA})_{2}\left[\mathrm{~Pb}_{3} \mathrm{I}_{10}\right]$ film exhibits more moisture resistant than $3 \mathrm{D} \mathrm{MAPbI}_{3}$ film. MAPI/PEAMAPI heterojunction PSC demonstrates a PCE up to $16.84 \%$ and improved moisture stability when exposure to air at constant $75 \% \mathrm{RH}$ in a sealed container at room temperature [330]. The MAPI-based device showed strong decolorization indicating advanced degradation of the perovskite film, whereas the MAPI/PEAMAPI heterojunction device maintained the dark brown color demonstrating intact perovskite absorber layer. Ethylenediamine (EDA) incorporated layered (EDA)(MA) $2\left[\mathrm{~Pb}_{3} \mathrm{I}_{10}\right]$ perovskite film also exhibits improved resistance to humidity-induced degradation. [333] The PCE of (EDA)(MA) $2\left[\mathrm{~Pb}_{3} \mathrm{I}_{10}\right]$-based PSC drops only $\sim 5 \%$ after 18 days while the $\mathrm{MAPbI}_{3}$-based deice drops $\sim 99 \%$. Aditya D. Mohite et al. reported high-efficiency $2 \mathrm{D}(\mathrm{BA})_{2}(\mathrm{MA})_{2} \mathrm{~Pb}_{3} \mathrm{I}_{10}$ and $(\mathrm{BA})_{2}(\mathrm{MA})_{2} \mathrm{~Pb}_{4} \mathrm{I}_{13}$ (BA denotes n-butylammonium) based PSC with greatly improved stability retaining over $60 \%$ of the PCE over $2250 \mathrm{~h}$ under constant, standard (AM 1.5G) illumination 
and enhanced tolerance to $65 \%$ RH. [334] $\mathrm{CA}_{2} \mathrm{PbI}_{4} / \mathrm{MAPbI}_{\mathrm{x}} \mathrm{Cl}_{3-\mathrm{x}}$ (CA denotes cyclopropylamine) perovskite exhibited significantly enhanced moisture stability showing no degradation after exposure to $63 \pm 5 \% \mathrm{RH}$ for 40 days while $3 \mathrm{D}$ perovskite decomposed completely under the same condition after 8 days. [335]

Kai Yao et al. [336,337] incorporated 2D material $(\mathrm{PEI})_{2} \mathrm{PbI}_{4}$ into $\mathrm{MAPbI}_{3}$ to tune the morphology of the perovskite layer by restraining the growth and aggregation of the perovskite crystals, which are beneficial to the formation of a continuous film with large domain sizes. In addition to the protection property originating from the hydrophobicity of the large polymer cation, the 2D materials work as insulating "wall" to resist moisture infiltration, which prevents the direct contact of water with the perovskite and decreases the chance of decomposition accompanied with a denser nature of the overall perovskite films. The efficiency of the $\left(\mathrm{MAPbI}_{3}\right)_{1-\mathrm{x}}\left[(\mathrm{PEI})_{2} \mathrm{PbI}_{4}\right]_{\mathrm{x}}$ cells for $\mathrm{x}=2 \%$ and $\mathrm{x}=4 \%$ decreased by $16 \%$ and $8 \%$ on the $14^{\text {th }}$ day exposure to $50 \%$ RH humidity, while the $\mathrm{MAPbI}_{3}$ cells decreased dramatically and showed complete failure in photovoltaic characteristic just after $120 \mathrm{~h}$ of exposure.

Materials preparation and packaging of PSC devices under proper conditions are important for tailoring material structure and property, and thus, maintaining the stability of device performance. Norman Pellet et al. [338] reported a 15\% efficiency mesoscopic $\mathrm{MAPbI}_{3} \mathrm{PSC}_{\mathrm{C}}$ with promising long-term stability fabricated by sequential deposition method. The device sealed in argon retained more than $80 \%$ of its original PCE during $500 \mathrm{~h}$ continuous operation at $45{ }^{\circ} \mathrm{C}$ under a light intensity of $\sim 100 \mathrm{mWcm}^{-2}$ at its maximum power point. Dong Yang et al. [339] fabricated PSCs by a technique of alternating layer-by-layer vacuum deposition of $\mathrm{PbCl}_{2}$ and $\mathrm{CH}_{3} \mathrm{NH}_{3} \mathrm{I}$ precursor layers, which can control the deposition environment and enable the fabrication of pure perovskite materials and in turn lead to better moisture protection and more stable performance of the devices. It is found that the topography of the underlying substrate affect the particle size and the crystallinity level of the perovskite film, and a well-structured perovskite film can survived a long-term degradation. [340] Additives, such as $\mathrm{NH}_{4} \mathrm{Cl}$ [341,342], $\mathrm{LiCl}$ [343] 1,8-diiodooctane (DIO) [344-347], 1-chloronaphthalene (CN) [348] , poly(ethyleneglycol) (PEG) [349-351] , polyvinypyrrolidone (PVP) [140,352], polyvinyl alcohol (PVA) [353], fullerene $\left(\mathrm{C}_{70}\right)$ [354], amine-polymer poly[(9,9-bis(3'-(N,Ndimethylamino) propyl)-2,7-fluorene)-alt-2,7-(9,9dioctylfluorene)] (PFN-P1) [355], imidazolium iodide salt [356], hydroiodic acid [34,357], hydrochloric acid [358-360], $\mathrm{HBr}$ [361], $\mathrm{H}_{2} \mathrm{O}$ [361,362], alkali metal halides [363] and hypophosphorous acid [364], were found beneficial to form smooth, continuous and uniform films, and significantly improve device performance and stability. Addition of 5-ammonium valebric acid iodide (5-AVAI) leads to the improved oxidation stability of $\mathrm{MAPbI}_{3}$ in the air. [365] Hydrazinium (HA)-loaded $\mathrm{MA}_{0.9} \mathrm{HA}_{0.1} \mathrm{MAPbI}_{3}$ based $\mathrm{PSC}$ exhibited enhanced performance and stability. [366] Alex K.-Y. Jen [347] prepared planar heterojunction PSC with enhanced stability by blade-coating in the presence of 1,8-diiodooctane (DIO) as additives, which served to improve the precursor solubility and prolong the crystallization time and inherent modulated the morphology of the perovskite films. [344,345] The PCE of blade-coated cell maintains about $95 \%$ of the initial PCE after $268 \mathrm{~h}$ of storage in air while the spin-coated cells exhibit rapid degradation in air in $120 \mathrm{~h}$, the color change from dark brown to yellow, as shown in Fig. S33b. It is considered that blade coating facilitates the 
formation of larger and denser crystalline domains due to longer time for self-assembling during the solvent drying process. The larger and denser grain structure, acting like airprotection barrier, can reduce the ingress of oxygen and moisture and thus enhance the stability. [347] Qing Zhao et al. incorporated PEG into perovskite film and found that the hygroscopic PEG scaffold could stabilize the perovskite film. [350,351] The perovskite film and the PSCs exhibit strong moisture resistant and self-healing property, the color and the performance of the PSCs recovering rapidly after removing from water vapour. [351] Ethyl cellulose (EC) is also incorporated into perovskite film to improve the photo- and moisture stability of PSCs. [367] The enhanced moisture stability and photostability of $\mathrm{MAPbI}_{3}$ is attributed to the hydrogen bonding between $\mathrm{EC}$ and $\mathrm{MAPbI}_{3}$, which leads to the stabilized crystal structure. $\mathrm{MAPbI}_{3}-\mathrm{NiO}$ composite-based PSCs without encapsulation retained $\sim 90 \%$ of its initial PCE for 60 days under ambient environment. [368] XPS and IR analysis showed the existence of $\mathrm{Pb}-\mathrm{O}, \mathrm{C}-\mathrm{O}, \mathrm{Ni}-\mathrm{N}$ and $\mathrm{N}-\mathrm{NiO}$ bonds, indicating strong chemical interaction between $\mathrm{NiO}$ and $\mathrm{MAPbI}_{3}$, which leads to the enhanced stability. $\mathrm{KCl}$ incorporation also demonstrates significant enhancement of PCE (from $11.40 \%$ to $15.08 \%$ ) and long-term stability (only $16.5 \%$ degradation during a period of 50 days store in dark environment, as shown in Fig. S33a [363] . Renqiang Yang et al. [369] introduced a small amount of Nmethyl-2-pyrrolidone (NMP) into the solution of GBL and DMSO during fabrication process for high-quality compact perovskite films and well-defined surfaces. A PCE of $11.7 \%$ is obtained and the unencapsulated device efficiency decreases $12.3 \%$ after over 20 days storage. Hsiang-Lin Hsu et al. [370] made use of EAI (Ethylammonium iodide) as additives to modify the crystallization of $\mathrm{CH}_{3} \mathrm{NH}_{3} \mathrm{PbI}_{3-\mathrm{x}} \mathrm{Cl}_{\mathrm{x}}$, leading to a dense perovskite $\mathrm{CH}_{3} \mathrm{NH}_{3} \mathrm{PbI}_{3-}$ ${ }_{\mathrm{x}} \mathrm{Cl}_{\mathrm{x}}$ absorbing layer and improved PCE and stability of the devices. Aliphatic fluorinated amphiphilic additive, 1,1,1-trifluoro-ethyl ammonium iodide (FEAI) also can be used in $\mathrm{MAPbI}_{3}$ perovskite to improve the stability without trading off the efficiency of the devices due to the hydrophobic CF3-terminal group over the surface of perovskite. [371] Yasuhiro Shirai et al. [355] reported the surface passivation of perovskite films by PFN-P1, which serves as surfactant and promotes uniform crystallization. The device containing PFN-P1 retained $\sim 90 \%$ of the initial PCE over 6 months and exhibited higher stability under continuous operation at maximum power point over $150 \mathrm{~h}$.

Recently, Michael Gratzel and co-workers [372] reported the crystal crosslinking [373] of $\mathrm{CH}_{3} \mathrm{NH}_{3} \mathrm{PbI}_{3}$ perovskite by containing butylphosphonic acid 4-ammonium chloride (4$\mathrm{ABPACl})$ in the precursor solution. $-\mathrm{PO}(\mathrm{OH})_{2}$ groups in phosphonic acid ammonium additive interact with the $-\mathrm{NH}_{3}{ }^{+}$terminal groups on the perovskite surface and form hydrogen bonding between them, leading to the crystal crosslinking of neighboring grains in the perovskite structure, as shown in Fig. S34. 4-ABPA surface modified perovskite grains can not only retard the ingress of water into the perovskite, but also block the $\mathrm{CH}_{3} \mathrm{NH}_{3} \mathrm{I}$ extraction and the formation of $\mathrm{PbI}_{2}$. The surface-anchored 4-ABPA groups shield the inner perovskite grains from moisture and thus slow down the degradation process. The $\mathrm{CH}_{3} \mathrm{NH}_{3} \mathrm{PbI}_{3}-\mathrm{ABPA}$ based devices maintain $90 \%$ of their initial PCE after one week, whereas the pristine $\mathrm{CH}_{3} \mathrm{NH}_{3} \mathrm{PbI}_{3}$ based devices retain only $70 \%$ under the same aging condition $\left(10 \mathrm{mWcm}^{-2} \mathrm{UV}\right.$-filtered simulated sun light at $45{ }^{\circ} \mathrm{C}$ for one week). 2-Aminothanethiol (2-AET) can also be used as a ligand to bridge the organic compound (MAI) and inorganic compound $\left(\mathrm{PbI}_{2}\right)$, which restrict the fast growth of $\mathrm{PbI}_{2}$ to realize the synchronous growth of $\mathrm{MAI}$ and $\mathrm{PbI}_{2}$ crystals, leading to 
the formation of a compact $\mathrm{MAPbI}_{3}$ film. [374] The $\mathrm{MAPbI}_{3}$ perovskite film with 2-AET exhibited excellent intrinsic water-resistance, with the perovskite crystal structure retained after immersion in water for more than 10 minutes, due to the compact $\left(\mathrm{PbI}_{2}\right)$-2-AET-(MAI) molecule barrier layers. Cross-linkable [6,6]-phenyl-C61-butyric styryl dendron ester (cPCBSD) was also incorporated into $\mathrm{MAPbI}_{3} \mathrm{Cl}_{3-\mathrm{x}}$ to enhance the crystallization and stability of the latter. [375] $\mathrm{MAPbI}_{3} \mathrm{Cl}_{3-\mathrm{x}}$ cc-PCBSD composite-based PSCs retained $84.6 \%$ of the initial PCE (from $16.9 \%$ to $14.3 \%$ ) after storage in ambient environment for $180 \mathrm{~h}$ while the $\mathrm{MAPbI}_{3} \mathrm{Cl}_{3-\mathrm{x}}$-based device decreased to $52.1 \%$ of the initial value (from $12.1 \%$ to $6.3 \%$ ). Heming Wang et al. also reported the incorporation of a photoactive conjugated polymer PTB7 into $\mathrm{MAPbI}_{3}$, leading to enhanced stability of $\mathrm{PTB} 7-\mathrm{MAPbI}_{3}$ composite based PSCs by providing a barrier protection to halide perovskite. [376] Yixin Zhao et al. [377] incorporated Ava into $\mathrm{MAPbBr}_{3}$ lattice, forming ultrasmooth and stable crosslinked 2D/3D Ava $\left(\mathrm{MAPbBr}_{3}\right)_{\mathrm{n}}$ perovskite film.

Aijun Du et al. [378] investigated electronic and optical properties of graphene/ $\mathrm{MAPbI}_{3}$ nanocomposite by first-principle calculation and the results show that the composite exhibits enhanced light absorption and reduced recombination. Furthermore, ab inito molecular dynamics simulation indicates that the hydrophobic graphene serves as water resistant barrier and protects $\mathrm{MAPbI}_{3}$ from the reaction with water. Hua Gui Yang and Hui Jun Zhao et al. [379] reported the functionalization of perovskite thin films by assembling hydrophobic tertiary and quaternary ammonium cations on perovskite surface and steric effects caused by bulky hydrophobic ammonium cations. They found that the change of surface $\mathrm{Pb}_{5 \mathrm{c}}-\mathrm{I}_{1 \mathrm{c}}$ bonds could effectively hinder the adsorption of $\mathrm{H}_{2} \mathrm{O}$ on the reactive $\mathrm{Pb}_{5 \mathrm{c}}$ sites, which leads to the improved moisture stability and outstanding photovoltaic properties.

Microstructure and crystallinity are crucial to achieve stable PSCs. Jinsong Huang et al. [380] reported a photo-stable wide $\mathrm{MAPbBr}_{\mathrm{x}} \mathrm{I}_{3-\mathrm{x}}$ perovskite device showing a PCE of $16.6 \%$, and the improved photo-stability of $\mathrm{MAPbBr}_{\mathrm{x}} \mathrm{I}_{3-\mathrm{x}}$ was contributed to an enhanced grain size and improved crystallinity. Jin Jang et al. [381] reported diethyl ether solvent engineering treated planar PSCs with enhanced PCE (9.20\%) and environmental stability of than 100 days, which was mainly attributed to a dense and uniform morphology and an enhanced grain size. Xiujuan Zhang et al. [382] reported aligned single-crystalline perovskite microwire (MW) arrays with long-term stability. The dark and photo-currents of the $\mathrm{CH}_{3} \mathrm{NH}_{3} \mathrm{PbI}_{3} \mathrm{MW}$ array-based photodetectors exhibited a mild fluctuation in the first 20 days in ambient condition at $45-55 \% \mathrm{RH}$ and then kept constant for the next 30 days while the film-based device nearly fully degraded after 40 days under the same condition. The enhanced long-term stability of the $\mathrm{CH}_{3} \mathrm{NH}_{3} \mathrm{PbI}_{3} \mathrm{MW}$ arrays was attributed to high-quality crystal structure and unique $1 \mathrm{D}$ enclosing surfaces with fewer grain boundaries.

Fig. 6 shows the initial PCEs and normalized PCEs after different storage time of the PSCs based on pristine and modified perovskite absorbers. Black squares are the initial PCEs of the devices and blue dots are the normalized PCEs after different storage time. The perovskite modification methods, encapsulation and storage condition of the devices are summarized in table 3. 


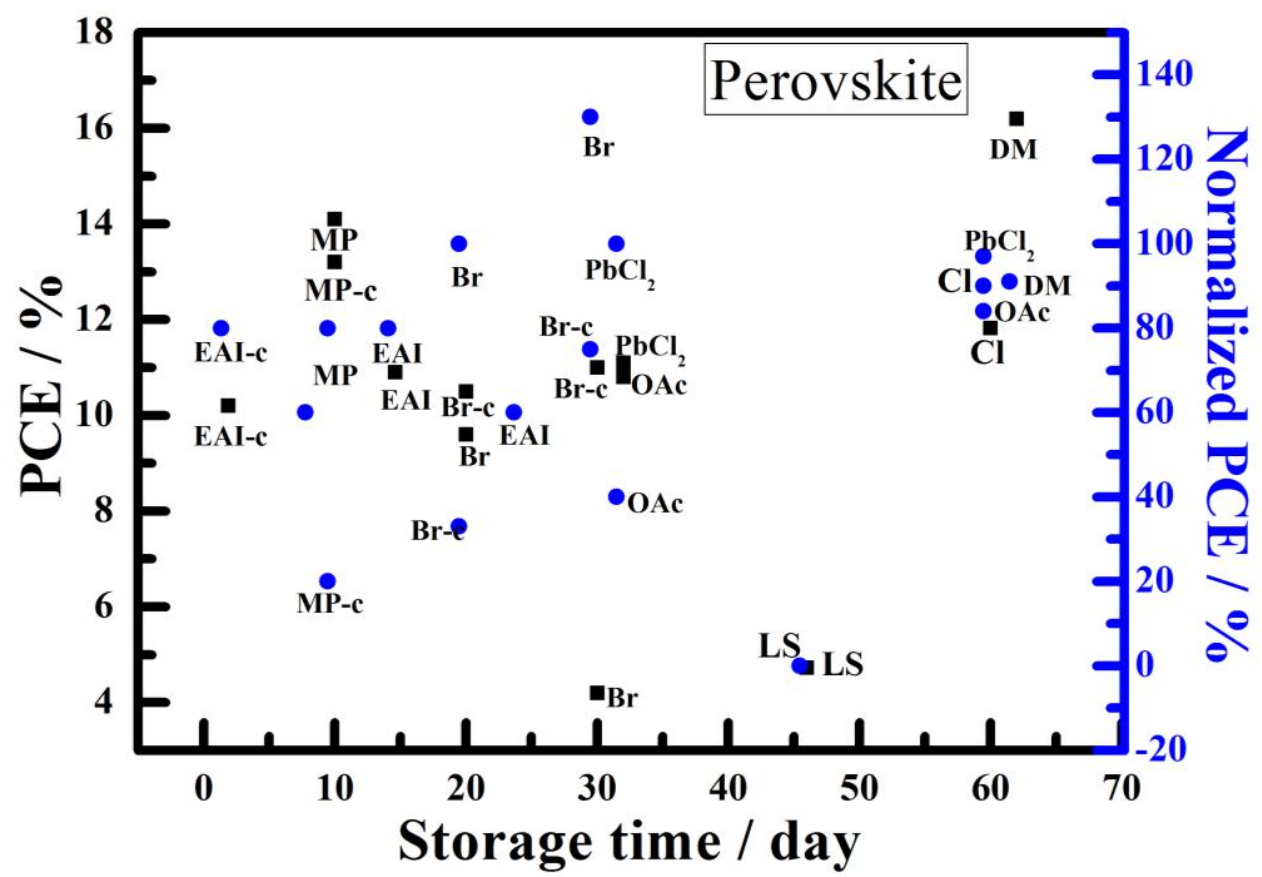

Fig. 6 Effect of perovskite modification on the stability of PSCs

Table 3 Modification of perovskite and storage condition of PSCs illustrated in Fig. 6

\begin{tabular}{|c|c|c|c|c|}
\hline Device configuration & Feature & Seal & Storage condition & Reference \\
\hline $\mathrm{TiO}_{2} /$ modified perovskite/HS-PhF5/spiro/Au & MP & \multirow[t]{2}{*}{ w/o } & air, RT, 45\% RH, & \multirow[t]{2}{*}[383]{} \\
\hline $\mathrm{TiO}_{2} /$ modified perovskite/spiro/Au & MP-c & & air, RT, 45\% RH & \\
\hline \multirow[t]{2}{*}{ PEDOT:PSS/MAPbI ${ }_{3-\mathrm{x}} \mathrm{Cl}_{\mathrm{x}} / \mathrm{PCBM} / \mathrm{Ca}-\mathrm{Ag}$} & \multirow[t]{2}{*}{$\mathrm{Cl}$} & \multirow[t]{2}{*}{$\mathrm{W}$} & illumination & \multirow[t]{2}{*}[384]{} \\
\hline & & & ambient & \\
\hline PEDOT:PSS/MAPbI ${ }_{3-\mathrm{x}} \mathrm{Cl}_{\mathrm{x}}-\mathrm{EAI} / \mathrm{PCBM} / \mathrm{Al}$ & EAI & \multirow[t]{2}{*}{ w/o } & \multirow[t]{2}{*}{$65^{\circ} \mathrm{C}$, dark, Air } & \multirow[t]{2}{*}[370]{} \\
\hline PEDOT:PSS/MAPbI ${ }_{3-\mathrm{x}} \mathrm{Cl}_{\mathrm{x}} / \mathrm{PCBM} / \mathrm{Al}$ & EAI-c & & & \\
\hline $\mathrm{TiO}_{2} / \mathrm{MAPbI}_{3-\mathrm{x}} \mathrm{Cl}_{\mathrm{x}} / \mathrm{Spiro} / \mathrm{Au}$ & DM & w/o & ambient & [339] \\
\hline thin film without $\mathrm{Br}$ & $\mathrm{Br}-\mathrm{c}$ & \multirow[t]{2}{*}{ w/o } & \multirow{2}{*}{$\begin{array}{l}\text { glovebox with } \mathrm{N} 2 \text {, } \\
\text { dark }\end{array}$} & \multirow[t]{2}{*}[385]{} \\
\hline thin film $\mathrm{Br}$ insertion & $\mathrm{Br}$ & & & \\
\hline $\mathrm{cTiO}_{2} / \mathrm{mTiO}_{2}+\mathrm{MAPbI}_{3} / \mathrm{PTAA} / \mathrm{Au}$ & $\mathrm{Br}-\mathrm{c}$ & \multirow[t]{2}{*}{ w/o } & $>55 \%$ RH,air,RT & \multirow[t]{2}{*}[210]{} \\
\hline $\mathrm{cTiO}_{2} / \mathrm{mTiO}_{2}+\mathrm{MAPb}\left(\mathrm{I}_{0.8} \mathrm{Br}_{0.2}\right)_{3} / \mathrm{PTAA} / \mathrm{Au}$ & $\mathrm{Br}$ & & $>55 \%$ RH,air,RT & \\
\hline \multirow[t]{3}{*}{$\mathrm{PbCl}_{2}$} & \multirow[t]{3}{*}{$\mathrm{PbCl}_{2}$} & \multirow[t]{6}{*}{ w/o } & air with light & \multirow[t]{6}{*}[386]{} \\
\hline & & & air without light & \\
\hline & & & $\mathrm{N}_{2}$ without light & \\
\hline \multirow[t]{3}{*}{$\mathrm{Pb}(\mathrm{OAc})_{2}$} & \multirow[t]{3}{*}{ OAc } & & air with light & \\
\hline & & & air without light & \\
\hline & & & $\mathrm{N}_{2}$ without light & \\
\hline $\mathrm{cTiO}_{2} /(\mathrm{PEA})_{2}\left(\mathrm{CH}_{3} \mathrm{NH}_{3}\right)_{2}\left[\mathrm{~Pb}_{3} \mathrm{I}_{10}\right] / \mathrm{Spiro}-/ \mathrm{Au}$ & LS & w/o & $52 \% \mathrm{RH}, \mathrm{RT}$ & [329] \\
\hline
\end{tabular}

\subsection{Interfacial engineering}

In typical perovskite solar cells, charge generation (photoactive perovsktie layer), transportation (HTM and ETM), and collection layers (front and back contact electrodes) are 
all stacked together, producing a seriers of interfaces and interfacial regions. Interfacial reactions and interfacial stability are factors affecting the stability of the device.

\subsubsection{Engineering of perovskite/ETM interface}

Interfacial reactions between perovskite and $\mathrm{ZnO}$ [114-116,118-120,123] or $\mathrm{TiO}_{2}$ [111] may lead to the degradation of the perovskite absorbing layer as discussed in Section 2.4. Various methods can be used to inhibit the interfacial reaction and improve the stability of the PSC, such as doping $\mathrm{ZnO}$ with $\mathrm{Al}$ [121,387] , $\mathrm{Mg}$ [122], inserting an interlayer such as $\mathrm{Al}_{2} \mathrm{O}_{3}$ [118,388] and PEI [120] between the perovskite and $\mathrm{ZnO}$, using $\mathrm{ZnO} / \mathrm{rGO}$ composite [116], efficient removal of basic hydroxyl groups, residual acetate ligands [114], fluorine plasma treatment [389] and processing solvent [118] .

Jinsong Huang et al. [390] reported efficient and water resistant PSCs by inserting a hydrophobic insulate tunneling layer between the perovskite and the ETL (PCBM). The device with a hydrophobic insulating fluoro-silane as the tunneling layer operated stably in water showing a Voc of $1.09 \mathrm{~V}$. The tunneling layer not only transports electrons and blocks holes, leading to reduced charge recombination and enhanced PCE, but also serves as protective layer to prevent perovskite from damage caused by water or moisture, leading to water-resistant PSC. Xuegong Yu et al. [391] introduced a fullerene [6,6]-phenyl-C61-butyric acid 2-((2-dimethylamino)ethyl)(methyl)-amino)-ethyl ester (PCBDAN) as interfacial modifier for $\mathrm{TiO}_{2}$ ETM in planar PSCs, which significantly improved the PCE and light soaking stability of the devices. Apart from the ETL/perovskite interface, the design and structuring of the interfaces of perovskite/HTL, HTL/hole contact electrode, perovskite/contact electrode in hole-conductor free or electron-conductor free devices are also important for improvement of the PSC stabilities.

\subsubsection{Engineering of perovskite/HTM interface}

To protect the perovskite from the corrosion of 4-tBP in the hole-transporting materials, Liduo Wang et al. [110] inserted a layer of MMT between perovskite $\mathrm{CH}_{3} \mathrm{NH}_{3} \mathrm{PbI}_{3}$ and $\mathrm{HTM}$ to avoid direct contact of tBP with $\mathrm{CH}_{3} \mathrm{NH}_{3} \mathrm{PbI}_{3}$. Meicheng Li et al. [392] reported a dual function F4TCNQ (2,3,5,6-tetrafluoro-7,7,8,8-tetracyano-quinodimethane) interfacial layer for highly efficient and stable PSCs. Liang-Sheng Liao et al. [393] introduced a thin perylene under layer between PEDOT:PSS and $\mathrm{CH}_{3} \mathrm{NH}_{3} \mathrm{PbI}_{\mathrm{x}} \mathrm{Cl}_{3-\mathrm{x}}$ and achieved a PCE of $17.06 \%$ and improved cell stability. Few-layer $\mathrm{MoS}_{2}$ flakes is also reported as an active buffer layer for boosting the shelf life of large-area PSCs. [394] Chih-Yu Chang et al. [395] also achieved high efficiency and improved stability PSCs with thiol-functionalized self-assembly monolayers. Compared to P3HT, P3TAA (poly(3-thiophene acetic acid) may interact with $\mathrm{MAPbI}_{3}$ to form a diffused interface for facilitating the hole transfer process and also result in better stability (P3TAA based device retained 55\% value of PCE after 10 days storage in ambient condition while P3HT based device only retained 27\%) [396] . An insulating Polystyrene nanofilm was also used for the perovskite/HTM interface engineering to decrease the electron/hole combination. [397] Furthermore, the polymeric contact also worked as a hydrophobic encapsulation layer protecting the perovskite against humidity.

$\mathrm{Au}$ and $\mathrm{Ag}$ electrodes are widely used in PSCs, however, $\mathrm{Au}$ and $\mathrm{Ag}$ atom may migrate through the HTM to the surface of perovskite absorbing layer and lead to the degradation of the device performance [398] .

Henry J. Snaith et al. [398] employed a thin layer of $\mathrm{Al}_{2} \mathrm{O}_{3}$ nanoparticles as a buffer 
layer sandwiched between the perovskite and the HTM, which inhibits the formation of shunting pathways and stabilizes the performance of the device. Yang et al. [244] prepared a p-i-n structure device using p-type $\mathrm{NiO}_{x}$ and n-type $\mathrm{ZnO}$ nanoparticles as $\mathrm{HTL}$ and ETL, respectively, showing enhanced air stability against moisture and oxygen degradation (retain about $90 \%$ of the original efficiency after stored in air at room temperature) compared with devices with organic charge transport layers (complete degraded after just 5 days), as shown in Fig. S35. The dense $\mathrm{ZnO}$ may completely isolate the perovskite and $\mathrm{Al}$ contact electrode from each other preventing the interfacial reaction between them. $\mathrm{ZnO}$ may further acts as a diffusion barrier against water. Tingli Ma et al. [399] replaced the precious metal back contact electrode with hydrophobic carbon to protect the perovskite absorbing layer from moisture corrosion, leading to the improved stability and low cost. The hole-conductor free, metal-electrode-free $\mathrm{m}-\mathrm{TiO}_{2} / \mathrm{CH}_{3} \mathrm{NH}_{3} \mathrm{PbI}_{3} /$ Carbon heterojunction PSC exhibits a PCE of $9 \%$. The $\mathrm{m}-\mathrm{TiO}_{2} / \mathrm{CH}_{3} \mathrm{NH}_{3} \mathrm{PbI}_{3} /$ Carbon shows a good stability stored in $70 \% \mathrm{RH}$ in dark for $120 \mathrm{~h}$ and remains the initial PCE with little decrease after stored in air in dark for more than 2000 h. $\mathrm{ZnO} / \mathrm{CH}_{3} \mathrm{NH}_{3} \mathrm{PbI}_{3} /$ Carbon heterojunction solar cell with $\mathrm{ZnO}$ as electron transporting layer demonstrates a conversion efficiency of $8 \%$ and restrains $80 \%$ of the initial efficiency after stored in ambient environment $\left(25^{\circ} \mathrm{C}, 30 \% \mathrm{RH}\right)$ for $480 \mathrm{~min}$ [400] .

\subsubsection{Engineering of $\mathrm{HTM} /$ contact electrode interface}

Inserting of HAT-CN (1,4,5,8,9,11-hexaazatriphenylenehexacarbonitrile) between HTM (TPD, a triphenylamine derivative of N,N'-di(3-methylphenyl)-N,N'-diphenyl-4,4'diaminobiphenyl) and back contact layer $(\mathrm{Au})$ may decrease the injection resistance between TPD and Au electrode, lower the voltage loss of the interface and improve the performance of the device. The efficiency can be significantly improved by inserting a thin layer of HAT-CN without adding ion additive and the PCE decreased by only $10 \%$ after about $1000 \mathrm{~h}$ without encapsulation because of the absence of lithium salts, avoiding use of lithium salts prevented the absorption of moisture [401] . Deposition of a hydrophobic layer of C-12-silane between perovskite absorbing layer and HTM improves the stability of the device in ambient environment due to the hydrophobicity of long alkyl chain that improves the water resistance of the perovskite absorbing layer [402] .

PEDOT:PSS is often used as HTM in inverted structure devices, however, the acidic PEDOT:PSS can not only decompose perovskite but also etch indium tin oxide (ITO), resulting in poor stability of the device. In order to overcome this problem, an $\mathrm{MoO}_{3}$ layer is inserted between ITO and PEDOT:PSS to eliminate direct contact between PEDOT:PSS and ITO to restrict erosion of ITO by the acidic PEDOT:PSS. The device with a thicker $\mathrm{MoO}_{3}$ layer remains $93 \%$ of its initial PCE for 10 days while the devices with a thin $\mathrm{MoO}_{3}$ layer or without an $\mathrm{MoO}_{3}$ layer exhibit fast degradation [403]. Amorphous $\mathrm{CuAlO}_{2}\left(\mathrm{a}: \mathrm{CuAlO}_{2}\right)$ is also used as a hole selective interfacial layer sandwiched between ITO and PEDOT:PSS to prevent the erosion of the ITO layer by the acidic PEDOT:PSS layer, as shown in Fig. S36. The device with an a: $\mathrm{CuAlO}_{2}$ layer retained about $80 \%$ of its initial efficiency on storage for $240 \mathrm{~h}$ in ambient while the device with pristine PEDOT:PSS retained only $35 \%$. [404]

\subsubsection{Engineering of ETM/contact electrode interface}

Commonly used contact electrode metals ( $\mathrm{Au}, \mathrm{Ag}, \mathrm{Al}, \mathrm{Ca}$, etc.) are found to penetrate 
tens of nanometers into fullerene derivatives, subsequently decrease the effective thickness of the ETL and even contact with the active perovskite layer [246]. Incorporation of a cathode buffer layer (CBL) between the metal electrode and ETL is an effective method to improve the performance and stability of the PSCs and OPVs. [245,405-409] Stelios A. Choulis et al. [410] reported the incorporation of an Aluminum doped $\mathrm{ZnO}$ interlayer between PCBM and $\mathrm{Au}$, resulting in enhanced device stability of p-i-n PSCs (maintaining $100 \%$ of the initial PCE for over $1000 \mathrm{~h}$ of exposure under ISOS-D-1 protocol. Martin Kaltenbrunner et al. [405] introduced a chromium oxide-chromium $\left(\mathrm{Cr}_{2} \mathrm{O}_{3} / \mathrm{Cr}\right)$ interlayer between the electron conduction layer and the contact electrode to protect the metal top contacts, which provides a buffer to shield the top contact metal from chemical etching caused by iodine liberated from the $\mathrm{MAPbI}_{3}$ layer. PET (Polyethylene terephthalate) substrate cell retained $80 \%$ of the initial PCE after $10 \mathrm{~h}$, and remain functional after 4 days of continuous operation, while Glass/ITO cells without $\mathrm{Cr}_{2} \mathrm{O}_{3} / \mathrm{Cr}$ have less than $4 \%$ initial PCE that rapidly drops below $2 \%$. Antonio Guerrero et al. also reported the use of $\mathrm{Cr}_{2} \mathrm{O}_{3} / \mathrm{Cr}$ as protective layer to enhance the stability. However, when the cathode contact was protect with $\mathrm{Cr}_{2} \mathrm{O}_{3} / \mathrm{Cr}$, new degradation features appeared due to modification of the energy bands close to the contacts [245] . Chang-Qi Ma et al. [411] reported the incorporation of a $\mathrm{ZnO}$ :PFN composite CBL to improve the PCE and performance stability of inverted heterojunction PSCs. Results show that ZnO:PFN can stabilize the interface property and in-turn improve the performance stability of the PSC. A thin $\mathrm{TiO}_{\mathrm{x}}$ thin layer was inserted between $\mathrm{PC}_{60} \mathrm{BM}$ and aluminum electrode interface as morphology-fixing agent. [412] $\mathrm{The}^{\mathrm{TiO}_{\mathrm{x}}}$ thin layer suppressed the delamination of $\mathrm{PC}_{60} \mathrm{BM}$ from the $\mathrm{MAPbI}_{3}$ layer and act as waterproof layer, leading to enhanced long-term stability. Chih-Yu Chang et al. [406] incorporated thiol-functionalized cationic surfactant (11mercaptoundecyl trimethylammonium bromide, MUTAB) into PCBM and Ag electrode interface as CBL, as shown in Fig. S37. The thiol function groups on MUTAB can react with $\mathrm{Ag}$ atoms to form covalent $\mathrm{Ag}-\mathrm{S}$ bonds and lead to the decrease of contact resistance between the active layer and Ag electrode, the improvement of ambient and thermal stability, and the reduction of the percolation threshold of ultrathin Ag film. The MUTAB CBL-based semitransparent PSC retained over $70 \%$ of the initial PCE after being exposed to air $\left(30^{\circ} \mathrm{C}\right.$, $\sim 60 \% \mathrm{RH}$ ) for 14 days without encapsulation. A cetyltrimethylammonium bromide (CTAB)doped PCBM was used as both an ETL and a CBL in $\mathrm{FAPbI}_{3}$-based PSCs, which maintained $80 \%$ and $60 \%$ of the initial PCE after exposure in ambient condition $\left(30^{\circ} \mathrm{C}, \sim 60 \% \mathrm{RH}\right)$ for $\sim 360 \mathrm{~h}$ (15 days) and continuous light illumination $(100 \mathrm{~mW} \mathrm{~cm}-2)$ in ambient atmosphere for $120 \mathrm{~h}$ [407] . A cross-linkable N,N-dimethyl-N-octadecyl(3-aminopropyl)trimethoxysilyl chloride silane (DMOAP) doped $\mathrm{PC}_{61} \mathrm{BM}$ based $\mathrm{PSC}$ with an effective thin-film encapsulation layer achieved promising long-term stability, exhibiting negligible $(<5 \%)$ loss in PCE after more than $5000 \mathrm{~h}$ of aging. [413] The hydrolysable alkoxysilane groups on DMOAP facilitate the formation of a cross-linking siloxane network on the perovskite/Ag interface, which can act as an effective protection layer to mitigate the undesirable reactions between the mobile halide ions and Ag electrodes. A hybrid fullerene cathode interlayer decorated with perfluoroalkyl side-chains was also used as cathode buffer layer in PSC, which exhibited good ambient stability, i.e. retaining $80 \%$ of its original PCE after exposed in ambient condition with $20 \% \mathrm{RH}$ for 2 weeks without encapsulation. [409] PSCs with two layers of PEI inserted between $\mathrm{s}-\mathrm{VO}_{\mathrm{x}}$ and perovskite layer, and electron transport layer and 
$\mathrm{LiF} / \mathrm{Al}$ layer, exhibited improved stability showing less than $10 \%$ decay in PCE during a 10 days observation. [414]

The PCE of the devices without $\mathrm{ZnO}$ interlayer dropped from $10.2 \%$ to $0.8 \%$ within $24 \mathrm{~h}$ while that of the device with $\mathrm{ZnO}$ layer decreased from $14.1 \%$ to $13.2 \%$, only about $6 \%$ degradation after 2 months of aging. [415]

Initial PCEs and normalized PCEs after different storage time of the devices upon interface engineering, together with the control sample, are shown in Fig. 7. Hollow squares are the initial PCEs of the devices and blue dots are the normalized PCE after different storage time. The device configurations, interface engineering approaches, encapsulation and storage conditions of the PSCs are summarized in table 4.

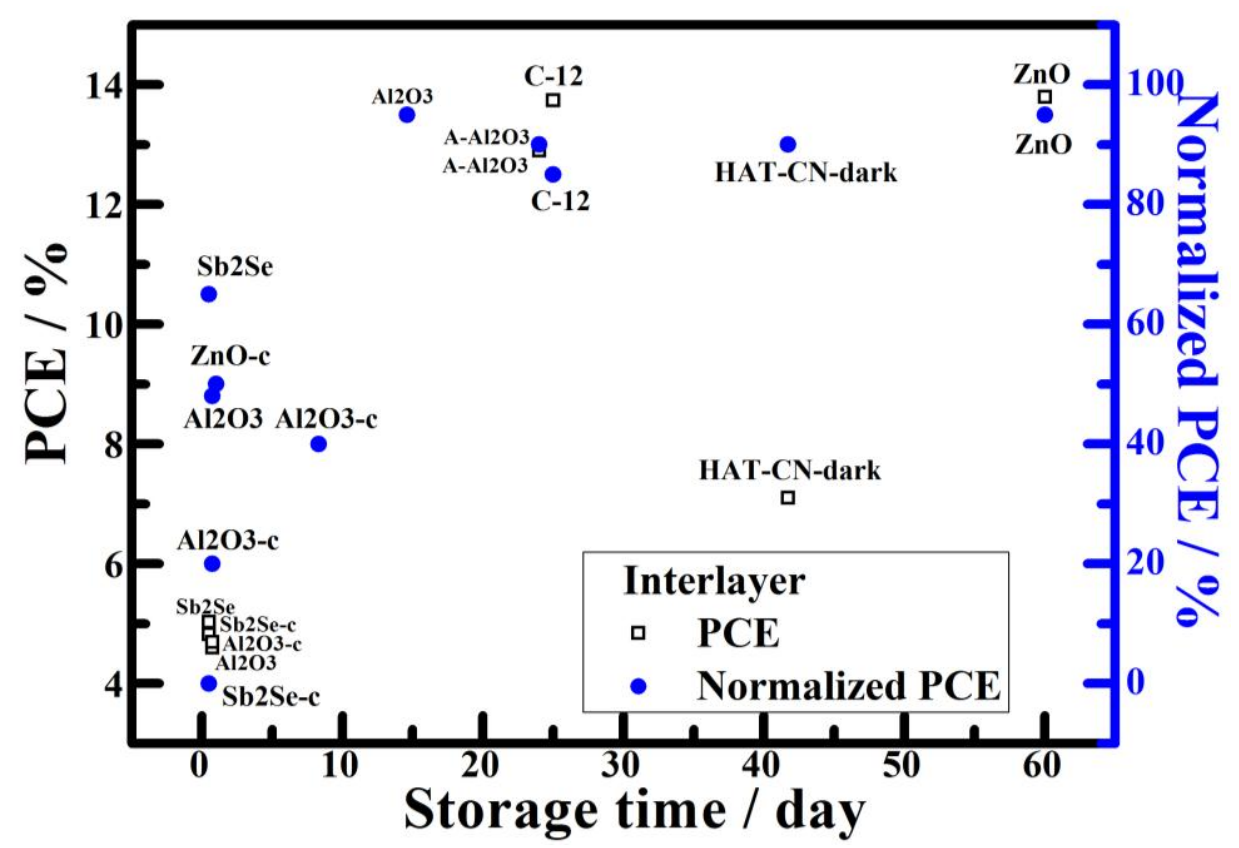

Fig. 7 Effect of interface engineering on the stability of PSCs

Table 4 Device configuration, encapsulation and storage condition of the PSCs illustrated in Fig. 7

\begin{tabular}{|c|c|c|c|c|}
\hline Device configuration & Feature & Seal & $\begin{array}{l}\text { Storage } \\
\text { condition }\end{array}$ & Reference \\
\hline porous $\mathrm{Al}_{2} \mathrm{O}_{3}$ buffered & $\mathrm{Al}_{2} \mathrm{O}_{3}$ & \multirow{2}{*}{$\begin{array}{l}\text { glass+epoxy } \\
\text { resin }\end{array}$} & \multirow{2}{*}{$\begin{array}{l}100 \mathrm{~mW} \mathrm{~cm}^{-} \\
2\end{array}$} & {$[398]$} \\
\hline control & $\mathrm{Al}_{2} \mathrm{O}_{3}-\mathrm{C}$ & & & \\
\hline $\mathrm{TiO}_{2} /$ perovskite/C12-silane/HTM/Ag & C12 & w/o & ambient & {$[402]$} \\
\hline $\begin{array}{l}\text { PEDOT:PSS/MAPbl }{ }_{3-\mathrm{x}} \mathrm{Cl}_{\mathrm{x}} / \mathrm{PCBM} / \\
\mathrm{ZnO} / \mathrm{Al}\end{array}$ & $\mathrm{ZnO}$ & \multirow[t]{2}{*}{ w/o } & \multirow[t]{2}{*}{$\begin{array}{l}\text { ambient } \\
\text { condition }\end{array}$} & \multirow[t]{2}{*}[415]{} \\
\hline PEDOTP:PSS/MAPb| ${ }_{3-x} \mathrm{Cl}_{x} / \mathrm{PCBM} / \mathrm{Al}$ & $\mathrm{ZnO}-\mathrm{c}$ & & & \\
\hline $\mathrm{TiO}_{2} / \mathrm{MAPb}_{3} /$ Spiro/ALD-Al ${ }_{2} \mathrm{O}_{3} / \mathrm{Ag}$ & $\mathrm{A}-\mathrm{Al}_{2} \mathrm{O}_{3}$ & \multirow{2}{*}{-} & \multirow{2}{*}{$\begin{array}{l}50 \% \mathrm{RH}, \text { air, } \\
\text { RT }\end{array}$} & {$[94]$} \\
\hline $\mathrm{TiO}_{2} / \mathrm{MAPbl}_{3} / \mathrm{Spiro} / \mathrm{Ag}$ & $\begin{array}{l}\text { A- } \mathrm{Al}_{2} \mathrm{O}_{3}- \\
\text { C }\end{array}$ & & & \\
\hline $\mathrm{TiO}_{2} /$ perovskite/HAT-CN/TPD/Au & HAT-CN- & w/o & $<20 \% \quad \mathrm{RH}$, & [401] \\
\hline
\end{tabular}




\begin{tabular}{|c|c|c|c|c|}
\hline \multirow[b]{2}{*}{$\mathrm{TiO}_{2} / \mathrm{MAPbl}_{3} / \mathrm{CuSCN} / \mathrm{Au}$} & \multicolumn{2}{|l|}{ dark } & \multicolumn{2}{|c|}{$\mathrm{RT}$, dark } \\
\hline & $\mathrm{Sb}_{2} \mathrm{Se}-\mathrm{C}$ & w/o & light & $100[111]$ \\
\hline $\mathrm{TiO}_{2} / \mathrm{Sb}_{2} \mathrm{Se} / \mathrm{MAPbl}_{3} / \mathrm{CuSCN} / \mathrm{Au}$ & \multicolumn{2}{|l|}{$\mathrm{Sb}_{2} \mathrm{Se}$} & \multicolumn{2}{|c|}{$\mathrm{mW} \mathrm{cm}-2$} \\
\hline $\mathrm{cTiO}_{2} / \mathrm{TiO}_{2}+\mathrm{MAPbl}_{3} /$ Spiro $/ \mathrm{Au}$ & $\mathrm{Al}_{2} \mathrm{O}_{3}-\mathrm{C}$ & w/o & $60 \%$ & $\mathrm{RH},[82]$ \\
\hline $\mathrm{CTiO}_{2} / \mathrm{TiO}_{2}+\mathrm{MAPbl}_{3} / \mathrm{Al}_{2} \mathrm{O}_{3} / \mathrm{Spiro} / \mathrm{Au}$ & $\mathrm{Al}_{2} \mathrm{O}_{3}$ & & $35^{\circ} \mathrm{C}$ & \\
\hline
\end{tabular}

\subsection{Protection layer}

The HTM materials discussed above in Section 4 can serve as a protection layer for the perovskite from moisture and oxygen attacks. Such a role as moisture barrier also functioned by HTM is especially manifested by the utilization of hydrophobic HTM materials such as conducting carbon-nanotube insulating polymer composite [192], oligothiophene [195] , PDPPDBTE [205], triphenylamine-based HTMs [206] polyaniline [207] etc. For example, Zuqiang Bian et al. [416] prepared high performance PSCs with ultrathin polythiophene as hole-transporting layer, which showed high stability in a low- $\mathrm{O}_{2}$ content and low-moisture atmosphere due to polythiphene HTM's protection of $\mathrm{CH}_{3} \mathrm{NH}_{3} \mathrm{PbI}_{3}$ perovskite from moisture. Hae Jung Son et al. [417] introduced a layer of polyethylene-imine (PEI) into $\mathrm{CH}_{3} \mathrm{NH}_{3} \mathrm{PbI}_{3} / \mathrm{HTM}$ interface, which leads to the increase of the adhesion between $\mathrm{CH}_{3} \mathrm{NH}_{3} \mathrm{PbI}_{3}$ and $\mathrm{HTM}$. The sequential strong adherence of the protective HTM onto the $\mathrm{CH}_{3} \mathrm{NH}_{3} \mathrm{PbI}_{3}$ layer further decreases direct exposure of $\mathrm{CH}_{3} \mathrm{NH}_{3} \mathrm{PbI}_{3}$ to the moisture. An $\mathrm{n}$ type polymer electron extraction layer, poly $\{[\mathrm{N}, \mathrm{N}$ '-bis(2-octyldodecyl)-naphthalene-1,4,5,8bis(dicarboximide)-2,6-diyl]-alt-5,5'-_2,2'-bithiophene)\} (P(NDI2OD-T2), can prevent the diffusion of water into the perovskite film, acting as an effective protective layer to result in improved device stability under ambient conditions maintaining $87 \%$ of initial PCE after 270 min compared to $3.5 \%$ of the initial value for the device using PCBM as electron extraction layer [242] . Zheng-Hong Lu et al. [418] proposed that the perovskite degradation follows the Avrami equation, a kinetics theory developed for quantifying phase transformations in solid-state materials. Capping the perovskite films with thin N,N'-Di(1-naphthyl)-N,N'diphenyl-(1,1'-biphenyl)-4,4'-diamine (NPB) films could significatnly slow down the the degradation of the perovskite structure. ETL also could act as protection layer against water penetration. Edward H. Sargent et al. [419] made use of a cross-linked remote-doped holeextracting contact (N4,N4'-Di(naphathalen-1-yl)-N4,N4'-bis(4-vinylphenyl)biphenyl-4,4'diamine, VNPB) as HTL to provide an insoluble and inert physical protection layer for the perovskite. A polymeric HTM based on 4,8-dithien-2-yl-benzo[1,2;4,5-d']bistriazole-altbenzo[1,2-b:4,5-b']dithiophenes (pBBTa-BDTs) is used to replace spiro-OMeTAD and yields high PCEs (12.3\%) and environmentally-stable PSCs [420]. The enhanced $85^{\circ} \mathrm{C} / 65 \% \mathrm{RH}$ stability is attributed to the smooth, conformal polymer coatings, which suppresses aerobic perovskite film degradation. Min Jae Ko et al. [421] reported the bi-functional octadecylamine-capped pyrite $\left(\mathrm{ODA}-\mathrm{FeS}_{2}\right)$ layer (charge extraction layer and moisture-proof layer) for long-term stability and high-performance of PSCs. ODA capped $\mathrm{FeS}_{2}$ NPs-based HTM is more hydrophobic than the spiro-OMeTAD and the ODA ligand can prevent the ionic exchange between $\mathrm{Fe}$ in $\mathrm{HTM}$ and $\mathrm{Pb}$ in perovskite layer, leading to long-term stability of ODA-FeS 2 NPs-based PSCs.

Apart from HTMs, hydrophobic contact electrode may also act as protection layer to 
prevent moisture and oxygen from reaching the surface of the perovskite absorbing layer.

Shihe Yang et al. [422] prepared a special structured PSC with seamless interface between the $\mathrm{CH}_{3} \mathrm{NH}_{3} \mathrm{PbI}_{3}$ active layer and the carbon hole-extraction layer electrode by using carbon and $\mathrm{CH}_{3} \mathrm{NH}_{3} \mathrm{I}$ mixed ink to transform $\mathrm{PbI}_{2}$ in-situ to $\mathrm{CH}_{3} \mathrm{NH}_{3} \mathrm{PbI}_{3}$, which showed a remarkably reduced charge recombination and improved stability. The device remain $90 \%$ of initial performance after stored in ambient environment $\left(25^{\circ} \mathrm{C}, 30 \% \mathrm{RH}\right)$ for 12 days. Shihe Yang et al. [423] further made use of a C+epoxy/Ag-paint cathode to improve the efficiency and stability of PSCs in watery environment, as shown in Fig. S38. The device demonstrated a stabilized PCE of $10.78 \%$ for $10 \mathrm{~h}$ under 1 sun illumination in high humidity atmosphere $(70-80 \% \mathrm{RH})$ and almost no performance degradation upon a thermal stressing lasts for about $250 \mathrm{~h}\left(50{ }^{\circ} \mathrm{C}, 70-90 \% \mathrm{RH}\right)$. The $\mathrm{C}+$ epoxy paint partly encapsulates the cell and the modified Ag paint further seals the whole device. Zhiyong Fan et al. [424] attached a nanocone array antireflection film to the front side of the glass substrate to improve optical transmittance and to achieve a water-repelling effect at the same time. The nano-cone antireflection film demonstrated excellent super-hydrophobicity with a water contact angle up to $155^{\circ}$ and a low roll-off angle of $13^{\circ}$.

Initial PCEs and normalized PCEs after different storage time of the devices using carbon as contact electrode and control samples are shown in Fig. 8. Black squares are the initial PCEs of the devices and blue dots are the normalized PCEs after different storage time. The device configurations and storage conditions of the PSCs are summarized in table 5.

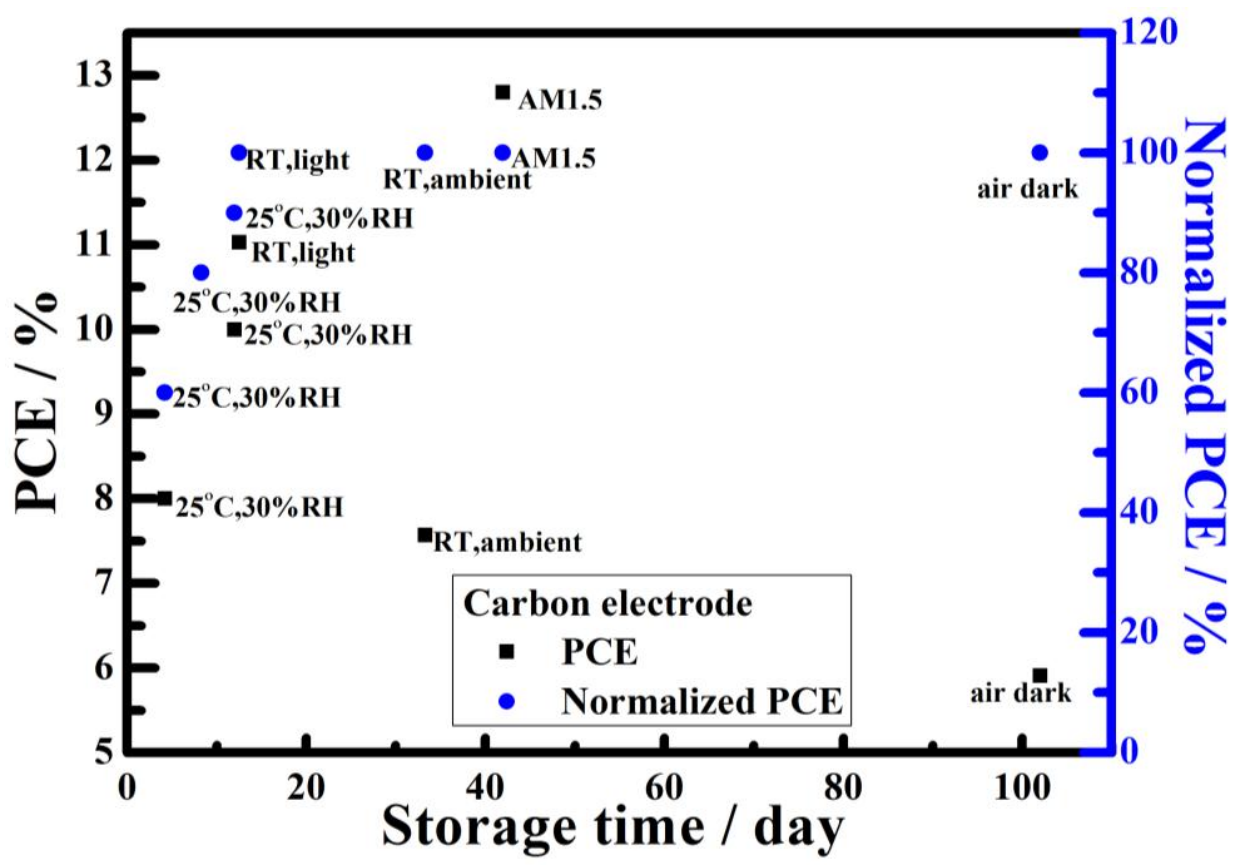

Fig. 8 Protection performance of carbon contact electrode of PSCs

Table 5 Device configuration and storage condition of the PSCs illustrated in Fig. 8

\begin{tabular}{|c|c|c|c|}
\hline Device configuration & Seal & Storage condition & Reference \\
\hline $\mathrm{c}-\mathrm{TiO}_{2} / \mathrm{TiO}_{2}, \mathrm{Al}_{2} \mathrm{O}_{3}+\mathrm{MAPb}{ }_{2} \mathrm{Br} /$ carbon & w/o & $25 \mathrm{~mW} \mathrm{~cm}^{-2}$ & {$[136]$} \\
\hline $\mathrm{c}-\mathrm{ZnO} / \mathrm{MAPbl}_{3} /$ carbon & $w / 0$ & $25^{\circ} \mathrm{C}, 30 \% \mathrm{RH}, \mathrm{AM} 1.5 \mathrm{G}$ & [400] \\
\hline $\mathrm{c}-\mathrm{TiO}_{2} / \mathrm{TiO}_{2}+\mathrm{ZrO}_{2}+(5-\mathrm{AVA})_{\times}(\mathrm{MA})_{1-}$ & w/o & AM1.5,1008h & [231] \\
\hline
\end{tabular}




\begin{tabular}{llll}
\hline${ }_{\mathrm{PPbl}} / \mathrm{C}$ & & & \\
$\mathrm{C}-\mathrm{TiO}_{2} / \mathrm{TiO}_{2}+\mathrm{MAPbl}_{3} / \mathrm{C}$ & w/o & Ambient, RT & {$[233]$} \\
$\mathrm{C}-\mathrm{TiO}_{2} / \mathrm{TiO}_{2}+\mathrm{MAPbl}_{3}+\mathrm{C}$ & w/o & Ambient air, 25ㅇ, 30\% & [422] \\
& & $\mathrm{RH}$ & \\
$\mathrm{m}-\mathrm{TiO}_{2} / \mathrm{MAPbl}_{3} / \mathrm{C}$ & w/o & Air, dark & [399] \\
\hline
\end{tabular}

\subsection{Encapsulation}

Encapsulation is generally necessary for almost all of the commercial solar cells. Encapsulation keeps the oxygen, moisture and corrosion elements out of the solar cells and improves the long-term stability of the devices. Due to the moisture sensitivity of perovskite and UV sensitivity of $\mathrm{TiO}_{2}$ scaffold and organic HTM/ETM, encapsulation is indispensable in PSCs applications.

Atomic layer deposition of $\mathrm{Al}_{2} \mathrm{O}_{3}, \mathrm{ZnO}, \mathrm{SnO}_{\mathrm{x}}$ are demonstrated an effective method to improve the humidity and thermal stability. Chih-Yu Chang et al. [425] applied atomic layer deposited (ALD) $\mathrm{ZnO}$ and $\mathrm{Al}_{2} \mathrm{O}_{3}$ films as $\mathrm{CBL}$ and encapsulation layer. Besides working as tuning working function of the electrode with high charge selectivity and good electrontransporting ability, the ALD $\mathrm{ZnO}$ film with excellent film coverage may also act as contact inhibitor between perovskite layer and $\mathrm{Ag}$ electrode to prevent the corrosion between the two components. The encapsulation layer $\mathrm{Al}_{2} \mathrm{O}_{3}$ exhibits excellent gas-barrier performance and also inhibits the permeating of oxygen and moisture, resulting in enhanced long-term airstability. The $\mathrm{ALD} \mathrm{Al}_{2} \mathrm{O}_{3}$ encapsulated device exhibited negligible degradation after exposure to ambient condition $\left(30{ }^{\circ} \mathrm{C}, 65 \% \mathrm{RH}\right)$ for more than 40 days. Alex B. F. Martinson et al. [426] deposited a pinhole-free $\mathrm{Al}_{2} \mathrm{O}_{3}$ over-layer directly on the perovskite surface by nonhydrolytic (nh) and Fig. S39 illustrated the water and thermal stability of $\mathrm{MAPbI}_{3-\mathrm{x}} \mathrm{Cl}_{\mathrm{x}}$ thin films with and without $\mathrm{Al}_{2} \mathrm{O}_{3}$ over layer encapsulation. The $3 \mathrm{~nm}$ nh- $\mathrm{Al}_{2} \mathrm{O}_{3}$ passivated $\mathrm{CH}_{3} \mathrm{NH}_{3} \mathrm{PbI}_{3-\mathrm{x}} \mathrm{Cl}_{\mathrm{x}}$ film remained stable for $24 \mathrm{~h}$ under $85 \% \mathrm{RH}$ while the pristine perovskite film exhibited substantial decomposition in less than $12 \mathrm{~h}$. Furthermore, the $18 \mathrm{~nm} \mathrm{hb}-\mathrm{Al}_{2} \mathrm{O}_{3}$ ( $3 \mathrm{~nm} \mathrm{Al}_{2} \mathrm{O}_{3}$ deposited by nh-ALD plus $15 \mathrm{~nm} \mathrm{Al}_{2} \mathrm{O}_{3}$ deposited by TMA $/ \mathrm{H}_{2} \mathrm{O}$ ALD) remained stable over $200 \mathrm{~h}$. The $18 \mathrm{~nm} \mathrm{hb}-\mathrm{Al}_{2} \mathrm{O}_{3}$ passivated film shows no signs of degradation for at least 15 min even exposure to $5 \mu \mathrm{L}$ liquid water. Alex B. F. Maritinson et al. [427] reported liquid water- and heat-resistant PSC with a layer of amorphous $\mathrm{TiO}_{2}$ ALD film deposited on the surface of PCBM. The pinhole-free ultrathin amorphous $\mathrm{TiO}_{2}$ ALD blocks the ingression of moisture/oxygen that leading to water-resistant and egression of MAI upon thermal degradation which stabilizing the perovskite against thermal stress. Atomic layer deposited $\mathrm{SnO}_{\mathrm{x}}$ buffer layer can inhibit the penetration of moisture and the diffusion of volatile decomposition product of $\mathrm{MAPbI}_{3}$ so as to suppress the thermal decomposition of the perovskite. [428,429]

Kijung Yong et al. [430] coated a hydrophobic Teflon film onto the top surface of the cell as encapsulation layer to block the water diffusion into the perovskite cell, as shown in Fig. S40. The passivated cell remains $95 \%$ of the initial PCE after storage in normal indoor conditions for 30 days while the PCE of the untreated cell deeply decreases $30 \%$ in the first 15 days and remains only $50 \%$ of the initial PCE after 30 days. Hydrophobic fluoroalkyl silane (triethoxy-1H,1H,2H,2H-tridecafluoro-n-octylsilane, $\mathrm{C}_{13}$-FAS) also can be used to coat 
onto the surface of $\mathrm{MAPbI}_{3}$ absorbing layer to improve the air stability of PSCs [431]. The PCE of the PSC coated with $\mathrm{C}_{13}$-FAS exhibited little degradation during the exposure in the air with $50 \% \mathrm{RH}$ for $500 \mathrm{~h}$, whereas the PCE of the PSCs without $\mathrm{C}_{13}$-FAS coating significantly decreased from about $12 \%$ to $1 \%$ in $250 \mathrm{~h}$. Hong Lin et al. [432] encapsulated the PSC with a layer of polymer poly(methylmethacrylate) (PMAA), which achieved outstanding stability in the dark and under illumination. The PCE of the encapsulated devices remained above $93 \%$ of the initial value after $1500 \mathrm{~h}$ storage in air $\left(75 \% \mathrm{RH}, 45{ }^{\circ} \mathrm{C}\right)$ in dark and $87 \%$ of the initial PCE after light soaking for about $400 \mathrm{~h}\left(100 \mathrm{~mW} \mathrm{~cm}{ }^{-2}, 39 \pm 7 \% \mathrm{RH}\right.$, $\left.20 \pm 6{ }^{\circ} \mathrm{C}\right)$. However, the unencapsulated device decreased to $42 \%$ and $46 \%$ of the initial PCE respectively. Guanglan Liao et al. [433] encapsulated the carbon counter electrode based PSCs with PDMS (polydimethylsiloxane) and demonstrated enhanced photovoltaic performance and stability. PDMS isolates the moisture in air, thus avoiding the degradation of $\mathrm{MAPbI}_{3}$ perovskite and leading to an impressive stability during a testing period of $3000 \mathrm{~h}$ in ambient atmosphere with $\sim 20 \% \mathrm{RH}$ at room temperature. On the contrary, the device without PDMS encapsulation exhibits substantial degradation after $1500 \mathrm{~h}$ storage in the same condition. Anders Hagfeldt et al. [434] coated the perovskite solar cell with a photocurable fluoropolymer, which not only achieved an easy-cleaning surface on the front side but also formed a strongly hydrophobic barrier layer toward environmental moisture on the back side of the device. The coated devices retained their full performance during prolonged operation for more than 6 months.

Hasitha C. Weerasinghe et al. [435] reported the encapsulation of PSCs to improving the lifetime and found that encapsulation could extend the lifetime significantly. The encapsulation architectures and PCE evolution with the storage time are illustrated in Fig. S41. "Partially"-encapsulated device maintained more than $80 \%$ of the initial PCE for over $400 \mathrm{~h}$ and "completely"-encapsulated device was stable during the entire test period (500 h), whereas the non-encapsulated device almost degraded completely in less than $200 \mathrm{~h}$.

Yi-Bing Chen et al. [27] investigated the degradation of planar-structured $\mathrm{CH}_{3} \mathrm{NH}_{3} \mathrm{PbI}_{3}$ PSCs with different encapsulation methods under different temperatures and humidity, as shown in Fig. S42. The devices encapsulated by glass cover and UV epoxy resin showed good performance at room temperature dry air (no obvious degradation after $120 \mathrm{~h}$ stored at $20 \sim 10{ }^{\circ} \mathrm{C}, 0 \% \mathrm{RH}$ ), and degraded at high temperature (degraded to $35 \%$ initial PCE after 120 $\mathrm{h}$ stored at $\left.55-85{ }^{\circ} \mathrm{C}, 10 \% \mathrm{RH}\right)$. The PCE of the device decreased to zero after $18 \mathrm{~h}$ aging at elevated temperature and humidity $\left(85{ }^{\circ} \mathrm{C}, 80 \% \mathrm{RH}\right)$, which is mainly due to the decomposition of $\mathrm{CH}_{3} \mathrm{NH}_{3} \mathrm{PbI}_{3}$ and the corrosion of the $\mathrm{Ag}$ back contact electrode. Reaction with $\mathrm{H}_{2} \mathrm{O}$ leads to the decomposition of $\mathrm{CH}_{3} \mathrm{NH}_{3} \mathrm{PbI}_{3}$. The hydroiodic acid formed during the decomposition of $\mathrm{CH}_{3} \mathrm{NH}_{3} \mathrm{PbI}_{3}$ can react with the $\mathrm{Ag}$, leading to the corrosion of $\mathrm{Ag}$ back contact electrode layer. Ag back contact electrode consumes the generated $\mathrm{HI}$ and shifts the reaction towards the further decomposition of the perovskite until the device is fully degraded. Replacing the Ag back contact with more stable conducting material, such as Au or carbonaceous materials, or improving the encapsulation grade to reduce the ingress of water therefore improves the PSC stability. The device encapsulated by glass cover and UV-curable epoxy resin plus a piece of desiccant in the recess in the middle of the glass appeared to have better stability (retain $5 \%$ initial PCE after $500 \mathrm{~h}$ stored at $55-85{ }^{\circ} \mathrm{C}, 80 \% \mathrm{RH}$ ) while the device encapsulated without desiccant degraded to zero only after $18 \mathrm{~h}$ under the same stress. 
Aleksandra B. Djurisic et al. [436] studied the encapsulation of perovskite solar cells for high humidity conditions. The encapsulated PSC, with active area covered with a $50 \mathrm{~nm}$ of electron beam deposited $\mathrm{SiO}_{2}$ layer and protected by a cover glass with a piece of desiccant sealed with UV-curable epoxy, exhibited stable performance (retention of $\sim 80 \%$ of initial PCE on average after $48 \mathrm{~h}$ ) under constant light soaking at $65 \% \mathrm{RH}$ and $85{ }^{\circ} \mathrm{C}$. Perovskite polygonal mirodisks encapsulated in polymer matrix of PMMA and PS gives a "waterresistant" perovskite microcrystalline laser in flexible photonics devices. [437]

\section{Summary and Perspectives}

In summary, the research has achieved significant understanding and discoveries on the stability of PSCs under different environmental conditions including moisture, oxygen, illumination and thermal exposure. Mixed perovskites ( $\mathrm{Cs}, \mathrm{Rb}$, FA incorporated perovskites), hybrid halide perovskites, pseudohalogen polyanions perovskites, two-dimension layered perovskites and additive reinforced perovskites exhibit enhanced stability comparing with pristine $\mathrm{MAPbI}_{3}$ perovskite. Using more hydrophobic ETM and $\mathrm{TiO}_{2}$ modification and substitution are effective methods to deal with the humidity sensitivity and UV-stability. As for HTMs, due to the hydroscopicity of dopants in spiro-OMeTAD and Lewis acid property of PEDOT:PSS, the modification of spiro-OMeTAD and PEDOT:PSS and the investigation of new hydrophobic polymer and small molecular semiconductor have achieved significant progresses. However, the carbon-carbon double bonds in organic HTMs are suffered from the thermal and illumination stress during the operation of the PSCs, inorganic HTM such as $\mathrm{NiO}_{x}$ and doped $\mathrm{NiO}_{x}, \mathrm{CuI}, \mathrm{CuSCN}, \mathrm{Cu}_{2} \mathrm{O}, \mathrm{CuS}$ are found exhibiting enhanced thermal and photo- stability. Furthermore, a type of HTM-free carbon based PSCs shows very good moisture, thermal and illumination stabilities. As for contact electrodes, Ag may diffuse through ETL and react with perovskite decomposition product and iodine ions may also diffuse through HTL and react with Ag electrode, both of which lead to the irreversible degradation of perovskite. $\mathrm{Cu}$ is inert in direct contact with perovskite in encapsulated PSCs and is predicted to be stable for almost 170 years at room temperature and 22 years at $40{ }^{\circ} \mathrm{C}$. [258] New preparation methods/conditions and additive treatments are investigated to achieve uniform, compact, pinhole-free and large grained films. Additives are found to be beneficial to form smooth, continuous and uniform films and significantly improve device performance and stability.

However, most of these studies were conducted by measuring the conversion efficiencies of the devices in different time intervals when they were usually stored in dark. Only a few of the devices were tested under continuous illumination. The long-term operation stability is very important for the commercial of PSCs.

While the study of environmental effects on the overall PSC performance and integrity is essential, the evaluation and improvement of the intrinsic structural behavior and property correlations for the PSCs and components are to be equally emphasized for ultimate commercialization of the technology. Although the PCE of PSC has been improved very fast and has achieved an authentication efficiency of $22.1 \%$ [3] at present, many fundamental questions remain to be answered about how the device mechanistically works in many cases. Research on the interfacial reactions, ion migration and interface engineering discussed in 
Section 8.2 has shed limited lights on the intrinsic stability of the PSCs. Therefore, it is imperative to investigate the intrinsic stability and improvements of the PSCs under continuous operation conditions.

To achieve long-term stable PSCs for uninterrupted commercial use, there appears to be multiple theoretical and technological hurdles to be overcome in the next few years. It is our belief that with deep and continuous understanding of the PSC fundamentals, the degradation during continuous operation under different environmental conditions can eventually be resolved through multiple strategies, such as modifications of the perovskite components to improve the crystal structural stability and resistance to unavoidable environmental stresses associated with illumination, oxygen, moisture and thermal stress. Other strategies include the use of protection layer to insulate the reactive oxygen and moisture from reaching sensitive perovskite, the rational design and engineering of the interfaces, the optimization of the cell structure and materials to overcome the intrinsic instability, and the encapsulation to keep oxygen and moisture out of the device.

\section{Acknowledgements}

This work was supported by the Jiangsu Province Industry, Study and Research Prospective Joint Research Project (BY2015002-02).

\section{Reference List}

[1] S. Brittman, G. Adhyaksa Widia Pratama, E.C. Garnett, The expanding world of hybrid perovskites: materials properties and emerging applications, MRS Communications. 5 (2015) $7-26$.

[2] A. Kojima, K. Teshima, Y. Shirai, T. Miyasaka, Organometal Halide Perovskites as Visible-Light Sensitizers for Photovoltaic Cells, J. Am. Chem. Soc. 131 (2009) 6050-6051.

[3] http://www.nrel.gov/ncpv/images/efficiency_chart.jpg, last accessed on 03/21/2017

[4] G. Niu, X. Guo, L. Wang, Review of recent progress in chemical stability of perovskite solar cells, J. Mater. Chem. A. 3 (2015) 8970-8980.

[5] T. Leijtens, G.E. Eperon, N.K. Noel, S.N. Habisreutinger, A. Petrozza, H.J. Snaith, Stability of Metal Halide Perovskite Solar Cells, Advanced Energy Materials. 5 (2015) 1500963-n/a.

[6] Y. Rong, L. Liu, A. Mei, X. Li, H. Han, Beyond Efficiency: the Challenge of Stability in Mesoscopic Perovskite Solar Cells, Advanced Energy Materials. 5 (2015) 1501066-n/a.

[7] N.H. Tiep, Z. Ku, H.J. Fan, Recent Advances in Improving the Stability of Perovskite Solar Cells, Advanced Energy Materials. 6 (2016) 1501420-n/a.

[8] T.A. Berhe, W. Su, C. Chen, C. Pan, J. Cheng, H. Chen, M. Tsai, L. Chen, A.A. Dubale, B. Hwang, Organometal halide perovskite solar cells: degradation and stability, Energy Environ.Sci. 9 (2016) 323-356. 
[9] M. Shahbazi, H. Wang, Progress in research on the stability of organometal perovskite solar cells, Solar Energy. 123 (2016) 74-87.

[10] M. Ye, X. Hong, F. Zhang, X. Liu, Recent advancements in perovskite solar cells: flexibility, stability and large scale, J.Mater.Chem.A. 4 (2016) 6755-6771.

[11] B. Li, Y. Li, C. Zheng, D. Gao, W. Huang, Advancements in the stability of perovskite solar cells: degradation mechanisms and improvement approaches, RSC Adv. 6 (2016) 38079-38091.

[12] D. Wang, M. Wright, N.K. Elumalai, A. Uddin, Stability of perovskite solar cells, Solar Energy Mater. Solar Cells. 147 (2016) 255-275.

[13] A.B. Djurisic, F. Liu, A.M.C. Ng, Q. Dong, M.K. Wong, A. Ng, C. Surya, Stability issues of the next generation solar cells, physica status solidi (RRL)-Rapid Research Letters. 10 (2016) 281-299.

[14] J. Yang, T.L. Kelly, Decomposition and Cell Failure Mechanisms in Lead Halide Perovskite Solar Cells, Inorg. Chem. 56 (2017) 92-101.

[15] T. Xu, L. Chen, Z. Guo, T. Ma, Strategic improvement of the long-term stability of perovskite materials and perovskite solar cells, Phys.Chem.Chem.Phys. 18 (2016) 2702627050 .

[16] D. Li, P. Liao, X. Shai, W. Huang, S. Liu, H. Li, Y. Shen, M. Wang, Recent progress on stability issues of organic-inorganic hybrid lead perovskite-based solar cells, RSC Adv. 6 (2016) 89356-89366.

[17] H. Kim, J. Seo, N. Park, Material and Device Stability in Perovskite Solar Cells, ChemSusChem. 9 (2016) 2528-2540.

[18] T.M. Koh, K. Thirumal, H.S. Soo, N. Mathews, Multidimensional Perovskites: A Mixed Cation Approach Towards Ambient Stable and Tunable Perovskite Photovoltaics, ChemSusChem. 9 (2016) 2541-2558.

[19] Y. Wang, Z. Jiang, L. Liao, New advances in small molecule hole-transporting materials for perovskite solar cells, Chinese Chemical Letters. 27 (2016) 1293-1303.

[20] T. Singh, J. Singh, T. Miyasaka, Role of Metal Oxide Electron-Transport Layer Modification on the Stability of High Performing Perovskite Solar Cells, ChemSusChem. 9 (2016) 2559-2566.

[21] R. Fan, Y. Huang, L. Wang, L. Li, G. Zheng, H. Zhou, The Progress of Interface Design in Perovskite-Based Solar Cells, Advanced Energy Materials. 6 (2016) 1600460-n/a.

[22] T. Liu, K. Chen, Q. Hu, R. Zhu, Q. Gong, Inverted Perovskite Solar Cells: Progresses and Perspectives, Advanced Energy Materials. 6 (2016) 1600457-n/a.

[23] N.K. Elumalai, A. Uddin, Hysteresis in organic-inorganic hybrid perovskite solar cells, Solar Energy Mater. Solar Cells. 157 (2016) 476.

[24] H. Kim, K. Lim, T. Lee, Planar heterojunction organometal halide perovskite solar cells: roles of interfacial layers, Energy Environ.Sci. 9 (2016) 12-30. 
[25] J. Boucle, N. Herlin-Boime, The benefits of graphene for hybrid perovskite solar cells, Synth. Met. 222 (2016) 3-16.

[26] X. Guo, C. Burda, Coordination engineering toward high performance organic-inorganic hybrid perovskites, Coord. Chem. Rev. 320-321 (2016) 53.

[27] Y. Han, S. Meyer, Y. Dkhissi, K. Weber, J.M. Pringle, U. Bach, L. Spiccia, Y. Cheng, Degradation observations of encapsulated planar $\mathrm{CH} 3 \mathrm{NH} 3 \mathrm{PbI} 3$ perovskite solar cells at high temperatures and humidity, J. Mater. Chem. A. 3 (2015) 8139-8147.

[28] T.C. Sum, N. Mathews, Advancements in perovskite solar cells: photophysics behind the photovoltaics, Energy Environ. Sci. 7 (2014) 2518-2534.

[29] T.J. Jacobsson, L.J. Schwan, M. Ottosson, A. Hagfeldt, T. Edvinsson, Determination of Thermal Expansion Coefficients and Locating the Temperature-Induced Phase Transition in Methylammonium Lead Perovskites Using X-ray Diffraction, Inorg. Chem. 54 (2015) 1067810685 .

[30] C. Quarti, E. Mosconi, J.M. Ball, V. D'Innocenzo, C. Tao, S. Pathak, H.J. Snaith, A. Petrozza, F. De Angelis, Structural and optical properties of methylammonium lead iodide across the tetragonal to cubic phase transition: implications for perovskite solar cells, Energy Environ.Sci. 9 (2016) 155-163.

[31] Y. Zhang, S. Chen, P. Xu, H. Xiang, X. Gong, A. Walsh, S. Wei, Intrinsic Instability of the Hybrid Halide Perovskite Semiconductor CH3NH3PbI3, arXiv:1506.01301. (2015).

[32] A. Alberti, I. Deretzis, G. Pellegrino, C. Bongiorno, E. Smecca, G. Mannino, F. Giannazzo, G.G. Condorelli, N. Sakai, T. Miyasaka, C. Spinella, A. La Magna, Similar Structural Dynamics for the Degradation of CH3NH3PbI3 in Air and in Vacuum, ChemPhysChem. 16 (2015) 3064-3071.

[33] E. Smecca, Y. Numata, I. Deretzis, G. Pellegrino, S. Boninelli, T. Miyasaka, A. La Magna, A. Alberti, Stability of solution-processed MAPbI3 and FAPbI3 layers, Phys.Chem.Chem.Phys. 18 (2016) 13413-13422.

[34] G.E. Eperon, S.D. Stranks, C. Menelaou, M.B. Johnston, L.M. Herz, H.J. Snaith, Formamidinium lead trihalide: a broadly tunable perovskite for efficient planar heterojunction solar cells, Energy Environ. Sci. 7 (2014) 982-988.

[35] M.R. Leyden, Y. Jiang, Y. Qi, Chemical vapor deposition grown formamidinium perovskite solar modules with high steady state power and thermal stability, J.Mater.Chem.A. 4 (2016) 13125-13132.

[36] A. Amat, E. Mosconi, E. Ronca, C. Quarti, P. Umari, M.K. Nazeeruddin, M. Gratzel, F. De Angelis, Cation-Induced Band-Gap Tuning in Organohalide Perovskites: Interplay of Spin-Orbit Coupling and Octahedra Tilting, Nano Lett. 14 (2014) 3608-3616.

[37] A. Binek, F.C. Hanusch, P. Docampo, T. Bein, Stabilization of the Trigonal HighTemperature Phase of Formamidinium Lead Iodide, J. Phys. Chem. Lett. 6 (2015) 1249-1253.

[38] N. Pellet, P. Gao, G. Gregori, T. Yang, M.K. Nazeeruddin, J. Maier, M. Grätzel, MixedOrganic-Cation Perovskite Photovoltaics for Enhanced Solar-Light Harvesting, Angewandte Chemie International Edition. 53 (2014) 3151-3157. 
[39] C.C. Stoumpos, C.D. Malliakas, M.G. Kanatzidis, Semiconducting Tin and Lead Iodide Perovskites with Organic Cations: Phase Transitions, High Mobilities, and Near-Infrared Photoluminescent Properties, Inorg. Chem. 52 (2013) 9019-9038.

[40] N.J. Jeon, J.H. Noh, W.S. Yang, Y.C. Kim, S. Ryu, J. Seo, S.I. Seok, Compositional engineering of perovskite materials for high-performance solar cells, Nature. 517 (2015) 476480.

[41] X. Zheng, C. Wu, S.K. Jha, Z. Li, K. Zhu, S. Priya, Improved Phase Stability of Formamidinium Lead Triiodide Perovskite by Strain Relaxation, ACS Energy Lett. (2016) 1014-1020.

[42] Z. Wang, Y. Zhou, S. Pang, Z. Xiao, J. Zhang, W. Chai, H. Xu, Z. Liu, N.P. Padture, G. Cui, Additive-Modulated Evolution of HC(NH2)2PbI3 Black Polymorph for Mesoscopic Perovskite Solar Cells, Chem. Mater. 27 (2015) 7149-7155.

[43] Y. Zhou, J. Kwun, H.F. Garces, S. Pang, N.P. Padture, Observation of phase-retention behavior of the $\mathrm{HC}(\mathrm{NH} 2) 2 \mathrm{PbI} 3$ black perovskite polymorph upon mesoporous $\mathrm{TiO} 2$ scaffolds, Chem.Commun. 52 (2016) 7273-7275.

[44] Z. Li, M. Yang, J. Park, S. Wei, J.J. Berry, K. Zhu, Stabilizing Perovskite Structures by Tuning Tolerance Factor: Formation of Formamidinium and Cesium Lead Iodide Solid-State Alloys, Chem. Mater. 28 (2016) 284-292.

[45] J. Lee, D. Kim, H. Kim, S. Seo, S.M. Cho, N. Park, Formamidinium and Cesium Hybridization for Photo- and Moisture-Stable Perovskite Solar Cell, Advanced Energy Materials. 5 (2015) 1501310-n/a.

[46] C. Yi, J. Luo, S. Meloni, A. Boziki, N. Ashari-Astani, C. Gratzel, S.M. Zakeeruddin, U. Rothlisberger, M. Gratzel, Entropic stabilization of mixed A-cation ABX3 metal halide perovskites for high performance perovskite solar cells, Energy Environ.Sci. 9 (2016) 656662.

[47] X. Xia, W. Wu, H. Li, B. Zheng, Y. Xue, J. Xu, D. Zhang, C. Gao, X. Liu, Spray reaction prepared $\mathrm{FA} 1-\mathrm{xCsxPbI} 3$ solid solution as a light harvester for perovskite solar cells with improved humidity stability, RSC Adv. 6 (2016) 14792-14798.

[48] R.J. Sutton, G.E. Eperon, L. Miranda, E.S. Parrott, B.A. Kamino, J.B. Patel, M.T. HÃ $\llbracket$ rantner, M.B. Johnston, A.A. Haghighirad, D.T. Moore, H.J. Snaith, Bandgap-Tunable Cesium Lead Halide Perovskites with High Thermal Stability for Efficient Solar Cells, Advanced Energy Materials. 6 (2016) 1502458.

[49] E.T. Hoke, D.J. Slotcavage, E.R. Dohner, A.R. Bowring, H.I. Karunadasa, M.D. McGehee, Reversible photo-induced trap formation in mixed-halide hybrid perovskites for photovoltaics, Chem. Sci. 6 (2015) 613-617.

[50] F. Brivio, C. Caetano, A. Walsh, Thermodynamic Origin of Photoinstability in the $\mathrm{CH}_{3} \mathrm{NH}_{3} \mathrm{~Pb}\left(\mathrm{I}_{1-\mathrm{x}} \mathrm{Br}_{\mathrm{x}}\right)_{3}$ Hybrid Halide Perovskite Alloy, J. Phys. Chem. Lett. 7 (2016) 10831087.

[51] R.E. Beal, D.J. Slotcavage, T. Leijtens, A.R. Bowring, R.A. Belisle, W.H. Nguyen, G.F. Burkhard, E.T. Hoke, M.D. McGehee, Cesium Lead Halide Perovskites with Improved Stability for Tandem Solar Cells, J. Phys. Chem. Lett. 7 (2016) 746-751. 
[52] Q. Ma, S. Huang, X. Wen, M.A. Green, A.W.Y. Ho-Baillie, Hole Transport Layer Free Inorganic $\mathrm{CsPbIBr} 2$ Perovskite Solar Cell by Dual Source Thermal Evaporation, Advanced Energy Materials. 6 (2016) 1502202.

[53] S. Dastidar, D.A. Egger, L.Z. Tan, S.B. Cromer, A.D. Dillon, S. Liu, L. Kronik, A.M. Rappe, A.T. Fafarman, High Chloride Doping Levels Stabilize the Perovskite Phase of Cesium Lead Iodide, Nano Lett. 16 (2016) 3563-3570.

[54] M. Saliba, T. Matsui, J. Seo, K. Domanski, J. Correa-Baena, M.K. Nazeeruddin, S.M. Zakeeruddin, W. Tress, A. Abate, A. Hagfeldt, M. Gratzel, Cesium-containing triple cation perovskite solar cells: improved stability, reproducibility and high efficiency, Energy Environ.Sci. 9 (2016) 1989-1997.

[55] J. Schoonman, Organic-inorganic lead halide perovskite solar cell materials: A possible stability problem, Chemical Physics Letters. 619 (2015) 193-195.

[56] F. Liu, Q. Dong, M.K. Wong, A.B. Djurisic, A. Ng, Z. Ren, Q. Shen, C. Surya, W.K. Chan, J. Wang, A.M.C. Ng, C. Liao, H. Li, K. Shih, C. Wei, H. Su, J. Dai, Is Excess PbI2 Beneficial for Perovskite Solar Cell Performance? Advanced Energy Materials. 6 (2016) 1502206 .

[57] J. Cao, F. Wang, H. Yu, Y. Zhou, H. Lu, N. Zhao, C. Wong, Porous PbI2 films for the fabrication of efficient, stable perovskite solar cells via sequential deposition, J.Mater.Chem.A. 4 (2016) 10223-10230.

[58] Y. Du, H. Cai, H. Wen, Y. Wu, Z. Li, J. Xu, L. Huang, J. Ni, J. Li, J. Zhang, Undesirable role of remnant $\mathrm{PbI} 2$ layer on low temperature processed planar perovskite solar cells, RSC Adv. 6 (2016) 101250-101258.

[59] H. Zhang, J. Mao, H. He, D. Zhang, H.L. Zhu, F. Xie, K.S. Wong, M. Gratzel, W.C.H. Choy, A Smooth CH3NH3PbI3 Film via a New Approach for Forming the PbI2 Nanostructure Together with Strategically High CH3NH3I Concentration for High Efficient Planar-Heterojunction Solar Cells, Advanced Energy Materials. 5 (2015) 1501354-n/a.

[60] R.K. Misra, S. Aharon, B. Li, D. Mogilyansky, I. Visoly-Fisher, L. Etgar, E.A. Katz, Temperature- and Component-Dependent Degradation of Perovskite Photovoltaic Materials under Concentrated Sunlight, J. Phys. Chem. Lett. (2014) 326-330.

[61] C. Law, L. Miseikis, S. Dimitrov, P. Shakya-Tuladhar, X. Li, P.R.F. Barnes, J. Durrant, B.C. O'Regan, Performance and Stability of Lead Perovskite/TiO2, Polymer/PCBM, and Dye Sensitized Solar Cells at Light Intensities up to 70 Suns, Adv Mater. 26 (2014) 6268-6273.

[62] R. Gottesman, E. Haltzi, L. Gouda, S. Tirosh, Y. Bouhadana, A. Zaban, E. Mosconi, F. De Angelis, Extremely Slow Photoconductivity Response of CH3NH3PbI3 Perovskites Suggesting Structural Changes under Working Conditions, J. Phys. Chem. Lett. 5 (2014) 2662-2669.

[63] R. Gottesman, L. Gouda, B.S. Kalanoor, E. Haltzi, S. Tirosh, E. Rosh-Hodesh, Y. Tischler, A. Zaban, C. Quarti, E. Mosconi, F. De Angelis, Photoinduced Reversible Structural Transformations in Free-Standing CH3NH3PbI3 Perovskite Films, J. Phys. Chem. Lett. 6 (2015) 2332-2338. 
[64] B. Philippe, B. Park, R. Lindblad, J. Oscarsson, S. Ahmadi, E.M.J. Johansson, H. Rensmo, Chemical and Electronic Structure Characterization of Lead Halide Perovskites and Stability Behavior under Different Exposures-A Photoelectron Spectroscopy Investigation, Chem. Mater. 27 (2015) 1720-1731.

[65] N. Klein-Kedem, D. Cahen, G. Hodes, Effects of Light and Electron Beam Irradiation on Halide Perovskites and Their Solar Cells, Acc. Chem. Res. 49 (2016) 347-354.

[66] H. Yuan, E. Debroye, K. Janssen, H. Naiki, C. Steuwe, G. Lu, M. Moris, E. Orgiu, H. Uji-i, F. De Schryver, P. Samori, J. Hofkens, M. Roeffaers, Degradation of Methylammonium Lead Iodide Perovskite Structures through Light and Electron Beam Driven Ion Migration, J. Phys. Chem. Lett. 7 (2016) 561-566.

[67] A.R. Milosavljevic, W. Huang, S. Sadhu, S. Ptasinska, Low-Energy Electron-Induced Transformations in Organolead Halide Perovskite, Angewandte Chemie. 128 (2016) 10237 10241.

[68] F. Lang, N.H. Nickel, J. Bundesmann, S. Seidel, A. Denker, S. Albrecht, V.V. Brus, J. Rappich, B. Rech, G. Landi, H.C. Neitzert, Radiation Hardness and Self-Healing of Perovskite Solar Cells, Adv Mater. 28 (2016) 8726-8731.

[69] B.L. Oksengendler, O.B. Ismailova, M.B. Marasulov, I.Z. Urolov, On the degradation mechanism of functioning solar cells based on organic-inorganic perovskites, Applied Solar Energy. 50 (2014) 255-259.

[70] W. Nie, J. Blancon, A.J. Neukirch, K. Appavoo, H. Tsai, M. Chhowalla, M.A. Alam, M.Y. Sfeir, C. Katan, J. Even, S. Tretiak, J.J. Crochet, G. Gupta, A.D. Mohite, Lightactivated photocurrent degradation and self-healing in perovskite solar cells, Nat Commun. 7 (2016) 11574.

[71] A. Merdasa, M. Bag, Y. Tian, E. Kallman, A. Dobrovolsky, I.G. Scheblykin, SuperResolution Luminescence Microspectroscopy Reveals the Mechanism of Photoinduced Degradation in $\mathrm{CH}_{3} \mathrm{NH}_{3} \mathrm{PbI}_{3}$ Perovskite Nanocrystals, J. Phys. Chem. C. 120 (2016) 1071110719.

[72] X. Tang, M. Brandl, B. May, I. Levchuk, Y. Hou, M. Richter, H. Chen, S. Chen, S. Kahmann, A. Osvet, F. Maier, H. Steinruck, R. Hock, G.J. Matt, C.J. Brabec, Photoinduced degradation of methylammonium lead triiodide perovskite semiconductors, J.Mater.Chem.A. 4 (2016) 15896-15903.

[73] F.T.F. O'Mahony, Y.H. Lee, C. Jellett, S. Dmitrov, D.T.J. Bryant, J.R. Durrant, B.C. O'Regan, M. Graetzel, M.K. Nazeeruddin, S.A. Haque, Improved environmental stability of organic lead trihalide perovskite-based photoactive-layers in the presence of mesoporous TiO2, J. Mater. Chem. A. 3 (2015) 7219-7223.

[74] N. Aristidou, I. Sanchez-Molina, T. Chotchuangchutchaval, M. Brown, L. Martinez, T. Rath, S.A. Haque, The Role of Oxygen in the Degradation of Methylammonium Lead Trihalide Perovskite Photoactive Layers, Angew. Chem. Int. Ed. 54 (2015) 8208-8212.

[75] D. Bryant, N. Aristidou, S. Pont, I. Sanchez-Molina, T. Chotchunangatchaval, S. Wheeler, J.R. Durrant, S.A. Haque, Light and oxygen induced degradation limits the operational stability of methylammonium lead triiodide perovskite solar cells, Energy Environ.Sci. 9 (2016) 1655-1660. 
[76] A.J. Pearson, G.E. Eperon, P.E. Hopkinson, S.N. Habisreutinger, J.T. Wang, H.J. Snaith, N.C. Greenham, Oxygen Degradation in Mesoporous $\mathrm{Al}_{2} \mathrm{O}_{3} / \mathrm{CH}_{3} \mathrm{NH}_{3} \mathrm{PbI}_{3-\mathrm{x}} \mathrm{Cl}_{\mathrm{x}}$ Perovskite Solar Cells: Kinetics and Mechanisms, Advanced Energy Materials. (2016) 1600014-n/a.

[77] S.J. Yoon, S. Draguta, J.S. Manser, O. Sharia, W.F. Schneider, M. Kuno, P.V. Kamat, Tracking Iodide and Bromide Ion Segregation in Mixed Halide Lead Perovskites during Photoirradiation, ACS Energy Lett. (2016) 290-296.

[78] D.J. Slotcavage, H.I. Karunadasa, M.D. McGehee, Light-induced Phase Segregation in Halide-perovskite Absorbers, ACS Energy Lett. 1 (2016) 1199-1205.

[79] R.K. Misra, L. Ciammaruchi, S. Aharon, D. Mogilyansky, L. Etgar, I. Visoly-Fisher, E.A. Katz, Effect of Halide Composition on the Photochemical Stability of Perovskite Photovoltaic Materials, ChemSusChem. 9 (2016) 2572-2577.

[80] F. Matsumoto, S.M. Vorpahl, J.Q. Banks, E. Sengupta, D.S. Ginger, Photodecomposition and Morphology Evolution of Organometal Halide Perovskite Solar Cells, J. Phys. Chem. C. 119 (2015) 20810-20816.

[81] H. Zhou, Q. Chen, G. Li, S. Luo, T. Song, H. Duan, Z. Hong, J. You, Y. Liu, Y. Yang, Interface engineering of highly efficient perovskite solar cells, Science. 345 (2014) 542-546.

[82] G. Niu, W. Li, F. Meng, L. Wang, H. Dong, Y. Qiu, Study on the stability of $\mathrm{CH} 3 \mathrm{NH} 3 \mathrm{PbI} 3$ films and the effect of post-modification by aluminum oxide in all-solid-state hybrid solar cells, J. Mater. Chem. A. 2 (2014) 705-710.

[83] J. Yang, B.D. Siempelkamp, D. Liu, T.L. Kelly, Investigation of CH3NH3PbI3 Degradation Rates and Mechanisms in Controlled Humidity Environments Using in Situ Techniques, ACS Nano. 9 (2015) 1955-1963.

[84] J.A. Christians, P.A. Miranda Herrera, P.V. Kamat, Transformation of the Excited State and Photovoltaic Efficiency of CH3NH3PbI3 Perovskite upon Controlled Exposure to Humidified Air, J. Am. Chem. Soc. 137 (2015) 1530-1538.

[85] X. Guo, C. McCleese, W. Lin, C. Burda, Curing of degraded MAPbI3 perovskite films, RSC Adv. 6 (2016) 60620-60625.

[86] A.M.A. Leguy, Y. Hu, M. Campoy-Quiles, M.I. Alonso, O.J. Weber, P. Azarhoosh, M. van Schilfgaarde, M.T. Weller, T. Bein, J. Nelson, P. Docampo, P.R.F. Barnes, Reversible Hydration of CH3NH3PbI3 in Films, Single Crystals, and Solar Cells, Chem. Mater. 27 (2015) 3397-3407.

[87] J.M. Frost, K.T. Butler, F. Brivio, C.H. Hendon, M. van Schilfgaarde, A. Walsh, Atomistic Origins of High-Performance in Hybrid Halide Perovskite Solar Cells, Nano Lett. 14 (2014) 2584-2590.

[88] H. Fang, P. Jena, Super-ion inspired colorful hybrid perovskite solar cells, J.Mater.Chem.A. 4 (2016) 4728-4737.

[89] M. Shirayama, M. Kato, T. Miyadera, T. Sugita, T. Fujiseki, S. Hara, H. Kadowaki, D. Murata, M. Chikamatsu, H. Fujiwara, Degradation mechanism of CH3NH3PbI3 perovskite materials upon exposure to humid air, J. Appl. Phys. 119 (2016) 115501. 
[90] J. Zhao, B. Cai, Z. Luo, Y. Dong, Y. Zhang, H. Xu, B. Hong, Y. Yang, L. Li, W. Zhang, C. Gao, Investigation of the Hydrolysis of Perovskite Organometallic Halide CH3NH3PbI3 in Humidity Environment, Scientific Reports. 6 (2016) 21976.

[91] D. Li, S.A. Bretschneider, V.W. Bergmann, I.M. Hermes, J. Mars, A. Klasen, H. Lu, W. Tremel, M. Mezger, H. Butt, S.A.L. Weber, R. Berger, Humidity-Induced Grain Boundaries in MAPbI3 Perovskite Films, J. Phys. Chem. C. 120 (2016) 6363-6368.

[92] Z. Song, A. Abate, S.C. Watthage, G.K. Liyanage, A.B. Phillips, U. Steiner, M. Graetzel, M.J. Heben, Perovskite Solar Cell Stability in Humid Air: Partially Reversible Phase Transitions in the PbI2-CH3NH3I-H2O System, Advanced Energy Materials. 6 (2016) 1600846-n/a.

[93] M. Ledinsky, P. Loper, B. Niesen, J. Holovsky, S. Moon, J. Yum, S. De Wolf, A. Fejfar, C. Ballif, Raman Spectroscopy of Organic-Inorganic Halide Perovskites, J. Phys. Chem. Lett. 6 (2015) 401-406.

[94] X. Dong, X. Fang, M. Lv, B. Lin, S. Zhang, J. Ding, N. Yuan, Improvement of the humidity stability of organic-inorganic perovskite solar cells using ultrathin $\mathrm{A} 12 \mathrm{O} 3$ layers prepared by atomic layer deposition, J. Mater. Chem. A. 3 (2015) 5360-5367.

[95] L. Hu, G. Shao, T. Jiang, D. Li, X. Lv, H. Wang, X. Liu, H. Song, J. Tang, H. Liu, Investigation of the Interaction between Perovskite Films with Moisture via in Situ Electrical Resistance Measurement, ACS Appl. Mater. Interfaces. 7 (2015) 25113-25120.

[96] A. Arakcheeva, D. Chernyshov, M. Spina, L. Forro, E. Horath, CH3NH3PbI3: precise structural consequences of water absorption at ambient conditions, Acta Crystallographica Section B. 72 (2016) 716-722.

[97] Z. Zhu, V.G. Hadjiev, Y. Rong, R. Guo, B. Cao, Z. Tang, F. Qin, Y. Li, Y. Wang, F. Hao, S. Venkatesan, W. Li, S. Baldelli, A.M. Guloy, H. Fang, Y. Hu, Y. Yao, Z. Wang, J. Bao, Interaction of Organic Cation with Water Molecule in Perovskite MAPbI3: From Dynamic Orientational Disorder to Hydrogen Bonding, Chem. Mater. 28 (2016) 7385-7393.

[98] Y. Li, X. Xu, C. Wang, C. Wang, F. Xie, J. Yang, Y. Gao, Degradation by Exposure of Coevaporated CH3NH3PbI3 Thin Films, J. Phys. Chem. C. 119 (2015) 23996-24002.

[99] C. Wang, Y. Li, X. Xu, C. Wang, F. Xie, Y. Gao, Degradation of co-evaporated perovskite thin film in air, Chemical Physics Letters. 649 (2016) 151.

[100] W. Huang, J.S. Manser, P.V. Kamat, S. Ptasinska, Evolution of Chemical Composition, Morphology, and Photovoltaic Efficiency of CH3NH3PbI3 Perovskite under Ambient Conditions, Chem. Mater. 28 (2016) 303-311.

[101] G. Grancini, V. D'Innocenzo, E.R. Dohner, N. Martino, A.R. Srimath Kandada, E. Mosconi, F. De Angelis, H.I. Karunadasa, E.T. Hoke, A. Petrozza, CH3NH3PbI3 perovskite single crystals: surface photophysics and their interaction with the environment, Chem. Sci. 6 (2015) 7305-7310.

[102] C. Muller, T. Glaser, M. Plogmeyer, M. Sendner, S. Doring, A.A. Bakulin, C. Brzuska, R. Scheer, M.S. Pshenichnikov, W. Kowalsky, A. Pucci, R. Lovrincic, Water Infiltration in Methylammonium Lead Iodide Perovskite: Fast and Inconspicuous, Chem. Mater. 27 (2015) 7835-7841. 
[103] E. Mosconi, J.M. Azpiroz, F. De Angelis, Ab Initio Molecular Dynamics Simulations of Methylammonium Lead Iodide Perovskite Degradation by Water, Chem. Mater. 27 (2015) 4885-4892.

[104] L. Zhang, M. Ju, W. Liang, The effect of moisture on the structures and properties of lead halide perovskites: a first-principles theoretical investigation, Phys.Chem.Chem.Phys. 18 (2016) 23174-23183.

[105] M.L. Petrus, Y. Hu, D. Moia, P. Calado, A.M.A. Leguy, P.R.F. Barnes, P. Docampo, The Influence of Water Vapor on the Stability and Processing of Hybrid Perovskite Solar Cells Made from Non-Stoichiometric Precursor Mixtures, ChemSusChem. 9 (2016) 26992707.

[106] C. Tong, W. Geng, Z. Tang, C. Yam, X. Fan, J. Liu, W. Lau, L. Liu, Uncovering the Veil of the Degradation in Perovskite CH3NH3PbI3 upon Humidity Exposure: A FirstPrinciples Study, J. Phys. Chem. Lett. (2015) 3289-3295.

[107] N.Z. Koocher, D. Saldana-Greco, F. Wang, S. Liu, A.M. Rappe, Polarization Dependence of Water Adsorption to CH3NH3PbI3 (001) Surfaces, J. Phys. Chem. Lett. 6 (2015) 4371-4378.

[108] L. Zhang, P.H.-. Sit, Ab Initio Study of Interaction of Water, Hydroxyl Radicals, and Hydroxide Ions with CH3NH3PbI3 and CH3NH3PbBr3 Surfaces, J. Phys. Chem. C. 119 (2015) 22370-22378.

[109] L. Zhang, P.H.-. Sit, Ab initio static and dynamic study of CH3NH3PbI3 degradation in the presence of water, hydroxyl radicals, and hydroxide ions, RSC Adv. 6 (2016) 7693876947.

[110] W. Li, H. Dong, L. Wang, N. Li, X. Guo, J. Li, Y. Qiu, Montmorillonite as bifunctional buffer layer material for hybrid perovskite solar cells with protection from corrosion and retarding recombination, J. Mater. Chem. A. 2 (2014) 13587-13592.

[111] S. Ito, S. Tanaka, K. Manabe, H. Nishino, Effects of Surface Blocking Layer of Sb2S3 on Nanocrystalline TiO2 for CH3NH3PbI3 Perovskite Solar Cells, J. Phys. Chem. C. 118 (2014) 16995-17000.

[112] J. Zhang, T. Pauporte, Effects of Oxide Contact Layer on the Preparation and Properties of CH3NH3PbI3 for Perovskite Solar Cell Application, J. Phys. Chem. C. 119 (2015) 1491914928.

[113] S. Kumar, A. Dhar, Accelerated Thermal-Aging-Induced Degradation of Organometal Triiodide Perovskite on ZnO Nanostructures and Its Effect on Hybrid Photovoltaic Devices, ACS Appl. Mater. Interfaces. 8 (2016) 18309-18320.

[114] J. Yang, B.D. Siempelkamp, E. Mosconi, F. De Angelis, T.L. Kelly, Origin of the Thermal Instability in CH3NH3PbI3 Thin Films Deposited on ZnO, Chem. Mater. 27 (2015) 4229-4236.

[115] Y. Dkhissi, S. Meyer, D. Chen, H.C. Weerasinghe, L. Spiccia, Y. Cheng, R.A. Caruso, Stability Comparison of Perovskite Solar Cells Based on Zinc Oxide and Titania on Polymer Substrates, ChemSusChem. 9 (2016) 687-695. 
[116] M.M. Tavakoli, R. Tavakoli, Z. Nourbakhsh, A. Waleed, U.S. Virk, Z. Fan, High Efficiency and Stable Perovskite Solar Cell Using ZnO/rGO QDs as an Electron Transfer Layer, Advanced Materials Interfaces. 3 (2016) 1500790-n/a.

[117] Y. Guo, X. Li, L.L. Kang, X. He, Z.Q. Ren, J.D. Wu, J.Y. Qi, Improvement of stability of $\mathrm{ZnO} / \mathrm{CH} 3 \mathrm{NH} 3 \mathrm{PbI} 3$ bilayer by aging step for preparing high-performance perovskite solar cells under ambient conditions, RSC Adv. 6 (2016) 62522-62528.

[118] C. Manspeaker, P. Scruggs, J. Preiss, D.A. Lyashenko, A.A. Zakhidov, Reliable Annealing of CH3NH3PbI3 Films Deposited on ZnO, J. Phys. Chem. C. 120 (2016) 63776382.

[119] J. Idigoras, A. Todinova, J.R. Sanchez-Valencia, A. Barranco, A. Borras, J.A. Anta, The interaction between hybrid organic-inorganic halide perovskite and selective contacts in perovskite solar cells: an infrared spectroscopy study, Phys.Chem.Chem.Phys. 18 (2016) 13583-13590.

[120] Y. Cheng, Q. Yang, J. Xiao, Q. Xue, H. Li, Z. Guan, H. Yip, S. Tsang, Decomposition of Organometal Halide Perovskite Films on Zinc Oxide Nanoparticles, ACS Appl. Mater. Interfaces. 7 (2015) 19986-19993.

[121] X. Zhao, H. Shen, Y. Zhang, X. Li, X. Zhao, M. Tai, J. Li, J. Li, X. Li, H. Lin, Aluminum-Doped Zinc Oxide as Highly Stable Electron Collection Layer for Perovskite Solar Cells, ACS Appl. Mater. Interfaces. 8 (2016) 7826-7833.

[122] J. Song, E. Zheng, L. Liu, X. Wang, G. Chen, W. Tian, T. Miyasaka, Magnesiumdoped Zinc Oxide as Electron Selective Contact Layers for Efficient Perovskite Solar Cells, ChemSusChem. 9 (2016) 2640-2647.

[123] Q. Hu, J. Wu, C. Jiang, T. Liu, X. Que, R. Zhu, Q. Gong, Engineering of ElectronSelective Contact for Perovskite Solar Cells with Efficiency Exceeding 15\%, ACS Nano. 8 (2014) 10161-10167.

[124] Y. Lei, L. Gu, W. He, Z. Jia, X. Yang, H. Jia, Z. Zheng, Intrinsic charge carrier dynamics and device stability of perovskite/ZnO mesostructured solar cells in moisture, J.Mater.Chem.A. 4 (2016) 5474-5481.

[125] P. Chen, X. Yin, M. Que, Y. Yang, W. Que, TiO2 passivation for improved efficiency and stability of $\mathrm{ZnO}$ nanorods based perovskite solar cells, RSC Adv. 6 (2016) 57996-58002.

[126] W. Dunlap-Shohl, R. Younts, B. Gautam, K. Gundogdu, D.B. Mitzi, Effects of Cd Diffusion and Doping in High-Performance Perovskite Solar Cells Using CdS as Electron Transport Layer, J. Phys. Chem. C. 120 (2016) 16437-16445.

[127] I. Deretzis, A. Alberti, G. Pellegrino, E. Smecca, F. Giannazzo, N. Sakai, T. Miyasaka, A. La Magna, Atomistic origins of $\mathrm{CH} 3 \mathrm{NH} 3 \mathrm{PbI} 3$ degradation to PbI2 in vacuum, Appl. Phys. Lett. 106 (2015) 131904.

[128] Z. Ku, N.H. Tiep, B. Wu, T.C. Sum, D. Fichou, H.J. Fan, Solvent engineering for fast growth of centimetric high-quality CH3NH3PbI3 perovskite single crystals, New J.Chem. 40 (2016) 7261-7264. 
[129] W. Xu, L. Liu, L. Yang, P. Shen, B. Sun, J.A. McLeod, Dissociation of Methylammonium Cations in Hybrid Organicâ€"Inorganic Perovskite Solar Cells, Nano Lett. 16 (2016) 4720-4725.

[130] E.J. Juarez-Perez, Z. Hawash, S.R. Raga, L.K. Ono, Y. Qi, Thermal degradation of $\mathrm{CH} 3 \mathrm{NH} 3 \mathrm{PbI} 3$ perovskite into $\mathrm{NH} 3$ and $\mathrm{CH} 3 \mathrm{I}$ gases observed by coupled thermogravimetrymass spectrometry analysis, Energy Environ.Sci. 9 (2016) 3406-3410.

[131] B. Brunetti, C. Cavallo, A. Ciccioli, G. Gigli, A. Latini, On the Thermal and Thermodynamic (In)Stability of Methylammonium Lead Halide Perovskites, Scientific Reports. 6 (2016) 31896.

[132] B. Conings, J. Drijkoningen, N. Gauquelin, A. Babayigit, J. D'Haen, L. D'Olieslaeger, A. Ethirajan, J. Verbeeck, J. Manca, E. Mosconi, F.D. Angelis, H. Boyen, Intrinsic Thermal Instability of Methylammonium Lead Trihalide Perovskite, Advanced Energy Materials. 5 (2015) 1500477.

[133] G. Divitini, S. Cacovich, F. Matteocci, L. Cina, A. Di Carlo, C. Ducati, In situ observation of heat-induced degradation of perovskite solar cells, Nature Energy. (2016) 15012 .

[134] M. Bag, L.A. Renna, R.Y. Adhikari, S. Karak, F. Liu, P.M. Lahti, T.P. Russell, M.T. Tuominen, D. Venkataraman, Kinetics of Ion Transport in Perovskite Active Layers and Its Implications for Active Layer Stability, J. Am. Chem. Soc. 137 (2015) 13130-13137.

[135] L. Tang, H. Mei, B. Wang, S. Peng, Study on structure, thermal stabilization and light absorption of lead-bromide perovskite light harvesters, J. Mater. Sci. : Mater. Electron. 26 (2015) 8726-8731.

[136] K. Cao, J. Cui, H. Zhang, H. Li, J. Song, Y. Shen, Y. Cheng, M. Wang, Efficient mesoscopic perovskite solar cells based on the $\mathrm{CH} 3 \mathrm{NH} 3 \mathrm{PbI} 2 \mathrm{Br}$ light absorber, J. Mater. Chem. A. 3 (2015) 9116-9122.

[137] A. Zohar, N. Kedem, I. Levine, D. Zohar, A. Vilan, D. Ehre, G. Hodes, D. Cahen, Impedance Spectroscopic Indication for Solid State Electrochemical Reaction in (CH3NH3)PbI3 Films, J. Phys. Chem. Lett. 7 (2016) 191-197.

[138] C. Xiao, Z. Li, H. Guthrey, J. Moseley, Y. Yang, S. Wozny, H. Moutinho, B. To, J.J. Berry, B. Gorman, Y. Yan, K. Zhu, M. Al-Jassim, Mechanisms of Electron-Beam-Induced Damage in Perovskite Thin Films Revealed by Cathodoluminescence Spectroscopy, J. Phys. Chem. C. 119 (2015) 26904-26911.

[139] D. Song, J. Ji, Y. Li, G. Li, M. Li, T. Wang, D. Wei, P. Cui, Y. He, J.M. Mbengue, Degradation of organometallic perovskite solar cells induced by trap states, Appl. Phys. Lett. 108 (2016).

[140] N.A. Manshor, Q. Wali, K.K. Wong, S.K. Muzakir, A. Fakharuddin, L. Schmidt-Mende, R. Jose, Humidity versus photo-stability of metal halide perovskite films in a polymer matrix, Phys.Chem.Chem.Phys. 18 (2016) 21629-21639.

[141] T. Leijtens, G.E. Eperon, S. Pathak, A. Abate, M.M. Lee, H.J. Snaith, Overcoming ultraviolet light instability of sensitized $\mathrm{TiO} 2$ with meso-superstructured organometal trihalide perovskite solar cells, Nat Commun. 4 (2013) 2885. 
[142] I. Hwang, M. Baek, K. Yong, Core/Shell Structured TiO2/CdS Electrode to Enhance the Light Stability of Perovskite Solar Cells, ACS Appl. Mater. Interfaces. 7 (2015) 27863 27870 .

[143] I. Hwang, K. Yong, Novel CdS Hole-Blocking Layer for Photostable Perovskite Solar Cells, ACS Appl. Mater. Interfaces. 8 (2016) 4226-4232.

[144] W. Li, J. Li, G. Niu, L. Wang, Effect of cesium chloride modification on the film morphology and UV-induced stability of planar perovskite solar cells, J.Mater.Chem.A. 4 (2016) 11688-11695.

[145] W. Li, W. Zhang, S. Van Reenen, R.J. Sutton, J. Fan, A.A. Haghighirad, M.B. Johnston, L. Wang, H.J. Snaith, Enhanced UV-light stability of planar heterojunction perovskite solar cells with caesium bromide interface modification, Energy Environ.Sci. 9 (2016) 490-498.

[146] X. Dong, X. Fang, M. Lv, B. Lin, S. Zhang, Y. Wang, N. Yuan, J. Ding, Method for improving illumination instability of organic--inorganic halide perovskite solar cells, Science Bulletin. 61 (2016) 236-244.

[147] Y. Li, J.K. Cooper, W. Liu, C. Sutter-Fella, M. Amani, J.W. Beeman, A. Javey, J.W. Ager, Y. Liu, F.M. Toma, I.D. Sharp, Defective TiO2 with high photoconductive gain for efficient and stable planar heterojunction perovskite solar cells, Nature Communications. 7 (2016) 12446.

[148] N. Chander, A.F. Khan, P.S. Chandrasekhar, E. Thouti, S.K. Swami, V. Dutta, V.K. Komarala, Reduced ultraviolet light induced degradation and enhanced light harvesting using YVO4:Eu3 + down-shifting nano-phosphor layer in organometal halide perovskite solar cells, Appl. Phys. Lett. 105 (2014) 033904.

[149] G. Murugadoss, S. Tanaka, G. Mizuta, S. Kanaya, H. Nishino, T. Umeyama, H. Imahori, S. Ito, Light stability tests of methylammonium and formamidinium $\mathrm{Pb}$-halide perovskites for solar cell applications, Japanese Journal of Applied Physics. 54 (2015) 08KF08.

[150] S.K. Pathak, A. Abate, P. Ruckdeschel, B. Roose, K.C. Gödel, Y. Vaynzof, A. Santhala, S. Watanabe, D.J. Hollman, N. Noel, A. Sepe, U. Wiesner, R. Friend, H.J. Snaith, U. Steiner, Performance and Stability Enhancement of Dye-Sensitized and Perovskite Solar Cells by Al Doping of TiO2, Advanced Functional Materials. 24 (2014) 6046-6055.

[151] B. Roose, K.C. Godel, S. Pathak, A. Sadhanala, J.P.C. Baena, B.D. Wilts, H.J. Snaith, U. Wiesner, M. Gratzel, U. Steiner, A. Abate, Enhanced Efficiency and Stability of Perovskite Solar Cells Through Nd-Doping of Mesostructured TiO2, Advanced Energy Materials. 5 (2015) 1501868-n/a.

[152] A. Agresti, S. Pescetelli, L. Cina, D. Konios, G. Kakavelakis, E. Kymakis, A.D. Carlo, Efficiency and Stability Enhancement in Perovskite Solar Cells by Inserting LithiumNeutralized Graphene Oxide as Electron Transporting Layer, Advanced Functional Materials. 26 (2016) 2686-2694.

[153] J. Li, W. Li, H. Dong, N. Li, X. Guo, L. Wang, Enhanced performance in hybrid perovskite solar cell by modification with spinel lithium titanate, J. Mater. Chem. A. 3 (2015) 8882-8889. 
[154] J. Song, E. Zheng, J. Bian, X. Wang, W. Tian, Y. Sanehira, T. Miyasaka, Lowtemperature $\mathrm{SnO}$-based electron selective contact for efficient and stable perovskite solar cells, J. Mater. Chem. A. 3 (2015) 10837-10844.

[155] L. Xiong, M. Qin, G. Yang, Y. Guo, H. Lei, Q. Liu, W. Ke, H. Tao, P. Qin, S. Li, H. $\mathrm{Yu}, \mathrm{G}$. Fang, Performance enhancement of high temperature SnO2-based planar perovskite solar cells: electrical characterization and understanding of the mechanism, J.Mater.Chem.A. 4 (2016) 8374-8383.

[156] J.P. Correa Baena, L. Steier, W. Tress, M. Saliba, S. Neutzner, T. Matsui, F. Giordano, T.J. Jacobsson, A.R. Srimath Kandada, S.M. Zakeeruddin, A. Petrozza, A. Abate, M.K. Nazeeruddin, M. Gratzel, A. Hagfeldt, Highly efficient planar perovskite solar cells through band alignment engineering, Energy Environ. Sci. 8 (2015) 2928-2934.

[157] J. Duan, Q. Xiong, B. Feng, Y. Xu, J. Zhang, H. Wang, Low-temperature processed $\mathrm{SnO} 2$ compact layer for efficient mesostructure perovskite solar cells, Appl. Surf. Sci. 391, Part B (2017) 677.

[158] Q. Liu, M. Qin, W. Ke, X. Zheng, Z. Chen, P. Qin, L. Xiong, H. Lei, J. Wan, J. Wen, G. Yang, J. Ma, Z. Zhang, G. Fang, Enhanced Stability of Perovskite Solar Cells with LowTemperature Hydrothermally Grown $\mathrm{SnO} 2$ Electron Transport Layers, Advanced Functional Materials. 26 (2016) 6069-6075.

[159] Z. Zhu, Y. Bai, X. Liu, C. Chueh, S. Yang, A.K.-. Jen, Enhanced Efficiency and Stability of Inverted Perovskite Solar Cells Using Highly Crystalline SnO2 Nanocrystals as the Robust Electron-Transporting Layer, Adv Mater. 28 (2016) 6478-6484.

[160] E.H. Anaraki, A. Kermanpur, L. Steier, K. Domanski, T. Matsui, W. Tress, M. Saliba, A. Abate, M. Gratzel, A. Hagfeldt, J. Correa-Baena, Highly efficient and stable planar perovskite solar cells by solution-processed tin oxide, Energy Environ.Sci. 9 (2016) 31283134.

[161] X. Liu, C. Chueh, Z. Zhu, S.B. Jo, Y. Sun, A.K.-. Jen, Highly crystalline Zn2SnO4 nanoparticles as efficient electron-transporting layers toward stable inverted and flexible conventional perovskite solar cells, J.Mater.Chem.A. 4 (2016) 15294-15301.

[162] S.S. Shin, W.S. Yang, J.H. Noh, J.H. Suk, N.J. Jeon, J.H. Park, J.S. Kim, W.M. Seong, S.I. Seok, High-performance flexible perovskite solar cells exploiting $\mathrm{Zn}_{2} \mathrm{SnO}_{4}$ prepared in solution below $100{ }^{\circ} \mathrm{C}$, Nat Commun. 6 (2015) 7410.

[163] F.J. Ramos, M. Oliva-Ramirez, M.K. Nazeeruddin, M. Gratzel, A. Gonzalez-Elipe, S. Ahmad, Nanocolumnar 1-dimensional TiO2 photoanodes deposited by PVD-OAD for perovskite solar cell fabrication, J. Mater. Chem. A. 3 (2015) 13291-13298.

[164] A. Fakharuddin, F. Di Giacomo, A.L. Palma, F. Matteocci, I. Ahmed, S. Razza, A. D'Epifanio, S. Licoccia, J. Ismail, A. Di Carlo, T.M. Brown, R. Jose, Vertical TiO2 Nanorods as a Medium for Stable and High-Efficiency Perovskite Solar Modules, ACS Nano. 9 (2015) 8420-8429.

[165] P. Qin, M. Paulose, M.I. Dar, T. Moehl, N. Arora, P. Gao, O.K. Varghese, M. GrÃătzel, M.K. Nazeeruddin, Stable and Efficient Perovskite Solar Cells Based on Titania Nanotube Arrays, Small. 11 (2015) 5533-5539. 
[166] A. Fakharuddin, F. Di Giacomo, I. Ahmed, Q. Wali, T.M. Brown, R. Jose, Role of morphology and crystallinity of nanorod and planar electron transport layers on the performance and long term durability of perovskite solar cells, J. Power Sources. 283 (2015) 61-67.

[167] S.W. Tong, J. Balapanuru, D. Fu, K.P. Loh, Thermally Stable Mesoporous Perovskite Solar Cells Incorporating Low-Temperature Processed Graphene/Polymer Electron Transporting Layer, ACS Appl. Mater. Interfaces. 8 (2016) 29496-29503.

[168] T. Malinauskas, D. Tomkute-Luksiene, R. Sens, M. Daskeviciene, R. Send, H. Wonneberger, V. Jankauskas, I. Bruder, V. Getautis, Enhancing Thermal Stability and Lifetime of Solid-State Dye-Sensitized Solar Cells via Molecular Engineering of the HoleTransporting Material Spiro-OMeTAD, ACS Appl. Mater. Interfaces. 7 (2015) 11107-11116.

[169] S. Wang, W. Yuan, Y.S. Meng, Spectrum-Dependent Spiro-OMeTAD Oxidization Mechanism in Perovskite Solar Cells, ACS Appl. Mater. Interfaces. 7 (2015) 24791-24798.

[170] R.S. Sanchez, E. Mas-Marza, Light-induced effects on Spiro-OMeTAD films and hybrid lead halide perovskite solar cells, Solar Energy Mater. Solar Cells. 158 (2016) 189-194.

[171] Y. Dkhissi, H. Weerasinghe, S. Meyer, I. Benesperi, U. Bach, L. Spiccia, R.A. Caruso, Y. Cheng, Parameters responsible for the degradation of $\mathrm{CH} 3 \mathrm{NH} 3 \mathrm{PbI} 3$-based solar cells on polymer substrates, Nano Energy. 22 (2016) 211-222.

[172] B. Xu, J. Huang, H. Ågren, L. Kloo, A. Hagfeldt, L. Sun, AgTFSI as p-Type Dopant for Efficient and Stable Solid-State Dye-Sensitized and Perovskite Solar Cells, ChemSusChem. 7 (2014) 3252-3256.

[173] L. Huang, Z. Hu, J. Xu, K. Zhang, J. Zhang, J. Zhang, Y. Zhu, Efficient and stable planar perovskite solar cells with a non-hygroscopic small molecule oxidant doped hole transport layer, Electrochim. Acta. 196 (2016) 328-336.

[174] Q. Luo, Y. Zhang, C. Liu, J. Li, N. Wang, H. Lin, Iodide-reduced graphene oxide with dopant-free spiro-OMeTAD for ambient stable and high-efficiency perovskite solar cells, J.Mater.Chem.A. 3 (2015) 15996-16004.

[175] A.L. Palma, L. Cinà, S. Pescetelli, A. Agresti, M. Raggio, R. Paolesse, F. Bonaccorso, A. Di Carlo, Reduced graphene oxide as efficient and stable hole transporting material in mesoscopic perovskite solar cells, Nano Energy. 22 (2016) 349-360.

[176] T. Leijtens, T. Giovenzana, S.N. Habisreutinger, J.S. Tinkham, N.K. Noel, B.A. Kamino, G. Sadoughi, A. Sellinger, H.J. Snaith, Hydrophobic Organic Hole Transporters for Improved Moisture Resistance in Metal Halide Perovskite Solar Cells, ACS Appl. Mater. Interfaces. 8 (2016) 5981-5989.

[177] A. Dubey, N. Adhikari, S. Venkatesan, S. Gu, D. Khatiwada, Q. Wang, L. Mohammad, M. Kumar, Q. Qiao, Solution processed pristine PDPP3T polymer as hole transport layer for efficient perovskite solar cells with slower degradation, Solar Energy Mater. Solar Cells. 145, Part 3 (2016) 193-199.

[178] X. Zhao, F. Zhang, C. Yi, D. Bi, X. Bi, P. Wei, J. Luo, X. Liu, S. Wang, X. Li, S.M. Zakeeruddin, M. Gratzel, A novel one-step synthesized and dopant-free hole transport 
material for efficient and stable perovskite solar cells, J.Mater.Chem.A. 4 (2016) 1633016334.

[179] J. Liu, Y. Wu, C. Qin, X. Yang, T. Yasuda, A. Islam, K. Zhang, W. Peng, W. Chen, L. Han, A dopant-free hole-transporting material for efficient and stable perovskite solar cells, Energy Environ.Sci. 7 (2014) 2963-2967.

[180] F. Zhang, C. Yi, P. Wei, X. Bi, J. Luo, G. Jacopin, S. Wang, X. Li, Y. Xiao, S.M. Zakeeruddin, M. Gratzel, A Novel Dopant-Free Triphenylamine Based Molecular "Butterfly" Hole-Transport Material for Highly Efficient and Stable Perovskite Solar Cells, Advanced Energy Materials. 6 (2016) 1600401-n/a.

[181] F. Zhang, X. Zhao, C. Yi, D. Bi, X. Bi, P. Wei, X. Liu, S. Wang, X. Li, S.M. Zakeeruddin, M. Gratzel, Dopant-free star-shaped hole-transport materials for efficient and stable perovskite solar cells, Dyes and Pigments. 136 (2017) 273-277.

[182] T. Matsui, I. Petrikyte, T. Malinauskas, K. Domanski, M. Daskeviciene, M. Steponaitis, P. Gratia, W. Tress, J. Correa-Baena, A. Abate, A. Hagfeldt, M. GrÃatzel, M.K. Nazeeruddin, V. Getautis, M. Saliba, Additive-Free Transparent Triarylamine-Based Polymeric HoleTransport Materials for Stable Perovskite Solar Cells, ChemSusChem. 9 (2016) 2567-2571.

[183] G. Kim, G. Kang, J. Kim, G.Y. Lee, H.I. Kim, L. Pyeon, J. Lee, T. Park, Dopant-free Polymeric Hole Transport Material for Highly Efficient and Stable Perovskite Solar Cells, Energy Environ.Sci. 9 (2016) 2326-2333.

[184] Y. Wang, Z. Yuan, G. Shi, Y. Li, Q. Li, F. Hui, B. Sun, Z. Jiang, L. Liao, Dopant-Free Spiro-Triphenylamine/Fluorene as Hole-Transporting Material for Perovskite Solar Cells with Enhanced Efficiency and Stability, Advanced Functional Materials. 26 (2016) 1375-1381.

[185] F. Zhang, X. Yang, M. Cheng, W. Wang, L. Sun, Boosting the efficiency and the stability of low cost perovskite solar cells by using CuPc nanorods as hole transport material and carbon as counter electrode, Nano Energy. 20 (2016) 108-116.

[186] Z. Hawash, L.K. Ono, S.R. Raga, M.V. Lee, Y. Qi, Air-Exposure Induced Dopant Redistribution and Energy Level Shifts in Spin-Coated Spiro-MeOTAD Films, Chem. Mater. 27 (2015) 562-569.

[187] M. Jung, S.R. Raga, L.K. Ono, Y. Qi, Substantial improvement of perovskite solar cells stability by pinhole-free hole transport layer with doping engineering, Sci. Rep. 5 (2015) 09863.

[188] L.K. Ono, S.R. Raga, M. Remeika, A.J. Winchester, A. Gabe, Y. Qi, Pinhole-free hole transport layers significantly improve the stability of MAPbI3-based perovskite solar cells under operating conditions, J. Mater. Chem. A. 3 (2015) 15451-15456.

[189] M. Li, Z. Wang, Y. Yang, Y. Hu, S. Feng, J. Wang, X. Gao, L. Liao, Copper Salts Doped Spiro-OMeTAD for High-Performance Perovskite Solar Cells, Advanced Energy Materials. 6 (2016) 1601156-n/a.

[190] Y. Kato, L.K. Ono, M.V. Lee, S. Wang, S.R. Raga, Y. Qi, Silver Iodide Formation in Methyl Ammonium Lead Iodide Perovskite Solar Cells with Silver Top Electrodes, Advanced Materials Interfaces. 2 (2015) 1500195. 
[191] S.S. Madhu, P. Nagarjuna, P.N. Kumar, S.P. Singh, M. Deepa, M.A.G. Namboothiry, Efficient organic-inorganic hybrid perovskite solar cells processed in air, Phys. Chem. Chem. Phys. 16 (2014) 24691-24696.

[192] S.N. Habisreutinger, T. Leijtens, G.E. Eperon, S.D. Stranks, R.J. Nicholas, H.J. Snaith, Carbon Nanotube/Polymer Composites as a Highly Stable Hole Collection Layer in Perovskite Solar Cells, Nano Lett. 14 (2014) 5561-5568.

[193] S.S. Reddy, K. Gunasekar, J.H. Heo, S.H. Im, C.S. Kim, D. Kim, J.H. Moon, J.Y. Lee, M. Song, S. Jin, Highly Efficient Organic Hole Transporting Materials for Perovskite and Organic Solar Cells with Long-Term Stability, Adv Mater. 28 (2016) 686-693.

[194] J. Cao, Y. Liu, X. Jing, J. Yin, J. Li, B. Xu, Y. Tan, N. Zheng, Well-Defined Thiolated Nanographene as Hole-Transporting Material for Efficient and Stable Perovskite Solar Cells, J. Am. Chem. Soc. 137 (2015) 10914-10917.

[195] L. Zheng, Y. Chung, Y. Ma, L. Zhang, L. Xiao, Z. Chen, S. Wang, B. Qu, Q. Gong, A hydrophobic hole transporting oligothiophene for planar perovskite solar cells with improved stability, Chem. Commun. 50 (2014) 11196-11199.

[196] X. Liu, L. Zhu, F. Zhang, J. You, Y. Xiao, D. Li, S. Wang, Q. Meng, X. Li, Stable Perovskite Solar Cells based on Hydrophobic Triphenylamine Hole-Transport Materials, Energy Technology. (2016) 1600303-n/a.

[197] X. Liu, F. Kong, Z. Tan, T. Cheng, W. Chen, T. Yu, F. Guo, J. Chen, J. Yao, S. Dai, Diketopyrrolopyrrole or benzodithiophene-arylamine small-molecule hole transporting materials for stable perovskite solar cells, RSC Adv. 6 (2016) 87454-87460.

[198] Z. Li, Z. Zhu, C. Chueh, J. Luo, A.K.-. Jen, Facile Thiol-Ene Thermal Crosslinking Reaction Facilitated Hole-Transporting Layer for Highly Efficient and Stable Perovskite Solar Cells, Advanced Energy Materials. (2016) 1601165-n/a.

[199] J. Ye, X. Li, J. Zhao, X. Mei, Q. Li, Efficient and stable perovskite solar cells based on functional graphene-modified P3HT hole-transporting layer, RSC Adv. 6 (2016) 3635636361 .

[200] T. Gatti, S. Casaluci, M. Prato, M. Salerno, F. Di Stasio, A. Ansaldo, E. Menna, A. Di Carlo, F. Bonaccorso, Boosting Perovskite Solar Cells Performance and Stability through Doping a Poly-3(hexylthiophene) Hole Transporting Material with Organic Functionalized Carbon Nanostructures, Advanced Functional Materials. 26 (2016) 7443-7453.

[201] M. Park, J. Park, I.K. Han, J.Y. Oh, High-performance flexible and air-stable perovskite solar cells with a large active area based on poly(3-hexylthiophene) nanofibrils, J.Mater.Chem.A. 4 (2016) 11307-11316.

[202] F. Wang, M. Endo, S. Mouri, Y. Miyauchi, Y. Ohno, A. Wakamiya, Y. Murata, K. Matsuda, Highly stable perovskite solar cells with an all-carbon hole transport layer, Nanoscale. 8 (2016) 11882-11888.

[203] P. Su, Y. Chen, J. Liu, L. Xiao, D. Kuang, M. Mayor, C. Su, Hydrophobic HoleTransporting Materials Incorporating Multiple Thiophene Cores with Long Alkyl Chains for Efficient Perovskite Solar Cells, Electrochim. Acta. 209 (2016) 529-540. 
[204] K. Liu, Y. Yao, J. Wang, L. Zhu, M. Sun, B. Ren, L. Xie, Y. Luo, Q. Meng, X. Zhan, Spiro[fluorene-9,9[prime or minute]-xanthene]-based hole transporting materials for efficient perovskite solar cells with enhanced stability, Mater.Chem.Front. 1 (2017) 100-110.

[205] Y.S. Kwon, J. Lim, H. Yun, Y. Kim, T. Park, A diketopyrrolopyrrole-containing hole transporting conjugated polymer for use in efficient stable organic-inorganic hybrid solar cells based on a perovskite, Energy Environ. Sci. 7 (2014) 1454-1460.

[206] S. Lv, L. Han, J. Xiao, L. Zhu, J. Shi, H. Wei, Y. Xu, J. Dong, X. Xu, D. Li, S. Wang, Y. Luo, Q. Meng, X. Li, Mesoscopic TiO2/CH3NH3PbI3 perovskite solar cells with new hole-transporting materials containing butadiene derivatives, Chem. Commun. 50 (2014) 6931-6934.

[207] Y. Xiao, G. Han, Y. Chang, H. Zhou, M. Li, Y. Li, An all-solid-state perovskitesensitized solar cell based on the dual function polyaniline as the sensitizer and p-type holetransporting material, J. Power Sources. 267 (2014) 1-8.

[208] J. Wang, Y. Chen, M. Liang, G. Ge, R. Zhou, Z. Sun, S. Xue, A new thermal-stable truxene-based hole-transporting material for perovskite solar cells, Dyes and Pigments. 125 (2016) 399-406.

[209] S. Ito, S. Tanaka, H. Vahlman, H. Nishino, K. Manabe, P. Lund, Carbon-Double-BondFree Printed Solar Cells from TiO2/CH3NH3PbI3/CuSCN/Au: Structural Control and Photoaging Effects, ChemPhysChem. 15 (2014) 1194-1200.

[210] J.H. Noh, S.H. Im, J.H. Heo, T.N. Mandal, S.I. Seok, Chemical Management for Colorful, Efficient, and Stable Inorganic-Organic Hybrid Nanostructured Solar Cells, Nano Lett. 13 (2013) 1764-1769.

[211] Q. Wang, C. Chueh, M. Eslamian, A.K.-. Jen, Modulation of PEDOT:PSS pH for Efficient Inverted Perovskite Solar Cells with Reduced Potential Loss and Enhanced Stability, ACS Appl. Mater. Interfaces. 8 (2016) 32068-32076.

[212] J.H. Kim, P. Liang, S.T. Williams, N. Cho, C. Chueh, M.S. Glaz, D.S. Ginger, A.K.-. Jen, High-Performance and Environmentally Stable Planar Heterojunction Perovskite Solar Cells Based on a Solution-Processed Copper-Doped Nickel Oxide Hole-Transporting Layer, Adv Mater. 27 (2015) 695-701.

[213] H. Zhang, J. Cheng, F. Lin, H. He, J. Mao, K.S. Wong, A.K.-. Jen, W.C.H. Choy, Pinhole-Free and Surface-Nanostructured NiOx Film by Room-Temperature Solution Process for High-Performance Flexible Perovskite Solar Cells with Good Stability and Reproducibility, ACS Nano. 10 (2016) 1503-1511.

[214] U. Kwon, B. Kim, D.C. Nguyen, J. Park, N.Y. Ha, S. Kim, S.H. Ko, S. Lee, D. Lee, H.J. Park, Solution-Processible Crystalline NiO Nanoparticles for High-Performance Planar Perovskite Photovoltaic Cells, Scientific Reports. 6 (2016) 30759.

[215] A. Huang, J. Zhu, J. Zheng, Y. Yu, Y. Liu, S. Yang, S. Bao, L. Lei, P. Jin, Achieving high-performance planar perovskite solar cells with co-sputtered Co-doping NiOx hole transport layers by efficient extraction and enhanced mobility, J.Mater.Chem.C. 4 (2016) 10839-10846. 
[216] J. Yeo, R. Kang, S. Lee, Y. Jeon, N. Myoung, C. Lee, D. Kim, J. Yun, Y. Seo, S. Kim, $\mathrm{S}$. Na, Highly efficient and stable planar perovskite solar cells with reduced graphene oxide nanosheets as electrode interlayer, Nano Energy. 12 (2015) 96-104.

[217] D. Lee, S. Na, S. Kim, Graphene oxide/PEDOT:PSS composite hole transport layer for efficient and stable planar heterojunction perovskite solar cells, Nanoscale. 8 (2016) 15131522.

[218] H. Chen, Y. Hou, C.E. Halbig, S. Chen, H. Zhang, N. Li, F. Guo, X. Tang, N. Gasparini, I. Levchuk, S. Kahmann, C.O. Ramirez Quiroz, A. Osvet, S. Eigler, C.J. Brabec, Extending the environmental lifetime of unpackaged perovskite solar cells through interfacial design, J.Mater.Chem.A. 4 (2016) 11604-11610.

[219] J. Kim, M.A. Mat Teridi, A. Mohd Yusoff Rashid bin, J. Jang, Stable and null current hysteresis perovskite solar cells based nitrogen doped graphene oxide nanoribbons hole transport layer, Scientific Reports. 6 (2016) 27773.

[220] J.W. Jo, M. Seo, M. Park, J. Kim, J.S. Park, I.K. Han, H. Ahn, J.W. Jung, B. Sohn, M.J. Ko, H.J. Son, Improving Performance and Stability of Flexible Planar-Heterojunction Perovskite Solar Cells Using Polymeric Hole-Transport Material, Advanced Functional Materials. (2016) 1600746-n/a.

[221] W.J. Jo, J.T. Nelson, S. Chang, V. Bulovic, S. Gradec $\square$ ak, M.S. Strano, K.K. Gleason, Oxidative Chemical Vapor Deposition of Neutral Hole Transporting Polymer for Enhanced Solar Cell Efficiency and Lifetime, Adv Mater. 28 (2016) 6399-6404.

[222] W. Chen, L. Deng, S. Dai, X. Wang, C. Tian, X. Zhan, S. Xie, R. Huang, L. Zheng, Low-cost solution-processed copper iodide as an alternative to PEDOT:PSS hole transport layer for efficient and stable inverted planar heterojunction perovskite solar cells, J. Mater. Chem. A. 3 (2015) 19353-19359.

[223] W. Chen, Y. Wu, Y. Yue, J. Liu, W. Zhang, X. Yang, H. Chen, E. Bi, I. Ashraful, M. GrÃatzel, L. Han, Efficient and stable large-area perovskite solar cells with inorganic charge extraction layers, Science. 350 (2015) 944-948.

[224] W. Sun, Y. Li, S. Ye, H. Rao, W. Yan, H. Peng, Y. Li, Z. Liu, S. Wang, Z. Chen, L. Xiao, Z. Bian, C. Huang, High-performance inverted planar heterojunction perovskite solar cells based on a solution-processed $\mathrm{CuOx}$ hole transport layer, Nanoscale. 8 (2016) 1080610813.

[225] Z. Yu, W. Fu, W. Liu, Z. Zhang, Y. Liu, J. Yan, T. Ye, W. Yang, H. Li, H. Chen, Solution-processed $\mathrm{CuOx}$ as an efficient hole-extraction layer for inverted planar heterojunction perovskite solar cells, Chinese Chemical Letters. 28 (2016) 13-18.

[226] M. Jung, Y.C. Kim, N.J. Jeon, W.S. Yang, J. Seo, J.H. Noh, S. Ilâ€...Seok, Thermal Stability of CuSCN Hole Conductor-Based Perovskite Solar Cells, ChemSusChem. 9 (2016) 2592-2596.

[227] J. Liu, S.K. Pathak, N. Sakai, R. Sheng, S. Bai, Z. Wang, H.J. Snaith, Identification and Mitigation of a Critical Interfacial Instability in Perovskite Solar Cells Employing Copper Thiocyanate Hole-Transporter, Advanced Materials Interfaces. 3 (2016) 1600571-n/a. 
[228] J.A. Christians, R.C.M. Fung, P.V. Kamat, An Inorganic Hole Conductor for OrganoLead Halide Perovskite Solar Cells. Improved Hole Conductivity with Copper Iodide, J. Am. Chem. Soc. 136 (2014) 758-764.

[229] B.A. Nejand, V. Ahmadi, S. Gharibzadeh, H.R. Shahverdi, Cuprous Oxide as a Potential Low-Cost Hole-Transport Material for Stable Perovskite Solar Cells, ChemSusChem. 9 (2016) 302-313.

[230] H. Rao, W. Sun, S. Ye, W. Yan, Y. Li, H. Peng, Z. Liu, Z. Bian, C. Huang, SolutionProcessed CuS NPs as an Inorganic Hole-Selective Contact Material for Inverted Planar Perovskite Solar Cells, ACS Appl. Mater. Interfaces. 8 (2016) 7800-7805.

[231] A. Mei, X. Li, L. Liu, Z. Ku, T. Liu, Y. Rong, M. Xu, M. Hu, J. Chen, Y. Yang, M. Grätzel, H. Han, A hole-conductor-free, fully printable mesoscopic perovskite solar cell with high stability, Science. 345 (2014) 295-298.

[232] X. Li, M. Tschumi, H. Han, S.S. Babkair, R.A. Alzubaydi, A.A. Ansari, S.S. Habib, M.K. Nazeeruddin, S.M. Zakeeruddin, M. GrÃatzel, Outdoor Performance and Stability under Elevated Temperatures and Long-Term Light Soaking of Triple-Layer Mesoporous Perovskite Photovoltaics, Energy Technology. 3 (2015) 551-555.

[233] F. Zhang, X. Yang, H. Wang, M. Cheng, J. Zhao, L. Sun, Structure Engineering of Hole-Conductor Free Perovskite-Based Solar Cells with Low-Temperature-Processed Commercial Carbon Paste As Cathode, ACS Appl. Mater. Interfaces. 6 (2014) 16140-16146.

[234] Z. Yu, B. Chen, P. Liu, C. Wang, C. Bu, N. Cheng, S. Bai, Y. Yan, X. Zhao, Stable Organicâ€"Inorganic Perovskite Solar Cells without Hole-Conductor Layer Achieved via Cell Structure Design and Contact Engineering, Advanced Functional Materials. 26 (2016) 48664873.

[235] A.K. Baranwal, S. Kanaya, T.A.N. Peiris, G. Mizuta, T. Nishina, H. Kanda, T. Miyasaka, H. Segawa, S. Ito, $100 \hat{a} € \% 0 \hat{A}^{\circ} \mathrm{C}$ Thermal Stability of Printable Perovskite Solar Cells Using Porous Carbon Counter Electrodes, ChemSusChem. 9 (2016) 2604-2608.

[236] S. Ito, G. Mizuta, S. Kanaya, H. Kanda, T. Nishina, S. Nakashima, H. Fujisawa, M. Shimizu, Y. Haruyama, H. Nishino, Light stability tests of CH3NH3PbI3 perovskite solar cells using porous carbon counter electrodes, Phys.Chem.Chem.Phys. 18 (2016) 27102-27108.

[237] S.G. Hashmi, D. Martineau, X. Li, M. Ozkan, A. Tiihonen, M.I. Dar, T. Sarikka, S.M. Zakeeruddin, J. Paltakari, P.D. Lund, M. GrÃătzel, Air Processed Inkjet Infiltrated Carbon Based Printed Perovskite Solar Cells with High Stability and Reproducibility, Advanced Materials Technologies. 2 (2017) 1600183-n/a.

[238] A.D. Sheikh, A. Bera, M.A. Haque, R.B. Rakhi, S.D. Gobbo, H.N. Alshareef, T. Wu, Atmospheric effects on the photovoltaic performance of hybrid perovskite solar cells, Solar Energy Mater. Solar Cells. 137 (2015) 6-14.

[239] S. Aharon, B.E. Cohen, L. Etgar, Hybrid Lead Halide Iodide and Lead Halide Bromide in Efficient Hole Conductor Free Perovskite Solar Cell, J. Phys. Chem. C. 118 (2014) 1716017165 .

[240] W. Liu, Y. Zhang, Electrical characterization of TiO2/CH3NH3PbI3 heterojunction solar cells, J. Mater. Chem. A. 2 (2014) 10244-10249. 
[241] D. Wei, T. Wang, J. Ji, M. Li, P. Cui, Y. Li, G. Li, J.M. Mbengue, D. Song, Photoinduced degradation of lead halide perovskite solar cells caused by the hole transport layer/metal electrode interface, J.Mater.Chem.A. 4 (2016) 1991-1998.

[242] S. Shao, Z. Chen, H.-. Fang, G.H. ten Brink, D. Bartesaghi, S. Adjokatse, L.J.A. Koster, B.J. Kooi, A. Facchetti, M.A. Loi, N-type polymers as electron extraction layers in hybrid perovskite solar cells with improved ambient stability, J.Mater.Chem.A. 4 (2016) 2419-2426.

[243] Z. Jiang, X. Chen, X. Lin, X. Jia, J. Wang, L. Pan, S. Huang, F. Zhu, Z. Sun, Amazing stable open-circuit voltage in perovskite solar cells using AgAl alloy electrode, Solar Energy Mater. Solar Cells. 146 (2016) 35-43.

[244] J. You, L. Meng, T. Song, T. Guo, Y.(. Yang, W. Chang, Z. Hong, H. Chen, H. Zhou, Q. Chen, Y. Liu, N. De Marco, Y. Yang, Improved air stability of perovskite solar cells via solution-processed metal oxide transport layers, Nat Nano. 11 (2016) 75-81.

[245] A. Guerrero, J. You, C. Aranda, Y.S. Kang, G. Garcia-Belmonte, H. Zhou, J. Bisquert, Y. Yang, Interfacial Degradation of Planar Lead Halide Perovskite Solar Cells, ACS Nano. 10 (2016) 218-224.

[246] G. Zhang, S.A. Hawks, C. Ngo, L.T. Schelhas, D.T. Scholes, H. Kang, J.C. Aguirre, S.H. Tolbert, B.J. Schwartz, Extensive Penetration of Evaporated Electrode Metals into Fullerene Films: Intercalated Metal Nanostructures and Influence on Device Architecture, ACS Appl. Mater. Interfaces. 7 (2015) 25247-25258.

[247] H. Sohrabpoor, G. Puccetti, N.E. Gorji, Modeling the degradation and recovery of perovskite solar cells, RSC Adv. 6 (2016) 49328-49334.

[248] J. Xiong, B. Yang, C. Cao, R. Wu, Y. Huang, J. Sun, J. Zhang, C. Liu, S. Tao, Y. Gao, J. Yang, Interface degradation of perovskite solar cells and its modification using an annealing-free TiO2 NPs layer, Organic Electronics. 30 (2016) 30-35.

[249] X. Dai, Y. Zhang, H. Shen, Q. Luo, X. Zhao, J. Li, H. Lin, Working from Both Sides: Composite Metallic Semitransparent Top Electrode for High Performance Perovskite Solar Cells, ACS Appl. Mater. Interfaces. 8 (2016) 4523-4531.

[250] E.M. Sanehira, d.V. Tremolet, P. Schulz, M.O. Reese, S. Ferrere, K. Zhu, L.Y. Lin, J.J. Berry, J.M. Luther, Influence of Electrode Interfaces on the Stability of Perovskite Solar Cells: Reduced Degradation Using MoOx/Al for Hole Collection, ACS Energy Lett. (2016) 38-45.

[251] L. Zhao, R.A. Kerner, Z. Xiao, Y.L. Lin, K.M. Lee, J. Schwartz, B.P. Rand, Redox Chemistry Dominates the Degradation and Decomposition of Metal Halide Perovskite Optoelectronic Devices, ACS Energy Lett. 1 (2016) 595-602.

[252] K. Domanski, J. Correa-Baena, N. Mine, M.K. Nazeeruddin, A. Abate, M. Saliba, W. Tress, A. Hagfeldt, M. GrÃătzel, Not All That Glitters Is Gold: Metal-Migration-Induced Degradation in Perovskite Solar Cells, ACS Nano. 10 (2016) 6306-6314.

[253] H. Back, G. Kim, J. Kim, J. Kong, T.K. Kim, H. Kang, H. Kim, J. Lee, S. Lee, K. Lee, Achieving long-term stable perovskite solar cells via ion neutralization, Energy Environ.Sci. 9 (2016) 1258-1263. 
[254] J.M. Azpiroz, E. Mosconi, J. Bisquert, F. De Angelis, Defect migration in methylammonium lead iodide and its role in perovskite solar cell operation, Energy Environ. Sci. 8 (2015) 2118-2127.

[255] J. Xu, A. Buin, A.H. Ip, W. Li, O. Voznyy, R. Comin, M. Yuan, S. Jeon, Z. Ning, J.J. McDowell, P. Kanjanaboos, J. Sun, X. Lan, L.N. Quan, D.H. Kim, I.G. Hill, P. Maksymovych, E.H. Sargent, Perovskite-fullerene hybrid materials suppress hysteresis in planar diodes, Nat Commun. 6 (2015) 7081.

[256] I. Jeong, H. Jin Kim, B. Lee, H. Jung Son, J. Young Kim, D. Lee, D. Kim, J. Lee, M.J. Ko, Highly efficient perovskite solar cells based on mechanically durable molybdenum cathode, Nano Energy. 17 (2015) 131-139.

[257] Y. Deng, Q. Dong, C. Bi, Y. Yuan, J. Huang, Air-Stable, Efficient Mixed-Cation Perovskite Solar Cells with $\mathrm{Cu}$ Electrode by Scalable Fabrication of Active Layer, Advanced Energy Materials. 6 (2016) 1600372.

[258] J. Zhao, X. Zheng, Y. Deng, T. Li, Y. Shao, A. Gruverman, J. Shield, J. Huang, Is Cu a stable electrode material in hybrid perovskite solar cells for a 30-year lifetime? Energy Environ.Sci. 9 (2016) 3650-3656.

[259] X. Jia, Z. Jiang, X. Chen, J. Zhou, L. Pan, F. Zhu, Z. Sun, S. Huang, Highly Efficient and Air Stable Inverted Polymer Solar Cells Using LiF-Modified ITO Cathode and MoO3/AgAl Alloy Anode, ACS Appl. Mater. Interfaces. 8 (2016) 3792-3799.

[260] Y. Luo, X. Chen, C. Zhang, J. Li, J. Shi, Z. Sun, Z. Wang, S. Huang, AgAl alloy electrode for efficient perovskite solar cells, RSC Adv. 5 (2015) 56037-56044.

[261] K.A. Bush, C.D. Bailie, Y. Chen, A.R. Bowring, W. Wang, W. Ma, T. Leijtens, F. Moghadam, M.D. McGehee, Thermal and Environmental Stability of Semi-Transparent Perovskite Solar Cells for Tandems Enabled by a Solution-Processed Nanoparticle Buffer Layer and Sputtered ITO Electrode, Adv Mater. 28 (2016) 3937-3943.

[262] E.W. Jones, P.J. Holliman, A. Connell, M.L. Davies, J. Baker, R.J. Hobbs, S. Ghosh, L. Furnell, R. Anthony, C. Pleydell-Pearce, A novel dimethylformamide (DMF) free bar-cast method to deposit organolead perovskite thin films with improved stability, Chem.Commun. 52 (2016) 4301-4304.

[263] P.J. Holliman, E.W. Jones, A. Connell, S. Ghosh, L. Furnell, R.J. Hobbs, Solvent issues during processing and device lifetime for perovskite solar cells, Materials Research Innovations. 19 (2015) 508-511.

[264] K.K. Bass, R.E. McAnally, S. Zhou, P.I. Djurovich, M.E. Thompson, B.C. Melot, Influence of moisture on the preparation, crystal structure, and photophysical properties of organohalide perovskites, Chem. Commun. 50 (2014) 15819-15822.

[265] G.E. Eperon, S.N. Habisreutinger, T. Leijtens, B.J. Bruijnaers, J.J. van Franeker, D.W. deQuilettes, S. Pathak, R.J. Sutton, G. Grancini, D.S. Ginger, R.A.J. Janssen, A. Petrozza, H.J. Snaith, The Importance of Moisture in Hybrid Lead Halide Perovskite Thin Film Fabrication, ACS Nano. 9 (2015) 9380-9393.

[266] C. Brownlee, Best Bet Is Wet for Hybrid Lead Halide Perovskite Films, ACS Nano. 9 (2015) 8641-8643. 
[267] B. Conings, A. Babayigit, T. Vangerven, J. D'Haen, J. Manca, H. Boyen, The impact of precursor water content on solution-processed organometal halide perovskite films and solar cells, J. Mater. Chem. A. 3 (2015) 19123-19128.

[268] M.K. Gangishetty, R.W.J. Scott, T.L. Kelly, Effect of relative humidity on crystal growth, device performance and hysteresis in planar heterojunction perovskite solar cells, Nanoscale. 8 (2016) 6300-6307.

[269] B. Jeong, S.M. Cho, S.H. Cho, J.H. Lee, I. Hwang, S.K. Hwang, J. Cho, T. Lee, C. Park, Humidity controlled crystallization of thin $\mathrm{CH} 3 \mathrm{NH} 3 \mathrm{PbI} 3$ films for high performance perovskite solar cell, physica status solidi (RRL) -Rapid Research Letters. 10 (2016) 381-387.

[270] R. Long, W. Fang, O.V. Prezhdo, Moderate Humidity Delays Electron-Hole Recombination in Hybrid Organic-Inorganic Perovskites: Time-Domain Ab Initio Simulations Rationalize Experiments, J. Phys. Chem. Lett. 7 (2016) 3215-3222.

[271] J. You, Y.(. Yang, Z. Hong, T. Song, L. Meng, Y. Liu, C. Jiang, H. Zhou, W. Chang, G. $\mathrm{Li}$, Y. Yang, Moisture assisted perovskite film growth for high performance solar cells, Applied Physics Letters. 105 (2014) 183902.

[272] B. Wang, Z. Zhang, S. Ye, H. Rao, Z. Bian, C. Huang, Y. Li, Room-temperature watervapor annealing for high-performance planar perovskite solar cells, J.Mater.Chem.A. 4 (2016) 17267-17273.

[273] S. Wozny, M. Yang, A.M. Nardes, C.C. Mercado, S. Ferrere, M.O. Reese, W. Zhou, K. Zhu, Controlled Humidity Study on the Formation of Higher Efficiency Formamidinium Lead Triiodide-Based Solar Cells, Chem. Mater. 27 (2015) 4814-4820.

[274] A.M. Soufiani, M.J.Y. Tayebjee, S. Meyer, A. Ho-Baillie, J. Sung Yun, R.W. MacQueen, L. Spiccia, M.A. Green, Z. Hameiri, Electro- and photoluminescence imaging as fast screening technique of the layer uniformity and device degradation in planar perovskite solar cells, J. Appl. Phys. 120 (2016) 035702.

[275] Y. Xu, L. Zhu, J. Shi, X. Xu, J. Xiao, J. Dong, H. Wu, Y. Luo, D. Li, Q. Meng, The Effect of Humidity upon the Crystallization Process of Two-Step Spin-Coated Organicâ€"Inorganic Perovskites, ChemPhysChem. 17 (2016) 112-118.

[276] W. Zhou, Y. Zhao, C. Shi, H. Huang, J. Wei, R. Fu, K. Liu, D. Yu, Q. Zhao, Reversible Healing Effect of Water Molecules on Fully Crystallized Metal-Halide Perovskite Film, J. Phys. Chem. C. 120 (2016) 4759-4765.

[277] C. Qin, T. Matsushima, T. Fujihara, W.J. Potscavage, C. Adachi, Degradation Mechanisms of Solution-Processed Planar Perovskite Solar Cells: Thermally Stimulated Current Measurement for Analysis of Carrier Traps, Adv Mater. 28 (2016) 466-471.

[278] B. Wang, T. Chen, Exceptionally Stable CH3NH3PbI3 Films in Moderate Humid Environmental Condition, Advanced Science. 3 (2016) 1500262-n/a.

[279] T.P. Gujar, M. Thelakkat, Highly Reproducible and Efficient Perovskite Solar Cells with Extraordinary Stability from Robust CH3NH3PbI3: Towards Large-Area Devices, Energy Technology. 4 (2016) 449-457. 
[280] H. Yen, P. Liang, C. Chueh, Z. Yang, A.K.-. Jen, H. Wang, Large Grained Perovskite Solar Cells Derived from Single-Crystal Perovskite Powders with Enhanced Ambient Stability, ACS Appl. Mater. Interfaces. 8 (2016) 14513-14520.

[281] J. Zhang, Y. Zhao, D. Yang, C. Li, S. Liu, Highly stabilized perovskite solar cell prepared using vacuum deposition, RSC Adv. 6 (2016) 93525-93531.

[282] K.C. Kwon, K. Hong, Q. Van Le, S.Y. Lee, J. Choi, K. Kim, S.Y. Kim, H.W. Jang, Inhibition of Ion Migration for Reliable Operation of Organolead Halide Perovskite-Based Metal/Semiconductor/Metal Broadband Photodetectors, Advanced Functional Materials. 26 (2016) 4213-4222.

[283] Y. Cheng, H. Li, J. Qing, Q. Yang, Z. Guan, C. Liu, S.H. Cheung, S.K. So, C. Lee, S. Tsang, The detrimental effect of excess mobile ions in planar $\mathrm{CH} 3 \mathrm{NH} 3 \mathrm{PbI} 3$ perovskite solar cells, J.Mater.Chem.A. 4 (2016) 12748-12755.

[284] Y. Zhang, Y. Wang, Z. Xu, J. Liu, J. Song, Y. Xue, Z. Wang, J. Zheng, L. Jiang, C. Zheng, F. Huang, B. Sun, Y. Cheng, Q. Bao, Reversible Structural Swell-Shrink and Recoverable Optical Properties in Hybrid Inorganicâ€"Organic Perovskite, ACS Nano. 10 (2016) 7031-7038.

[285] D.A. Egger, L. Kronik, A.M. Rappe, Theory of Hydrogen Migration in OrganicInorganic Halide Perovskites, Angew. Chem. Int. Ed. 54 (2015) 12437-12411.

[286] J. Haruyama, K. Sodeyama, L. Han, Y. Tateyama, First-Principles Study of Ion Diffusion in Perovskite Solar Cell Sensitizers, J. Am. Chem. Soc. 137 (2015) 10048-10051.

[287] D. Yang, W. Ming, H. Shi, L. Zhang, M. Du, Fast Diffusion of Native Defects and Impurities in Perovskite Solar Cell Material CH3NH3PbI3, Chem. Mater. 28 (2016) 43494357.

[288] Z. Xiao, Y. Yuan, Y. Shao, Q. Wang, Q. Dong, C. Bi, P. Sharma, A. Gruverman, J. Huang, Giant switchable photovoltaic effect in organometal trihalide perovskite devices, Nat Mater. 14 (2015) 193-198.

[289] Y. Yuan, J. Chae, Y. Shao, Q. Wang, Z. Xiao, A. Centrone, J. Huang, Photovoltaic Switching Mechanism in Lateral Structure Hybrid Perovskite Solar Cells, Advanced Energy Materials. 5 (2015) 1500615-n/a.

[290] Y. Yuan, Q. Wang, Y. Shao, H. Lu, T. Li, A. Gruverman, J. Huang, Electric-FieldDriven Reversible Conversion Between Methylammonium Lead Triiodide Perovskites and Lead Iodide at Elevated Temperatures, Advanced Energy Materials. 6 (2016) 1501803-n/a.

[291] J. Yang, W. Yin, J. Park, S. Wei, Fast self-diffusion of ions in CH3NH3PbI3: the interstiticaly mechanism versus vacancy-assisted mechanism, J.Mater.Chem.A. 4 (2016) 13105-13112.

[292] J. Xing, Q. Wang, Q. Dong, Y. Yuan, Y. Fang, J. Huang, Ultrafast ion migration in hybrid perovskite polycrystalline thin films under light and suppression in single crystals, Phys.Chem.Chem.Phys. 18 (2016) 30484-30490. 
[293] S. Cacovich, G. Divitini, C. Ireland, F. Matteocci, A. Diâ€...Carlo, C. Ducati, Elemental Mapping of Perovskite Solar Cells by Using Multivariate Analysis: An Insight into Degradation Processes, ChemSusChem. 9 (2016) 2673-2678.

[294] D.W. deQuilettes, W. Zhang, V.M. Burlakov, D.J. Graham, T. Leijtens, A. Osherov, V. Bulovic, H.J. Snaith, D.S. Ginger, S.D. Stranks, Photo-induced halide redistribution in organic-inorganic perovskite films, Nat Commun. 7 (2016) 11683.

[295] M. De Bastiani, G. Dell'Erba, M. Gandini, V. D'Innocenzo, S. Neutzner, A.R.S. Kandada, G. Grancini, M. Binda, M. Prato, J.M. Ball, M. Caironi, A. Petrozza, Ion Migration and the Role of Preconditioning Cycles in the Stabilization of the J-V Characteristics of Inverted Hybrid Perovskite Solar Cells, Advanced Energy Materials. 5 (2015) 1501453-n/a.

[296] Y. Deng, Z. Xiao, J. Huang, Light-Induced Self-Poling Effect on Organometal Trihalide Perovskite Solar Cells for Increased Device Efficiency and Stability, Advanced Energy Materials. 5 (2015) 1500721-n/a.

[297] T. Leijtens, E.T. Hoke, G. Grancini, D.J. Slotcavage, G.E. Eperon, J.M. Ball, M. De Bastiani, A.R. Bowring, N. Martino, K. Wojciechowski, M.D. McGehee, H.J. Snaith, A. Petrozza, Mapping Electric Field-Induced Switchable Poling and Structural Degradation in Hybrid Lead Halide Perovskite Thin Films, Advanced Energy Materials. 5 (2015) 1500962n/a.

[298] C. Eames, J.M. Frost, P.R.F. Barnes, B.C. O/'Regan, A. Walsh, M.S. Islam, Ionic transport in hybrid lead iodide perovskite solar cells, Nat Commun. 6 (2015) 7497.

[299] T. Yang, G. Gregori, N. Pellet, M. Gratzel, J. Maier, The Significance of Ion Conduction in a Hybrid Organic-Inorganic Lead-Iodide-Based Perovskite Photosensitizer, Angew. Chem. Int. Ed. 54 (2015) 7905-7910.

[300] J. Carrillo, A. Guerrero, S. Rahimnejad, O. Almora, I. Zarazua, E. Mas-Marza, J. Bisquert, G. Garcia-Belmonte, Ionic Reactivity at Contacts and Aging of Methylammonium Lead Triiodide Perovskite Solar Cells, Advanced Energy Materials. 6 (2016) 15022461502246 .

[301] K. Miyano, M. Yanagida, N. Tripathi, Y. Shirai, Hysteresis, Stability, and Ion Migration in Lead Halide Perovskite Photovoltaics, J. Phys. Chem. Lett. 7 (2016) 2240-2245.

[302] Q. Jeangros, M. Duchamp, J. Werner, M. Kruth, R. Dunin-Borkowski, B. Niesen, C. Ballif, A. Hessler-Wyser, In Situ TEM Analysis of Organic-Inorganic Metal-Halide Perovskite Solar Cells under Electrical Bias, Nano Lett. 16 (2016) 7013-7018.

[303] F. Huang, L. Jiang, A.R. Pascoe, Y. Yan, U. Bach, L. Spiccia, Y. Cheng, Fatigue behavior of planar $\backslash \mathrm{CH} 3 \mathrm{NH} 3 \mathrm{PbI} \backslash \backslash$ perovskite solar cells revealed by light on/off diurnal cycling, Nano Energy. 27 (2016) 509.

[304] F. El-Mellouhi, A. Marzouk, E.T. Bentria, S.N. Rashkeev, S. Kais, F.H. Alharbi, Hydrogen Bonding and Stability of Hybrid Organicâ€"Inorganic Perovskites, ChemSusChem. 9 (2016) 2648-2655.

[305] F. El-Mellouhi, E.T. Bentria, S.N. Rashkeev, S. Kais, F.H. Alharbi, Enhancing Intrinsic Stability of Hybrid Perovskite Solar Cell by Strong, yet Balanced, Electronic Coupling, Scientific Reports. 6 (2016) 30305. 
[306] R. Ruess, F. Benfer, F. Bocher, M. Stumpp, D. Schlettwein, Stabilization of OrganicInorganic Perovskite Layers by Partial Substitution of Iodide by Bromide in Methylammonium Lead Iodide, ChemPhysChem. 17 (2016) 1505-1511.

[307] W. Zhu, C. Bao, F. Li, T. Yu, H. Gao, Y. Yi, J. Yang, G. Fu, X. Zhou, Z. Zou, A halide exchange engineering for $\mathrm{CH}_{3} \mathrm{NH}_{3} \mathrm{PbI}_{3-\mathrm{x}} \mathrm{Br}_{\mathrm{x}}$ perovskite solar cells with high performance and stability, Nano Energy. 19 (2016) 17-26.

[308] X. Zheng, B. Chen, M. Yang, C. Wu, B. Orler, R.B. Moore, K. Zhu, S. Priya, The Controlling Mechanism for Potential Loss in CH3NH3PbBr3 Hybrid Solar Cells, ACS Energy Lett. 1 (2016) 424-430.

[309] S.S. Mali, C.S. Shim, C.K. Hong, Highly stable and efficient solid-state solar cells based on methylammonium lead bromide $(\mathrm{CH} 3 \mathrm{NH} 3 \mathrm{PbBr} 3)$ perovskite quantum dots, NPG Asia Mater. 7 (2015) e208.

[310] F. Wang, X. Li, X. Yin, Z. Fu, Y. Lu, Thermal Behaviors of Methylammonium Lead Trihalide Perovskites with or without Chlorine Doping, J. Phys. Chem. C. 120 (2016) 1500915016.

[311] G. Niu, H. Yu, J. Li, D. Wang, L. Wang, Controlled orientation of perovskite films through mixed cations toward high performance perovskite solar cells, Nano Energy. 27 (2016) 87.

[312] C.G. Bischak, C.L. Hetherington, H. Wu, S. Aloni, D.F. Ogletree, D.T. Limmer, N.S. Ginsberg, Origin of Reversible Photoinduced Phase Separation in Hybrid Perovskites, Nano Lett. 17 (2017) 1028-1033.

[313] Z. Yang, A. Rajagopal, S.B. Jo, C. Chueh, S. Williams, C. Huang, J.K. Katahara, H.W. Hillhouse, A.K.-. Jen, Stabilized Wide Bandgap Perovskite Solar Cells by Tin Substitution, Nano Lett. 16 (2016) 7739-7747.

[314] M. Kulbak, S. Gupta, N. Kedem, I. Levine, T. Bendikov, G. Hodes, D. Cahen, Cesium Enhances Long-Term Stability of Lead Bromide Perovskite-Based Solar Cells, J. Phys. Chem. Lett. 7 (2016) 167-172.

[315] S. Bai, N. Cheng, Z. Yu, P. Liu, C. Wang, X. Zhao, Cubic: Column composite structure $(\mathrm{NH} 2 \mathrm{CH}=\mathrm{NH} 2) \times(\mathrm{CH} 3 \mathrm{NH} 3) 1-\mathrm{xPbI} 3$ for efficient hole-transport material-free and insulation layer free perovskite solar cells with high stability, Electrochim. Acta. 190 (2016) 775-779.

[316] J. Xi, Z. Wu, K. Xi, H. Dong, B. Xia, T. Lei, F. Yuan, W. Wu, B. Jiao, X. Hou, Initiating crystal growth kinetics of a -HC(NH2)2PbI3 for flexible solar cells with longterm stability, Nano Energy. 26 (2016) 438-445.

[317] N. Arora, M.I. Dar, M. Abdi-Jalebi, F. Giordano, N. Pellet, G. Jacopin, R.H. Friend, S.M. Zakeeruddin, M. GrÃatzel, Intrinsic and Extrinsic Stability of Formamidinium Lead Bromide Perovskite Solar Cells Yielding High Photovoltage, Nano Lett. 16 (2016) 7155-7162.

[318] R.L.Z. Hoye, R.E. Brandt, A. Osherov, V. Stevanovic, S.D. Stranks, M.W.B. Wilson, H. Kim, A.J. Akey, J.D. Perkins, R.C. Kurchin, J.R. Poindexter, E.N. Wang, M.G. Bawendi, V. Bulovic, T. Buonassisi, Methylammonium Bismuth Iodide as a Lead-Free, Stable Hybrid Organic-Inorganic Solar Absorber, Chemistry - A European Journal. 22 (2016) 2605-2610. 
[319] M. Lyu, J. Yun, M. Cai, Y. Jiao, P.V. Bernhardt, M. Zhang, Q. Wang, A. Du, H. Wang, G. Liu, L. Wang, Organic--inorganic bismuth (III)-based material: A lead-free, air-stable and solution-processable light-absorber beyond organolead perovskites, Nano Research. 9 (2016) 692-702.

[320] Y. Chen, B. Li, W. Huang, D. Gao, Z. Liang, Efficient and reproducible CH3NH3PbI3x(SCN)x perovskite based planar solar cells, Chem. Commun. 51 (2015) 11997-11999.

[321] A. Halder, R. Chulliyil, A.S. Subbiah, T. Khan, S. Chattoraj, A. Chowdhury, S.K. Sarkar, Pseudohalide ( $\left.\mathrm{SCN}^{-}\right)$-Doped MAPbI3 Perovskites: A Few Surprises, J. Phys. Chem. Lett. 6 (2015) 3483-3489.

[322] Q. Jiang, D. Rebollar, J. Gong, E.L. Piacentino, C. Zheng, T. Xu, Pseudohalide-Induced Moisture Tolerance in Perovskite CH3NH3Pb(SCN)2I Thin Films, Angew. Chem. Int. Ed. 54 (2015) 7617-7620.

[323] M. Daub, H. Hillebrecht, Synthesis, Single-Crystal Structure and Characterization of (CH3NH3)2Pb(SCN)2I2, Angewandte Chemie International Edition. 54 (2015) 11016-11017.

[324] Q. Tai, P. You, H. Sang, Z. Liu, C. Hu, H.L.W. Chan, F. Yan, Efficient and stable perovskite solar cells prepared in ambient air irrespective of the humidity, Nat Commun. 7 (2016) 11105.

[325] J. Liu, J. Shi, D. Li, F. Zhang, X. Li, Y. Xiao, S. Wang, Molecular design and photovoltaic performance of a novel thiocyanate-based layered organometal perovskite material, Synth. Met. 215 (2016) 56-63.

[326] Y. Chiang, H. Cheng, M. Li, T. Guo, P. Chen, Low-Pressure Vapor-Assisted Solution Process for Thiocyanate-Based Pseudohalide Perovskite Solar Cells, ChemSusChem. 9 (2016) 2620-2627.

[327] S. Yang, W. Liu, L. Zuo, X. Zhang, T. Ye, J. Chen, C. Li, G. Wu, H. Chen, Thiocyanate assisted performance enhancement of formamidinium based planar perovskite solar cells through a single one-step solution process, J.Mater.Chem.A. 4 (2016) 9430-9436.

[328] A.M. Ganose, C.N. Savory, D.O. Scanlon, (CH3NH3)2Pb(SCN)2I2: A More Stable Structural Motif for Hybrid Halide Photovoltaics? J. Phys. Chem. Lett. 6 (2015) 4594-4598.

[329] I.C. Smith, E.T. Hoke, D. Solis-Ibarra, M.D. McGehee, H.I. Karunadasa, A Layered Hybrid Perovskite Solar-Cell Absorber with Enhanced Moisture Stability, Angewandte Chemie International Edition. 53 (2014) 11232-11235.

[330] Y. Hu, J. Schlipf, M. Wussler, M.L. Petrus, W. Jaegermann, T. Bein, P. MullerBuschbaum, P. Docampo, Hybrid Perovskite/Perovskite Heterojunction Solar Cells, ACS Nano. 10 (2016) 5999-6007.

[331] M. Wei, W. Sun, Y. Liu, Z. Liu, L. Xiao, Z. Bian, Z. Chen, Highly luminescent and stable layered perovskite as the emitter for light emitting diodes, physica status solidi (a). 213 (2016) 2727-2732.

[332] L. Pedesseau, D. Sapori, B. Traore, R. Robles, H. Fang, M.A. Loi, H. Tsai, W. Nie, J. Blancon, A. Neukirch, S. Tretiak, A.D. Mohite, C. Katan, J. Even, M. Kepenekian, Advances 
and Promises of Layered Halide Hybrid Perovskite Semiconductors, ACS Nano. 10 (2016) 9776-9786.

[333] W. Jiang, J. Ying, W. Zhou, K. Shen, X. Liu, X. Gao, F. Guo, Y. Gao, T. Yang, A new layered nano hybrid perovskite film with enhanced resistance to moisture-induced degradation, Chemical Physics Letters. 658 (2016) 71-75.

[334] H. Tsai, W. Nie, J. Blancon, C.C. Stoumpos, R. Asadpour, B. Harutyunyan, A.J. Neukirch, R. Verduzco, J.J. Crochet, S. Tretiak, L. Pedesseau, J. Even, M.A. Alam, G. Gupta, J. Lou, P.M. Ajayan, M.J. Bedzyk, M.G. Kanatzidis, A.D. Mohite, High-efficiency twodimensional Ruddlesden-Popper perovskite solar cells, Nature. 532 (2016) 312-316.

[335] C. Ma, C. Leng, Y. Ji, X. Wei, K. Sun, L. Tang, J. Yang, W. Luo, C. Li, Y. Deng, S. Feng, J. Shen, S. Lu, C. Du, H. Shi, 2D/3D perovskite hybrids as moisture-tolerant and efficient light absorbers for solar cells, Nanoscale. 8 (2016) 18309-18314.

[336] K. Yao, X. Wang, F. Li, L. Zhou, Mixed perovskite based on methyl-ammonium and polymeric-ammonium for stable and reproducible solar cells, Chem. Commun. 51 (2015) 15430-15433.

[337] K. Yao, X. Wang, Y. Xu, F. Li, L. Zhou, Multilayered Perovskite Materials Based on Polymeric-Ammonium Cations for Stable Large-Area Solar Cell, Chem. Mater. 28 (2016) 3131-3138.

[338] J. Burschka, N. Pellet, S. Moon, R. Humphry-Baker, P. Gao, M.K. Nazeeruddin, M. Gratzel, Sequential deposition as a route to high-performance perovskite-sensitized solar cells, Nature. 499 (2013) 316-319.

[339] D. Yang, Z. Yang, W. Qin, Y. Zhang, S.(. Liu, C. Li, Alternating precursor layer deposition for highly stable perovskite films towards efficient solar cells using vacuum deposition, J. Mater. Chem. A. 3 (2015) 9401-9405.

[340] C. Seth, D. Khushalani, Degradation and regeneration of hybrid perovskites, RSC Adv. 6 (2016) 101846-101852.

[341] J. He, T. Chen, Additive regulated crystallization and film formation of CH3NH3PbI3xBrx for highly efficient planar-heterojunction solar cells, J. Mater. Chem. A. 3 (2015) 18514-18520.

[342] C. Zuo, L. Ding, An 80.11\% FF record achieved for perovskite solar cells by using the NH4Cl additive, Nanoscale. 6 (2014) 9935-9938.

[343] Y. Sheng, Y. Hu, A. Mei, P. Jiang, X. Hou, M. Duan, L. Hong, Y. Guan, Y. Rong, Y. Xiong, H. Han, Enhanced electronic properties in CH3NH3PbI3via LiCl mixing for holeconductor-free printable perovskite solar cells, J.Mater.Chem.A. 4 (2016) 16731-16736.

[344] Z. Yang, C. Chueh, F. Zuo, J.H. Kim, P. Liang, A.K.-. Jen, High-Performance Fully Printable Perovskite Solar Cells via Blade-Coating Technique under the Ambient Condition, Adv. Energy Mater. 5 (2015) 1500328.

[345] P. Liang, C. Liao, C. Chueh, F. Zuo, S.T. Williams, X. Xin, J. Lin, A.K.-. Jen, Additive Enhanced Crystallization of Solution-Processed Perovskite for Highly Efficient PlanarHeterojunction Solar Cells, Adv Mater. 26 (2014) 3748-3754. 
[346] C. Chueh, C. Liao, F. Zuo, S.T. Williams, P. Liang, A.K.-. Jen, The roles of alkyl halide additives in enhancing perovskite solar cell performance, J. Mater. Chem. A. 3 (2015) 90589062.

[347] J.H. Kim, S.T. Williams, N. Cho, C. Chueh, A.K.-. Jen, Enhanced Environmental Stability of Planar Heterojunction Perovskite Solar Cells Based on Blade-Coating, Adv. Energy Mater. 5 (2015) 1401229.

[348] X. Song, W. Wang, P. Sun, W. Ma, Z. Chen, Additive to regulate the perovskite crystal film growth in planar heterojunction solar cells, Applied Physics Letters. 106 (2015) 033901.

[349] C. Chang, C. Chu, Y. Huang, C. Huang, S. Chang, C. Chen, C. Chao, W. Su, Tuning Perovskite Morphology by Polymer Additive for High Efficiency Solar Cell, ACS Appl. Mater. Interfaces. 7 (2015) 4955-4961.

[350] J. Wei, H. Li, Y. Zhao, W. Zhou, R. Fu, Y. Leprince-Wang, D. Yu, Q. Zhao, Suppressed hysteresis and improved stability in perovskite solar cells with conductive organic network, Nano Energy. 26 (2016) 139-147.

[351] Y. Zhao, J. Wei, H. Li, Y. Yan, W. Zhou, D. Yu, Q. Zhao, A polymer scaffold for selfhealing perovskite solar cells, Nat Commun. 7 (2016) 10228.

[352] Y. Guo, K. Shoyama, W. Sato, E. Nakamura, Polymer Stabilization of Lead(II) Perovskite Cubic Nanocrystals for Semitransparent Solar Cells, Advanced Energy Materials. 6 (2016) 1502317-n/a.

[353] Y. Sun, Y. Wu, X. Fang, L. Xu, Z. Ma, Y. Lu, W. Zhang, q. yu, N. Yuan, J. Ding, Long-term Stability of Organic-Inorganic Hybrid Perovskite Solar Cells with High Efficiency Under High Humidity Conditions, J.Mater.Chem.A. 5 (2016) 1374-1379.

[354] J. Pascual, I. Kosta, T.T. Ngo, A. Chuvilin, G. Cabanero, H.J. Grande, E.M. Barea, I. Mora-Sero, J.L. Delgado, R. Tena-Zaera, Electron Transport Layer-Free Solar Cells Based on Perovskite-Fullerene Blend Films with Enhanced Performance and Stability, ChemSusChem. 9 (2016) 2679-2685.

[355] N. Tripathi, Y. Shirai, M. Yanagida, A. Karen, K. Miyano, Novel Surface Passivation Technique for Low-Temperature Solution-Processed Perovskite PV Cells, ACS Appl. Mater. Interfaces. 8 (2016) 4644-4650.

[356] M. Salado, F.J. Ramos, V.M. Manzanares, P. Gao, M.K. Nazeeruddin, P.J. Dyson, S. Ahmad, Extending the Lifetime of Perovskite Solar Cells using a Perfluorinated Dopant, ChemSusChem. 9 (2016) 2708-2714.

[357] J.H. Heo, D.H. Song, H.J. Han, S.Y. Kim, J.H. Kim, D. Kim, H.W. Shin, T.K. Ahn, C. Wolf, T. Lee, S.H. Im, Planar CH3NH3PbI3 Perovskite Solar Cells with Constant 17.2\% Average Power Conversion Efficiency Irrespective of the Scan Rate, Adv Mater. 27 (2015) 3424-3430.

[358] L. Yang, J. Wang, W.W. Leung, Lead Iodide Thin Film Crystallization Control for High-Performance and Stable Solution-Processed Perovskite Solar Cells, ACS Appl. Mater. Interfaces. 7 (2015) 14614-14619. 
[359] G. Li, T. Zhang, Y. Zhao, Hydrochloric acid accelerated formation of planar $\mathrm{CH} 3 \mathrm{NH} 3 \mathrm{PbI} 3$ perovskite with high humidity tolerance, J. Mater. Chem. A. 3 (2015) 1967419678.

[360] J. Pan, C. Mu, Q. Li, W. Li, D. Ma, D. Xu, Room-Temperature, HydrochlorideAssisted, One-Step Deposition for Highly Efficient and Air-Stable Perovskite Solar Cells, Adv Mater. 28 (2016) 8309-8314.

[361] J.H. Heo, D.H. Song, S.H. Im, Planar CH3NH3PbBr3 Hybrid Solar Cells with 10.4\% Power Conversion Efficiency, Fabricated by Controlled Crystallization in the Spin-Coating Process, Adv Mater. 26 (2014) 8179-8183.

[362] C. Wu, C. Chiang, Z. Tseng, M.K. Nazeeruddin, A. Hagfeldt, M. Gratzel, High efficiency stable inverted perovskite solar cells without current hysteresis, Energy Environ. Sci. 8 (2015) 2725-2733.

[363] K.M. Boopathi, R. Mohan, T. Huang, W. Budiawan, M. Lin, C. Lee, K. Ho, C. Chu, Synergistic improvements in stability and performance of lead iodide perovskite solar cells incorporating salt additives, J.Mater.Chem.A. 4 (2016) 1591-1597.

[364] W. Zhang, S. Pathak, N. Sakai, T. Stergiopoulos, P.K. Nayak, N.K. Noel, A.A. Haghighirad, V.M. Burlakov, D.W. deQuilettes, A. Sadhanala, W. Li, L. Wang, D.S. Ginger, R.H. Friend, H.J. Snaith, Enhanced optoelectronic quality of perovskite thin films with hypophosphorous acid for planar heterojunction solar cells, Nat Commun. 6 (2015) 10030.

[365] H. Hoshi, N. Shigeeda, T. Dai, Improved oxidation stability of tin iodide cubic perovskite treated by 5-ammonium valeric acid iodide, Mater Lett. 183 (2016) 391.

[366] A.F. Akbulatov, L.A. Frolova, D.A. Anokhin, K.L. Gerasimov, N.N. Dremova, P. Troshin, Hydrazinium-loaded perovskite solar cells with the enhanced performance and stability, J.Mater.Chem.A. 4 (2016) 18378-18382.

[367] J. He, C. Ng, K.Y. Wong, W. Liu, T. Chen, Photostability and Moisture Stability of CH3NH3PbI3-based Solar Cells by Ethyl Cellulose, ChemPlusChem. 81 (2016) 1292-1298.

[368] Y. Wang, W. Rho, H. Yang, T. Mahmoudi, S. Seo, D. Lee, Y. Hahn, Air-stable, holeconductor-free high photocurrent perovskite solar cells with $\mathrm{CH} 3 \mathrm{NH} 3 \mathrm{PbI} 3-\mathrm{NiO}$ nanoparticles composite, Nano Energy. 27 (2016) 535.

[369] X. Bao, Y. Wang, Q. Zhu, N. Wang, D. Zhu, J. Wang, A. Yang, R. Yang, Efficient planar perovskite solar cells with large fill factor and excellent stability, J. Power Sources. 297 (2015) 53-58.

[370] H. Hsu, C. Chang, C. Chen, B. Jiang, R. Jeng, C. Cheng, High-performance and highdurability perovskite photovoltaic devices prepared using ethylammonium iodide as an additive, J. Mater. Chem. A. 3 (2015) 9271-9277.

[371] D. Bi, P. Gao, R. Scopelliti, E. Oveisi, J. Luo, M. Gratzel, A. Hagfeldt, M.K. Nazeeruddin, High-Performance Perovskite Solar Cells with Enhanced Environmental Stability Based on Amphiphile-Modified CH3NH3PbI3, Adv Mater. 28 (2016) 2910-2915.

[372] X. Li, Ibrahim Dar M., C. Yi, J. Luo, M. Tschumi, S.M. Zakeeruddin, M.K. Nazeeruddin, H. Han, M. Gratzel, Improved performance and stability of perovskite solar 
cells by crystal crosslinking with alkylphosphonic acid w-ammonium chlorides, Nat Chem. 7 (2015) 703-711.

[373] L. Sun, Perovskite solar cells: Crystal crosslinking, Nat Chem. 7 (2015) 684-685.

[374] B. Li, C. Fei, K. Zheng, X. Qu, T. Pullerits, G. Cao, J. Tian, Constructing waterresistant $\mathrm{CH} 3 \mathrm{NH} 3 \mathrm{PbI} 3$ perovskite films via coordination interaction, J.Mater.Chem.A. 4 (2016) 17018-17024.

[375] M. Li, Y. Chao, T. Kang, Z. Wang, Y. Yang, S. Feng, Y. Hu, X. Gao, L. Liao, C. Hsu, Enhanced crystallization and stability of perovskites by a cross-linkable fullerene for highperformance solar cells, J.Mater.Chem.A. 4 (2016) 15088-15094.

[376] H. Wang, Y. Rahaq, V. Kumar, A composite light-harvesting layer from photoactive polymer and halide perovskite for planar heterojunction solar cells, Scientific Reports. 6 (2016) 29567.

[377] T. Zhang, L. Xie, L. Chen, N. Guo, G. Li, Z. Tian, B. Mao, Y. Zhao, In Situ Fabrication of Highly Luminescent Bifunctional Amino Acid Crosslinked 2D/3D

$\mathrm{NH} 3 \mathrm{C} 4 \mathrm{H} 9 \mathrm{COO}(\mathrm{CH} 3 \mathrm{NH} 3 \mathrm{PbBr} 3) n$ Perovskite Films, Advanced Functional Materials. 27 (2017) 1603568-n/a.

[378] Y. Jiao, F. Ma, G. Gao, H. Wang, J. Bell, T. Frauenheim, A. Du, Graphene-covered perovskites: an effective strategy to enhance light absorption and resist moisture degradation, RSC Adv. 5 (2015) 82346-82350.

[379] S. Yang, Y. Wang, P. Liu, Y. Cheng, H.J. Zhao, H.G. Yang, Functionalization of perovskite thin films with moisture-tolerant molecules, Nature Energy. (2016) 15016.

[380] M. Hu, C. Bi, Y. Yuan, Y. Bai, J. Huang, Stabilized Wide Bandgap MAPbBr ${ }_{x} I_{3-x}$ Perovskite by Enhanced Grain Size and Improved Crystallinity, Advanced Science. 3 (2016) 1500301-n/a.

[381] G.R. Perumallapelli, S.R. Vasa, J. Jang, Improved morphology and enhanced stability via solvent engineering for planar heterojunction perovskite solar cells, Organic Electronics. 31 (2016) 142-148.

[382] W. Deng, X. Zhang, L. Huang, X. Xu, L. Wang, J. Wang, Q. Shang, S. Lee, J. Jie, Aligned Single-Crystalline Perovskite Microwire Arrays for High-Performance Flexible Image Sensors with Long-Term Stability, Adv Mater. 28 (2016) 2201-2208.

[383] J. Cao, J. Yin, S. Yuan, Y. Zhao, J. Li, N. Zheng, Thiols as interfacial modifiers to enhance the performance and stability of perovskite solar cells, Nanoscale. 7 (2015) 94439447.

[384] N. Tripathi, M. Yanagida, Y. Shirai, T. Masuda, L. Han, K. Miyano, Hysteresis-free and highly stable perovskite solar cells produced via a chlorine-mediated interdiffusion method, J. Mater. Chem. A. 3 (2015) 12081-12088.

[385] B. Suarez, V. Gonzalez-Pedro, T.S. Ripolles, R.S. Sanchez, L. Otero, I. Mora-Sero, Recombination Study of Combined Halides (Cl, Br, I) Perovskite Solar Cells, J. Phys. Chem. Lett. 5 (2014) 1628-1635. 
[386] F.K. Aldibaja, L. Badia, E. Mas-Marza, R.S. Sanchez, E.M. Barea, I. Mora-Sero, Effect of different lead precursors on perovskite solar cell performance and stability, J. Mater. Chem. A. 3 (2015) 9194-9200.

[387] M.A. Mahmud, N.K. Elumalai, M.B. Upama, D. Wang, M. Wright, T. Sun, C. Xu, F. Haque, A. Uddin, Simultaneous enhancement in stability and efficiency of low-temperature processed perovskite solar cells, RSC Adv. 6 (2016) 86108-86125.

[388] H. Si, Q. Liao, Z. Zhang, Y. Li, X. Yang, G. Zhang, Z. Kang, Y. Zhang, An innovative design of perovskite solar cells with $\mathrm{Al} 2 \mathrm{O} 3$ inserting at $\mathrm{ZnO}$ /perovskite interface for improving the performance and stability, Nano Energy. 22 (2016) 223-231.

[389] E. Polydorou, A. Zeniou, D. Tsikritzis, A. Soultati, I. Sakellis, S. Gardelis, T.A. Papadopoulos, J. Briscoe, L.C. Palilis, S. Kennou, E. Gogolides, P. Argitis, D. Davazoglou, M. Vasilopoulou, Surface passivation effect by fluorine plasma treatment on $\mathrm{ZnO}$ for efficiency and lifetime improvement of inverted polymer solar cells, J.Mater.Chem.A. 4 (2016) 11844-11858.

[390] Q. Wang, Q. Dong, T. Li, A. Gruverman, J. Huang, Thin Insulating Tunneling Contacts for Efficient and Water-Resistant Perovskite Solar Cells, Adv Mater. 28 (2016) 6734-6739.

[391] Y. Zhang, P. Wang, X. Yu, J. Xie, X. Sun, H. Wang, J. Huang, L. Xu, C. Cui, M. Lei, D. Yang, Enhanced performance and Light Soaking Stability of Planar Perovskite Solar Cells using Amine-based Fullerene Interfacial Modifier, J.Mater.Chem.A. 4 (2016) 18509-18515.

[392] D. Song, D. Wei, P. Cui, M. Li, Z. Duan, T. Wang, J. Ji, Y. Li, J.M. Mbengue, Y. Li, Y. He, M. Trevor, N. Park, Dual function interfacial layer for highly efficient and stable lead halide perovskite solar cells, J.Mater.Chem.A. 4 (2016) 6091-6097.

[393] Z. Wang, X. Gong, M. Li, Y. Hu, J. Wang, H. Ma, L. Liao, Induced Crystallization of Perovskites by a Perylene Underlayer for High-Performance Solar Cells, ACS Nano. 10 (2016) 5479-5489.

[394] A. Capasso, F. Matteocci, L. Najafi, M. Prato, J. Buha, L. Cina, V. Pellegrini, A.D. Carlo, F. Bonaccorso, Few-Layer MoS2 Flakes as Active Buffer Layer for Stable Perovskite Solar Cells, Advanced Energy Materials. 6 (2016) 1600920-n/a.

[395] C. Chang, Y. Chang, W. Huang, W. Liao, H. Wang, C. Yeh, B. Tsai, Y. Huang, C. Tsao, Achieving high efficiency and improved stability in large-area ITO-free perovskite solar cells with thiol-functionalized self-assembled monolayers, J.Mater.Chem.A. 4 (2016) 7903-7913.

[396] A. Shit, A.K. Nandi, Interface engineering of hybrid perovskite solar cells with poly(3thiophene acetic acid) under ambient conditions, Phys.Chem.Chem.Phys. 18 (2016) 1018210190 .

[397] X. Wen, J. Wu, M. Ye, D. Gao, C. Lin, Interface engineering via an insulating polymer for highly efficient and environmentally stable perovskite solar cells, Chem.Commun. 52 (2016) 11355-11358.

[398] S. Guarnera, A. Abate, W. Zhang, J.M. Foster, G. Richardson, A. Petrozza, H.J. Snaith, Improving the Long-Term Stability of Perovskite Solar Cells with a Porous A12O3 Buffer Layer, J. Phys. Chem. Lett. 6 (2015) 432-437. 
[399] H. Zhou, Y. Shi, Q. Dong, H. Zhang, Y. Xing, K. Wang, Y. Du, T. Ma, Hole-

Conductor-Free, Metal-Electrode-Free TiO2/CH3NH3PbI3 Heterojunction Solar Cells Based on a Low-Temperature Carbon Electrode, J. Phys. Chem. Lett. 5 (2014) 3241-3246.

[400] H. Zhou, Y. Shi, K. Wang, Q. Dong, X. Bai, Y. Xing, Y. Du, T. Ma, Low-Temperature Processed and Carbon-Based $\mathrm{ZnO} / \mathrm{CH} 3 \mathrm{NH} 3 \mathrm{PbI} 3 / \mathrm{C}$ Planar Heterojunction Perovskite Solar Cells, J. Phys. Chem. C. 119 (2015) 4600-4605.

[401] Y. Ma, Y. Chung, L. Zheng, D. Zhang, X. Yu, L. Xiao, Z. Chen, S. Wang, B. Qu, Q. Gong, D. Zou, Improved Hole-Transporting Property via HAT-CN for Perovskite Solar Cells without Lithium Salts, ACS Appl. Mater. Interfaces. 7 (2015) 6406-6411.

[402] J. Zhang, Z. Hu, L. Huang, G. Yue, J. Liu, X. Lu, Z. Hu, M. Shang, L. Han, Y. Zhu, Bifunctional alkyl chain barriers for efficient perovskite solar cells, Chem. Commun. 51 (2015) 7047-7050.

[403] F. Hou, Z. Su, F. Jin, X. Yan, L. Wang, H. Zhao, J. Zhu, B. Chu, W. Li, Efficient and stable planar heterojunction perovskite solar cells with an MoO3/PEDOT:PSS hole transporting layer, Nanoscale. 7 (2015) 9427-9432.

[404] F. Igbari, M. Li, Y. Hu, Z. Wang, L. Liao, A room-temperature CuAlO2 hole interfacial layer for efficient and stable planar perovskite solar cells, J.Mater.Chem.A. 4 (2016) 13261335 .

[405] M. Kaltenbrunner, G. Adam, E.D. Glowacki, M. Drack, R. Schwodiauer, L. Leonat, D.H. Apaydin, H. Groiss, M.C. Scharber, M.S. White, N.S. Sariciftci, S. Bauer, Flexible high power-per-weight perovskite solar cells with chromium oxide-metal contacts for improved stability in air, Nat Mater. 14 (2015) 1032-1039.

[406] C. Chang, Y. Chang, W. Huang, K. Lee, A. Cho, C. Hsu, Enhanced Performance and Stability of Semitransparent Perovskite Solar Cells Using Solution-Processed ThiolFunctionalized Cationic Surfactant as Cathode Buffer Layer, Chem. Mater. 27 (2015) 71197127.

[407] C. Chang, W. Huang, Y. Chang, K. Lee, C. Chen, A solution-processed n-doped fullerene cathode interfacial layer for efficient and stable large-area perovskite solar cells, J. Mater. Chem. A. 4 (2016) 640-648.

[408] C. Chang, W. Huang, J. Wu, Y. Chang, K. Lee, C. Chen, Room-Temperature SolutionProcessed n-Doped Zirconium Oxide Cathode Buffer Layer for Efficient and Stable Organic and Hybrid Perovskite Solar Cells, Chem. Mater. 28 (2016) 242-251.

[409] Z. Zhu, C. Chueh, F. Lin, A.K.-. Jen, Enhanced Ambient Stability of Efficient Perovskite Solar Cells by Employing a Modified Fullerene Cathode Interlayer, Advanced Science. 3 (2016) 1600027-n/a.

[410] A. Savva, I. BurguÃ@s-Ceballos, S.A. Choulis, Improved Performance and Reliability of p-i-n Perovskite Solar Cells via Doped Metal Oxides, Advanced Energy Materials. 6 (2016) 1600285-n/a.

[411] X. Jia, L. Zhang, Q. Luo, H. Lu, X. Li, Z. Xie, Y. Yang, Y. Li, X. Liu, C. Ma, Power Conversion Efficiency and Device Stability Improvement of Inverted Perovskite Solar Cells 
by Using a ZnO:PFN Composite Cathode Buffer Layer, ACS Appl. Mater. Interfaces. 8 (2016) 18410-18417.

[412] S. Ahn, W. Jang, J.H. Park, D.H. Wang, Morphology fixing agent for [6,6]-phenyl C61butyric acid methyl ester (PC60BM) in planar-type perovskite solar cells for enhanced stability, RSC Adv. 6 (2016) 51513-51519.

[413] C. Chang, W. Huang, Y. Chang, Highly-Efficient and Long-Term Stable Perovskite Solar Cells Enabled by a Cross-Linkable n-Doped Hybrid Cathode Interfacial Layer, Chem. Mater. 28 (2016) 6305-6312.

[414] P. Li, C. Liang, Y. Zhang, F. Li, Y. Song, G. Shao, Polyethyleneimine high-energy hydrophilic surface interfacial treatment toward efficient and stable perovskite solar cells, ACS Appl. Mater. Interfaces. 8 (2016) 32574-32580.

[415] L.Q. Zhang, X.W. Zhang, Z.G. Yin, Q. Jiang, X. Liu, J.H. Meng, Y.J. Zhao, H.L. Wang, Highly efficient and stable planar heterojunction perovskite solar cells via a low temperature solution process, J. Mater. Chem. A. 3 (2015) 12133-12138.

[416] W. Yan, Y. Li, Y. Li, S. Ye, Z. Liu, S. Wang, Z. Bian, C. Huang, Stable highperformance hybrid perovskite solar cells with ultrathin polythiophene as hole-transporting layer, Nano Research. 8 (2015) 2474-2480.

[417] J.H. Yun, I. Lee, T. Kim, M.J. Ko, J.Y. Kim, H.J. Son, Synergistic enhancement and mechanism study of mechanical and moisture stability of perovskite solar cells introducing polyethylene-imine into the $\mathrm{CH} 3 \mathrm{NH} 3 \mathrm{PbI} 3 / \mathrm{HTM}$ interface, J. Mater. Chem. A. 3 (2015) 22176-22182.

[418] C.D.T. Tran, Y. Liu, E.S. Thibau, A. Llanos, Z. Lu, Stability of organometal perovskites with organic overlayers, AIP Advances. 5 (2015) 087185-1-087185-6.

[419] J. Xu, O. Voznyy, R. Comin, X. Gong, G. Walters, M. Liu, P. Kanjanaboos, X. Lan, E.H. Sargent, Crosslinked Remote-Doped Hole-Extracting Contacts Enhance Stability under Accelerated Lifetime Testing in Perovskite Solar Cells, Adv Mater. 28 (2016) 2807-2815.

[420] H. Liao, T.L.D. Tam, P. Guo, Y. Wu, E.F. Manley, W. Huang, N. Zhou, C.M.M. Soe, B. Wang, M.R. Wasielewski, L.X. Chen, M.G. Kanatzidis, A. Facchetti, R.P.H. Chang, T.J. Marks, Dopant-Free Hole Transporting Polymers for High Efficiency, Environmentally Stable Perovskite Solar Cells, Advanced Energy Materials. 6 (2016) 1600502-n/a.

[421] B. Koo, H. Jung, M. Park, J. Kim, H.J. Son, J. Cho, M.J. Ko, Pyrite-Based BiFunctional Layer for Long-Term Stability and High-Performance of Organo-Lead Halide Perovskite Solar Cells, Advanced Functional Materials. 26 (2016) 5400-5407.

[422] Z. Wei, H. Chen, K. Yan, S. Yang, Inkjet Printing and Instant Chemical Transformation of a CH3NH3PbI3/Nanocarbon Electrode and Interface for Planar Perovskite Solar Cells, Angewandte Chemie. 126 (2014) 13455-13459.

[423] Z. Wei, X. Zheng, H. Chen, X. Long, Z. Wang, S. Yang, A multifunctional C + epoxy/Ag-paint cathode enables efficient and stable operation of perovskite solar cells in watery environments, J.Mater.Chem.A. 3 (2015) 16430-16434. 
[424] M.M. Tavakoli, K. Tsui, Q. Zhang, J. He, Y. Yao, D. Li, Z. Fan, Highly Efficient Flexible Perovskite Solar Cells with Antireflection and Self-Cleaning Nanostructures, ACS Nano. 9 (2015) 10287-10295.

[425] C. Chang, K. Lee, W. Huang, H. Siao, Y. Chang, High-Performance, Air-Stable, LowTemperature Processed Semitransparent Perovskite Solar Cells Enabled by Atomic Layer Deposition, Chem. Mater. 27 (2015) 5122-5130.

[426] I.S. Kim, A.B.F. Martinson, Stabilizing hybrid perovskites against moisture and temperature via non-hydrolytic atomic layer deposited overlayers, J. Mater. Chem. A. 3 (2015) 20092-20096.

[427] I.S. Kim, D.H. Cao, D.B. Buchholz, J.D. Emery, O.K. Farha, J.T. Hupp, M.G. Kanatzidis, A.B.F. Martinson, Liquid Water- and Heat-Resistant Hybrid Perovskite Photovoltaics via an Inverted ALD Oxide Electron Extraction Layer Design, Nano Lett. 16 (2016) 7786-7790.

[428] K.A. Bush, A.F. Palmstrom, Z.J. Yu, M. Boccard, R. Cheacharoen, J.P. Mailoa, D.P. McMeekin, R.L.Z. Hoye, C.D. Bailie, T. Leijtens, I.M. Peters, M.C. Minichetti, N. Rolston, R. Prasanna, S. Sofia, D. Harwood, W. Ma, F. Moghadam, H.J. Snaith, T. Buonassisi, Z.C. Holman, S.F. Bent, M.D. McGehee, 23.6\%-efficient monolithic perovskite/silicon tandem solar cells with improved stability, Nature Energy. 2 (2017) 17009.

[429] K.O. Brinkmann, J. Zhao, N. Pourdavoud, T. Becker, T. Hu, S. Olthof, K. Meerholz, L. Hoffmann, T. Gahlmann, R. Heiderhoff, M.F. Oszajca, N.A. Luechinger, D. Rogalla, Y. Chen, B. Cheng, T. Riedl, Suppressed decomposition of organometal halide perovskites by impermeable electron-extraction layers in inverted solar cells, Nature Communications. 8 (2017) 13938.

[430] I. Hwang, I. Jeong, J. Lee, M.J. Ko, K. Yong, Enhancing Stability of Perovskite Solar Cells to Moisture by the Facile Hydrophobic Passivation, ACS Appl. Mater. Interfaces. 7 (2015) 17330-17336.

[431] H. Xiong, Y. Rui, Y. Li, Q. Zhang, H. Wang, Hydrophobic coating over a $\mathrm{CH} 3 \mathrm{NH} 3 \mathrm{PbI} 3$ absorbing layer towards air stable perovskite solar cells, J.Mater.Chem.C. 4 (2016) 6848-6854.

[432] Q. Luo, H. Ma, Y. Zhang, X. Yin, Z. Yao, N. Wang, J. Li, S. Fan, K. Jiang, H. Lin, Cross-stacked superaligned carbon nanotube electrodes for efficient hole conductor-free perovskite solar cells, J.Mater.Chem.A. 4 (2016) 5569-5577.

[433] Z. Liu, B. Sun, T. Shi, Z. Tang, G. Liao, Enhanced photovoltaic performance and stability of carbon counter electrode based perovskite solar cells encapsulated by PDMS, J.Mater.Chem.A. 4 (2016) 10700-10709.

[434] F. Bella, G. Griffini, J. Correa-Baena, G. Saracco, M. Grlatzel, A. Hagfeldt, S. Turri, C. Gerbaldi, Improving efficiency and stability of perovskite solar cells with photocurable fluoropolymers, Science. (2016).

[435] H.C. Weerasinghe, Y. Dkhissi, A.D. Scully, R.A. Caruso, Y. Cheng, Encapsulation for improving the lifetime of flexible perovskite solar cells, Nano Energy. 18 (2015) 118-125. 
[436] Q. Dong, F. Liu, M.K. Wong, H.W. Tam, A.B. DjuriÅ $i$ ï̈ Chan, A.M.C. Ng, Encapsulation of Perovskite Solar Cells for High Humidity Conditions, ChemSusChem. 9 (2016) 2597-2603.

[437] H. Zhang, Q. Liao, X. Wang, J. Yao, H. Fu, Water-Resistant Perovskite Polygonal Microdisks Laser in Flexible Photonics Devices, Advanced Optical Materials. (2016) 1600335-n/a. 